FHWA/IN/JTRP-2007/2

Final Report

ALTERNATIVES TO FUEL TAX:

A STATE LEVEL PERSPECTIVE

JungEun (Jen) Oh

Kumares C. Sinha

February 2008 


\section{TECHNICAL Summary}

INDOT Research

Technology Transfer and Project Implementation Information

TRB Subject Code: 14-5 Financial Sources

Publication No.: FHWA/IN/JTRP-2007/2, SPR-2934

February 2008

Final Report

\section{Alternatives to Fuel Tax: A State Level Perspective}

\section{Introduction}

The current and imminent revenue shortfall of the highway financing system, which is currently based on motor fuel taxes, has been widely diagnosed both at the national and state levels. A 2005 needs study assessing highway needs and future revenue during 2006-2020 for Indiana concluded that the annual funding gap during this period would be \$0.86-1.12 billion. Under the current fuel-tax-based system, it is predicted that the shortfall would grow larger in the future, primarily because the current fuel tax rate is fixed per gallon while vehicle fuel economy is improving and the use of alternative fuels is increasing. The growing funding gap indicates that there is an urgent need to improve the current structure of the highway financing mechanism or to develop a new financing strategy. In this regard, establishing new highway pricing schemes are needed that satisfactorily attain goals such as adequacy in revenue, efficiency of the highway system, equity between highway users, and technological and financial feasibility. The study explored and evaluated alternative financing options in order to provide the most recommendable strategy to resolve the current and future highway funding problem of Indiana.

\section{Findings}

In order to search for alternatives to the current fuel-tax-based state highway funding system, several types of user charging schemes that have been demonstrated or implemented in other states and countries were examined. The examples were studied to understand financing concepts, impacts on users and transportation systems, and caveats in their implementations. Based on that, possible guidelines for pricing implementation were drawn for several aspects, such as design of the pricing scheme, technology issues, legal and institutional issues, and public acceptability.

By synthesizing previous studies that evaluated pricing schemes, a methodological framework for evaluation of alternative user charging schemes was established. Evaluation criteria included: (i) revenue adequacy (sufficiency, stability, and accountability), (ii) system efficiency, (iii) equity between users, (iv) cost of implementation, (v) public acceptability, and (vi) policy alignment. For each criterion, definitions and measurement methods were provided.

On the basis of the current and projected financing situation and highway demand of Indiana, the following alternative financing schemes were developed: (1) enhancement of the current tax system; (2) addition of new funding sources to supplement the current system; and (3) replacement of the current system with new financing schemes. The analyses include, for alternative (2), forecast of annual toll revenue of a typical new interstate for various toll rate scenarios, which was estimated to range from $\$ 40$ million to $\$ 90$ million, using the Indiana Statewide Travel Demand Model (ISTDM). For alternative (3), a distance-based pricing scheme that charges on average 2.9 cents for each vehicle-mile-traveled was suggested. Separate fee rates were also found by road functional class, with which each of highway sub-system (road functional class) can be self-financed. A more comprehensive 
pricing structure, which provides separate rates by vehicle class as well as road functional class, was also established as a result of the highway cost allocation study. Under the suggested pricing structure, automobiles are charged 1.21 cents per mile, single unit trucks 9.18 cents per mile, and combination trucks 23.54 cents per mile.

Each alternative was evaluated according to the established criteria, either quantitatively or qualitatively. By combining the evaluation result for each criterion, alternatives were comprehensively compared. The most innovative approach, to replace the current fuel tax system, appears to have the best potential in achieving revenue adequacy, system efficiency, and equity. On the other hand, the implementation of this alternative could be cost-prohibitive as well as face strong opposition from the public at this time. However, experience has shown that the implementation costs likely will decline as the necessary technologies mature in the market and public attitude can change over time. The long-term goals proposed at the federal level align very well with the comprehensive pricing scheme alternative.

\section{Implementation}

Stepwise adaptation of a new system is proposed, targeting a long-term goal of a usagebased comprehensive road pricing. The study outlines short-, medium-, and long-term highway financing strategies, which comprise goals, possible actions, public outreach, and required information. In the short-term, it is suggested to implement funding tools that require negligible cost to plan and launch, including an increase of and inflation-indexing of the fuel tax system, and indexing of the vehicle registration fee system, supplemented by other minor tax adjustments where possible. In the medium-term, a pilot study for the Indiana Statewide Comprehensive Usage-based Road Pricing (ISCURP) could be completed. In both the short- and medium-term, a strategy is needed to inform and educate the public as the new system is gradually ushered in. In the long-term, a structure needs to be designed whereby highway agencies could know exactly how much their provision and maintenance costs by facility type and user classification are. It also should be technologically possible to charge users fees/taxes distinctively. To implement such a system, data acquisition and analyses modules that interactively calibrate system costs and assist in setting relevant prices for each group of users are needed.

\section{Contacts}

For more information:

Prof. Kumares C. Sinha

Principal Investigator

School of Civil Engineering

Purdue University

West Lafayette, IN 47907-2051

Phone: (765) 494-2211

Fax: (765) 496-7996

E-mail: $\underline{\text { sinha@ecn.purdue.edu }}$

\section{Indiana Department of Transportation}

Division of Research

1205 Montgomery Street

P.O. Box 2279

West Lafayette, IN 47906

Phone: (765) 463-1521

Fax: (765) 497-1665

\section{Purdue University}

Joint Transportation Research Program

School of Civil Engineering

West Lafayette, IN 47907-1284

Phone: (765) 494-9310

Fax: (765) 496-7996

E:mail: jtrp@ecn.purdue.edu 
Final Report

FHWA/IN/JTRP-2007/02

\title{
ALTERNATIVES TO FUEL TAX: A STATE LEVEL PERSPECTIVE
}

\author{
By \\ JungEun (Jen) Oh \\ Graduate Research Assistant \\ and \\ Kumares C. Sinha \\ Olson Distinguished Professor of Civil Engineering \\ School of Civil Engineering \\ Purdue University \\ Joint Transportation Research Program \\ Project No. C-36-73B \\ File No. 3-4-24 \\ SPR-2934 \\ In Cooperation with the \\ Indiana Department of Transportation \\ and the Federal Highway Administration \\ U.S. Department of Transportation
}

The contents of this report reflect the views of the authors, who are responsible for the facts and the accuracy of the data presented herein. The contents do not necessarily reflect the official views or policies of the Indiana Department of Transportation or the Federal Highway Administration. This report does not constitute a standard, specification or regulation

Purdue University

West Lafayette, IN, 47907

February 2008 


\section{ACKNOWLEDGEMENTS}

The guidance provided by the following Study Advisory Committee members is gratefully

acknowledged: Gary Eaton, Samy Noureldin, and Bernard Seel of INDOT; Jay DuMontelle of FHWA

Indiana Division; Mike Byers of the ACPA Indiana Chapter; Lloyd Bandy of APAI; and Dennis

Faulkenberg of Ice Miller. The authors, however, are solely responsible for the contents of the report. 
TECHNICAL REPORT STANDARD TITLE PAGE

\begin{tabular}{|c|c|c|c|c|}
\hline $\begin{array}{l}\text { 1. } \text { Report No. } \\
\text { FHWA/IN/JTRP-2007/2 }\end{array}$ & \multicolumn{2}{|c|}{ 2. Government Accession No. } & \multicolumn{2}{|c|}{ 3. Recipient's Catalog No. } \\
\hline \multirow{2}{*}{\multicolumn{3}{|c|}{$\begin{array}{l}\text { 4. Title and Subtitle } \\
\text { Alternatives to Fuel Tax: A State Level Perspective }\end{array}$}} & \multicolumn{2}{|l|}{$\begin{array}{l}\text { 5. } \text { Report Date } \\
\text { February } 2008\end{array}$} \\
\hline & & & \multicolumn{2}{|c|}{ 6. Performing Organization Code } \\
\hline \multicolumn{3}{|c|}{$\begin{array}{l}\text { 7. Author(s) } \\
\text { Jung Eun Oh and Kumares Sinha }\end{array}$} & \multicolumn{2}{|c|}{$\begin{array}{l}\text { 8. Performing Organization Report No. } \\
\text { FHWA/IN/JTRP-2007/2 }\end{array}$} \\
\hline \multirow{2}{*}{\multicolumn{3}{|c|}{$\begin{array}{l}\text { 9. Performing Organization Name and Address } \\
\text { Joint Transportation Research Program } \\
1284 \text { Civil Engineering Building } \\
\text { Purdue University } \\
\text { West Lafayette, IN 47907-1284 }\end{array}$}} & \multicolumn{2}{|l|}{ 10. Work Unit No. } \\
\hline & & & \multicolumn{2}{|c|}{$\begin{array}{l}\text { 11. Contract or Grant No. } \\
\text { SPR-2934 }\end{array}$} \\
\hline \multirow{2}{*}{\multicolumn{3}{|c|}{$\begin{array}{l}\text { 12. Sponsoring Agency Name and Address } \\
\text { Indiana Department of Transportation } \\
\text { State Office Building } \\
100 \text { North Senate Avenue } \\
\text { Indianapolis, IN } 46204\end{array}$}} & \multicolumn{2}{|c|}{$\begin{array}{l}\text { 13. Type of Report and Period Covered } \\
\text { Final Report }\end{array}$} \\
\hline & & & \multicolumn{2}{|c|}{ 14. Sponsoring Agency Code } \\
\hline \multicolumn{5}{|l|}{$\begin{array}{l}\text { 15. Supplementary Notes } \\
\text { Prepared in cooperatio }\end{array}$} \\
\hline \multicolumn{5}{|c|}{ 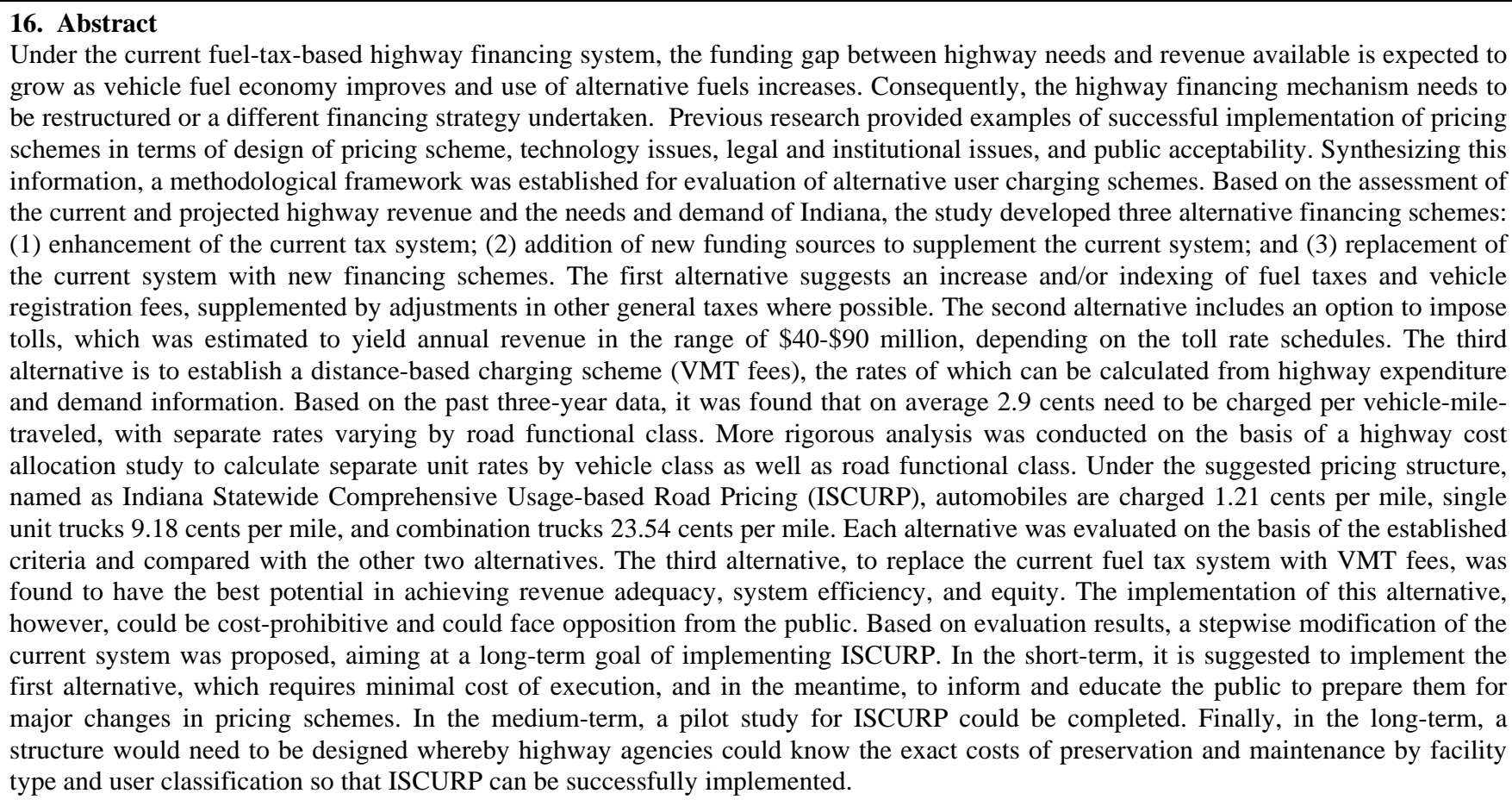 } \\
\hline \multicolumn{2}{|c|}{$\begin{array}{l}\text { 17. Key Words } \\
\text { Highway financing system, motor fuel tax, road pricing, } \\
\text { distance-based pricing, weight-distance charging, road } \\
\text { privatization, toll revenue assessment, system efficiency, spatial } \\
\text { equity, modal equity, highway cost allocation study }\end{array}$} & \multicolumn{3}{|c|}{$\begin{array}{l}\text { 18. Distribution Statement } \\
\text { No restrictions. This document is available to the public through the } \\
\text { National Technical Information Service, Springfield, VA } 22161\end{array}$} \\
\hline 19. Security Classif. (of this report) & 20. Security Classif. (c & is page) & 21. No. of Pages & 22. Price \\
\hline Unclassified & Unclassi & & 166 & \\
\hline
\end{tabular}

Form DOT F 1700.7 (8-69) 


\section{TABLE OF CONTENTS}

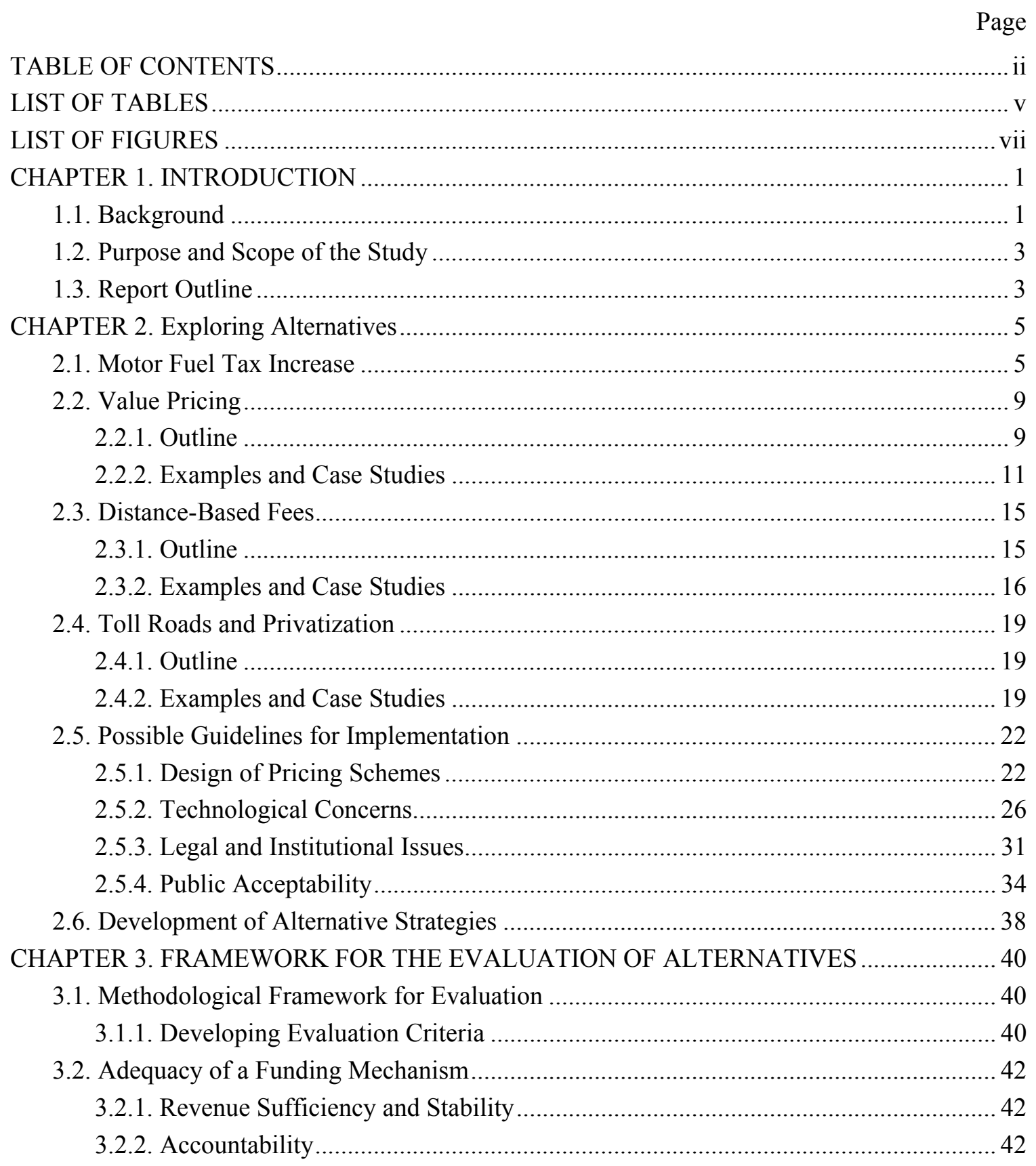




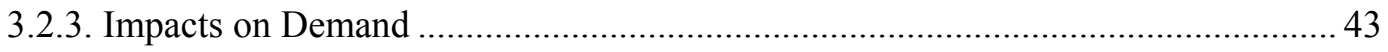

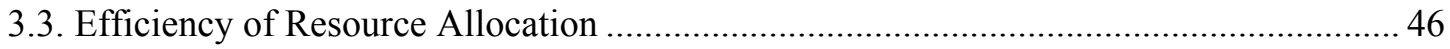

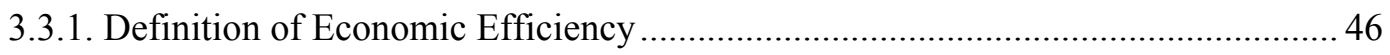

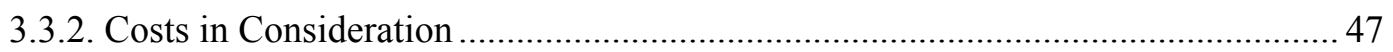

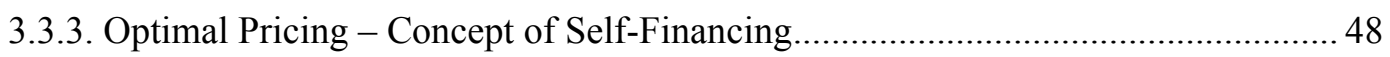

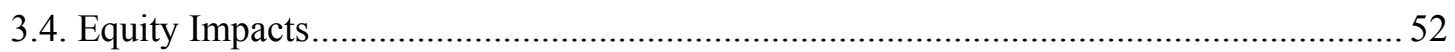

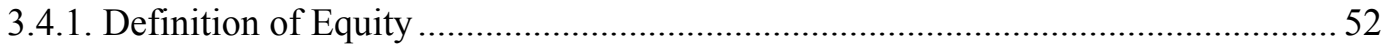

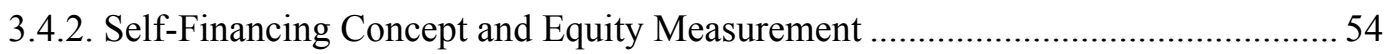

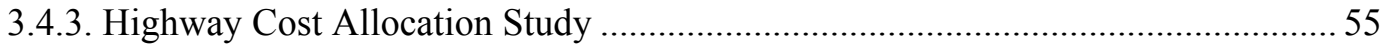

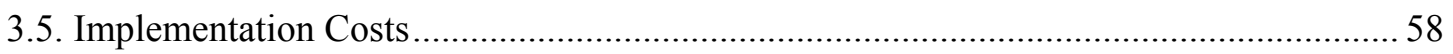

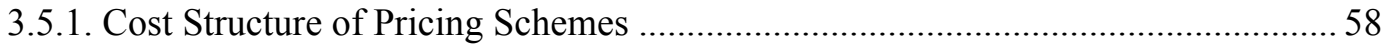

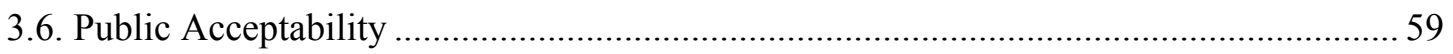

3.6.1. Factors that Affect Public Acceptability ………................................................... 59

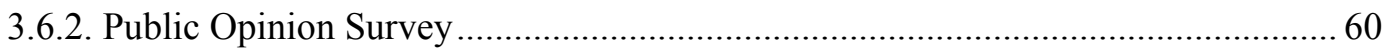

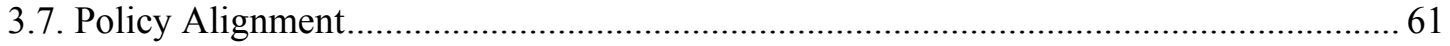

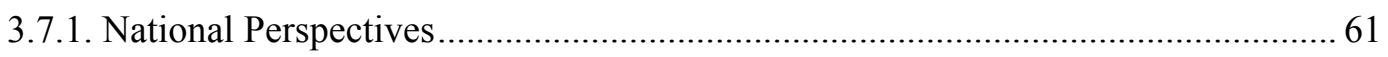

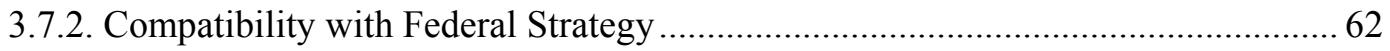

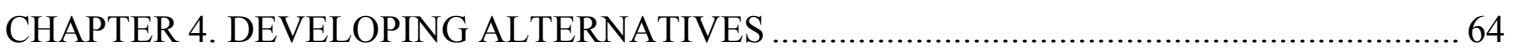

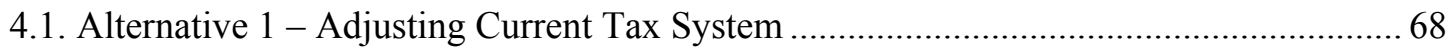

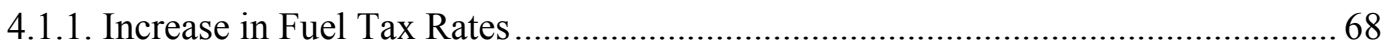

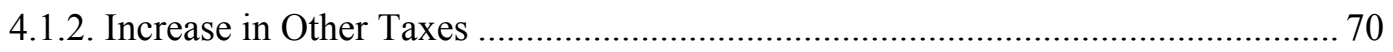

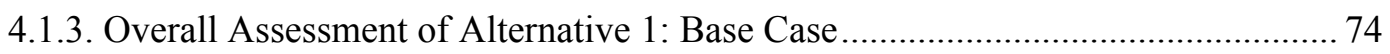

4.2. Alternative 2 - Current Tax System Supplemented by Other User Fees ......................... 76

4.2.1. Fuel Tax Supplemented by Toll Pricing .............................................................. 76

4.2.2. Fuel Tax Supplemented by Privatization of Road Segments .................................. 81

4.2.3. Fuel Tax Supplemented by Usage-Based Fees .................................................... 83

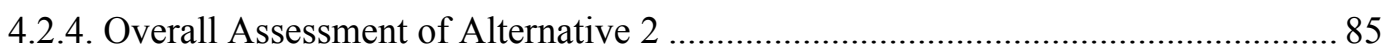

4.3. Alternative 3 - Replacing Fuel Taxes with New Pricing Schemes ................................. 86

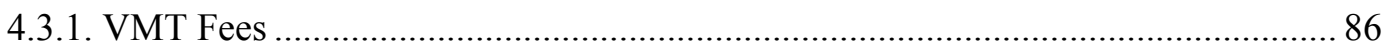

4.3.2. Future Adaptation of VMT Fees - Comprehensive Pricing ................................... 91

4.3.3. Overall Assessment of Alternative 3 ........................................................................ 95

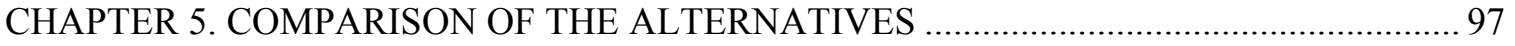

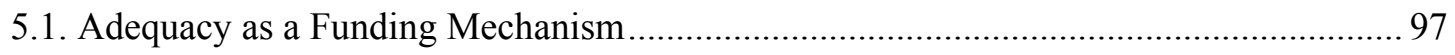

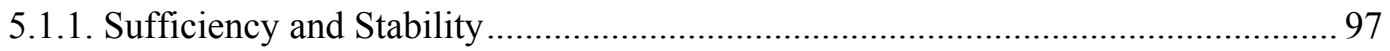

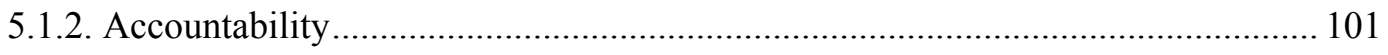

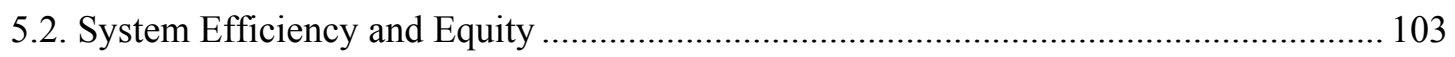

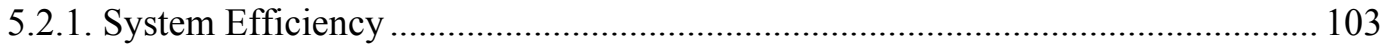

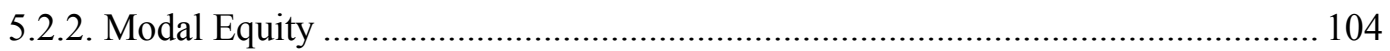




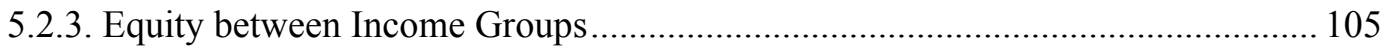

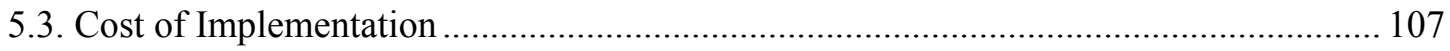

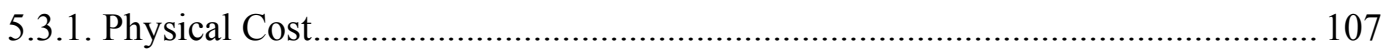

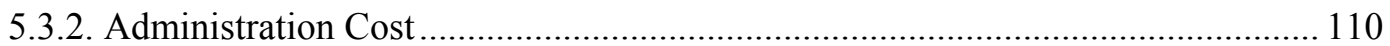

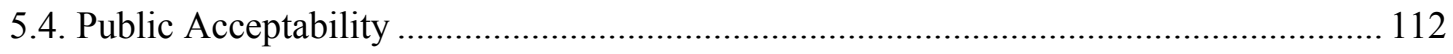

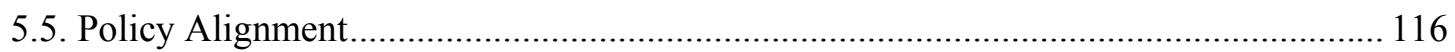

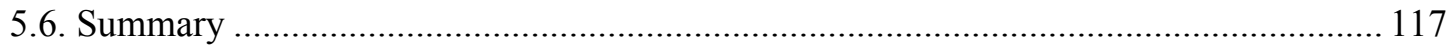

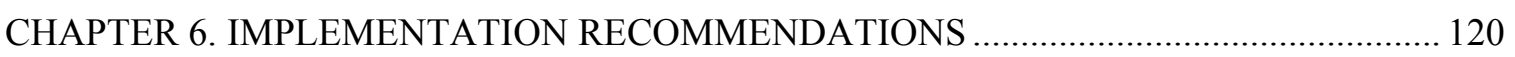

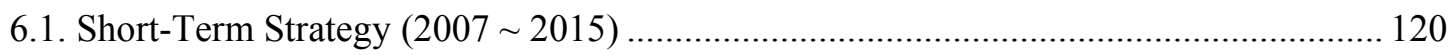

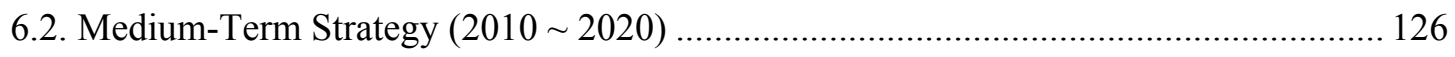

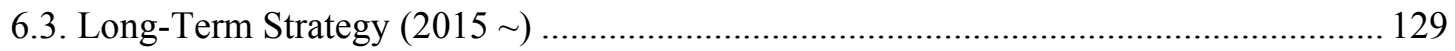

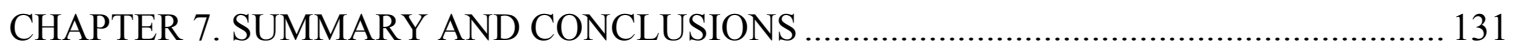

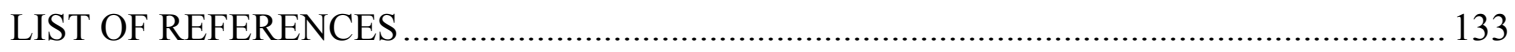

Appendix A. Forecasting Toll Revenue on a Typical Interstate of Indiana .......................... 142

Appendix B. Calculation of ISCURP Fee Rates Using Highway Cost Allocation Study..... 150 


\section{LIST OF TABLES}

Table Page

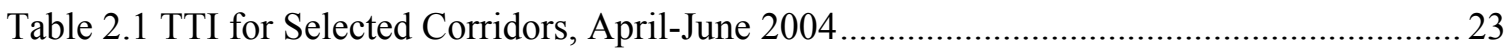

Table 2.2 Highway Costs and Equity Ratios by Vehicle Classes ................................................. 25

Table 2.3 Comparison of Ratios of Franchise Prices to Annual Revenues .................................. 26

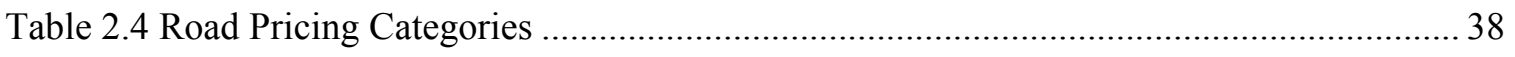

Table 3.1 System of Alternatives Evaluation: Possible Format of Outcome ................................ 41

Table 3.2 Elasticity of Traffic Demand with respect to Tolls....................................................... 44

Table 3.3 Elasticity of Traffic Demand with respect to Fuel Prices .............................................. 44

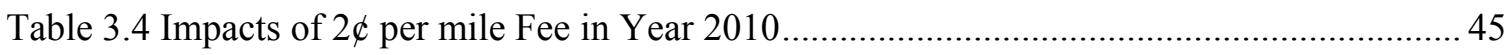

Table 3.5 Vehicle Travel Reduction of VMT Fee by Income Quintile (\%) ................................. 45

Table 3.6 Comparison of Costs and Charge Concepts............................................................... 48

Table 3.7 Equity Ratios Obtained from FHWA Highway Cost Allocation Study

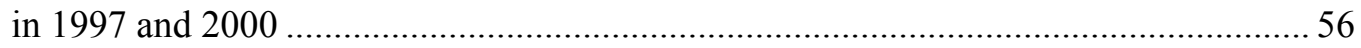

Table 3.8 Equity Ratios Obtained from Indiana Highway Cost Allocation Studies....................... 57

Table 4.1 Disbursements for the Indiana State-Administered Highways by

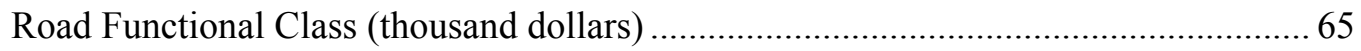

Table 4.2 State Highway Asset Information by Road Functional Class and Pavement Type ....... 65

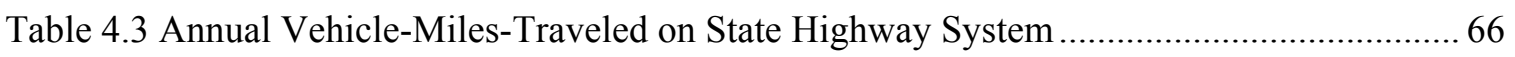

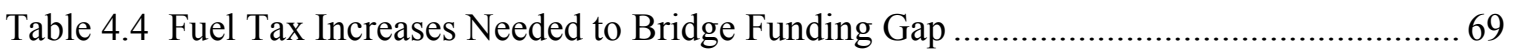

Table 4.5 Revenue and Distribution of Sales Tax, Indiana (thousand dollars, \%) ........................ 72

Table 4.6 Demand Elasticity of Indiana's Interstate Users with Respect to Toll Rate ................. 78

Table 4.7 Forecast of Toll Revenues from a Typical Indiana Interstate (in thousand dollars) ..... 79

Table 4.8 Estimated Cost of Implementation for Technology Options ......................................... 84

Table 4.9 VMT Values and VMT Fee Rates to Cover State Highway Disbursements .................. 88

Table 4.10 Mileage Fee Rate to Cover Highway Expenditure, Maintaining

Vehicle Registration Fee (thousand dollars, cents per mile)..................................... 88

Table 4.11 Mileage Fee Rate to Meet Future Needs in Year 2010 (thousand dollars, vehicles, cents per mile)

Table 4.12 Mileage Fee Rate to Meet Future Needs, Maintaining Vehicle Registration

Fee (thousand dollars, vehicles, cents per mile) (Year 2010) ..................................... 90

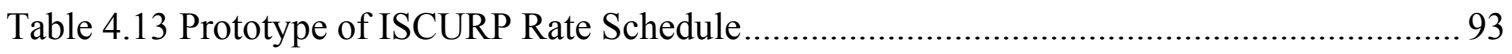


Table 4.14 Initial Reference Values of ISCURP Fee Rates (cents per mile)............................... 94

Table 5.1 Fuel Efficiency Forecasts by Energy Price Scenario ..................................................... 98

Table 5.2 Self-Financing Ratio under Current Fuel Tax System by Road Function Class.......... 105

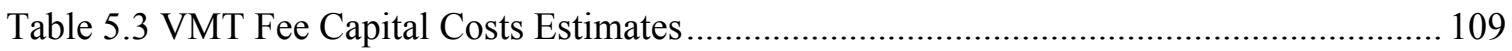

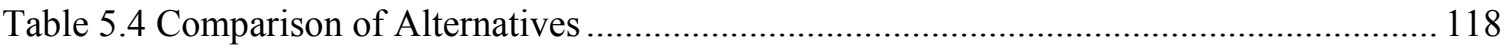

Table 6.1 Forecast of Annual Revenue for Fuel Tax Increase Cases (CPI-Based) ..................... 121

Table 6.2 Forecast of Annual Revenue for Fuel Tax Increase Cases (PPI-Based) ..................... 122

Table 6.3 Revenue Forecast for Fuel Tax Indexing Cases (CPI-Based) ...................................... 123

Table 6.4 Revenue Forecast for Fuel Tax Indexing Cases (PPI-Based) ..................................... 123

Table 6.5 Revenue Forecast for Vehicle Registration Fee.......................................................... 124

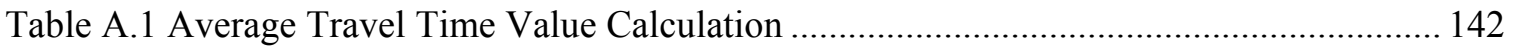

Table A.2 Toll Impact on Demand (annual VMT in 1000) by Vehicle Type and

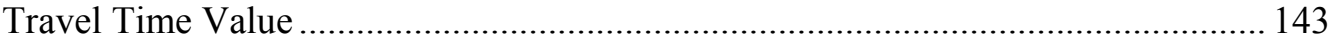

Table A.3 Toll Impact on Annual Revenue (in \$1000) by Vehicle Type and

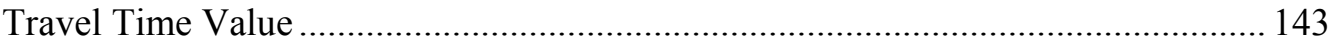

Table A.4 Arc Elasticity of Demand with Respect to Toll Rate ............................................... 145

Table A.5 Arc Elasticity of Revenue with Respect to Toll Rate ................................................. 145

Table A.6 Toll Rates of Indiana Toll Road by Vehicle Type (2007) ....................................... 147

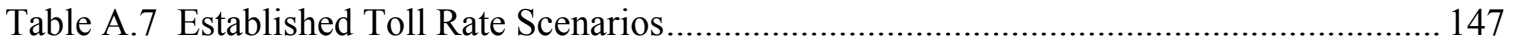

Table A.8 The Minimum and Maximum Annual VMT by Scenario (in 000's) ......................... 148

Table A.9 The Minimum and Maximum Annual Revenues by Scenario

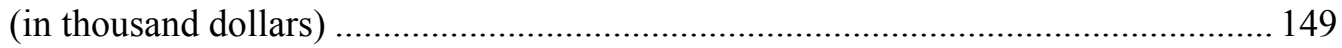

Table B.1 Bridge Design Increment Used in the Indiana Study in 1984 ..................................... 152

Table B.2 Annual State Highway Expenditure by Road Functional Class

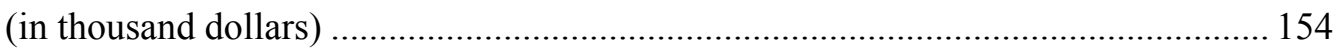

Table B.3 Annual VMT by Vehicle Configuration and Road Functional Class (2005)

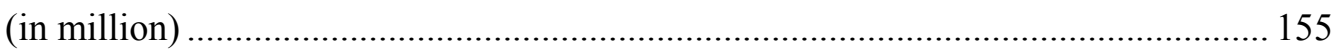

Table B.4 HCAS Results: Cost Responsibility with the Base Case Inputs (cents/mile) ............. 156

Table B.5 Cost Responsibility with Various NLR Portion of Maintenance Cost (cents/mile).... 157

Table B.6 Cost Responsibility with Various Minimum Pavement Thickness (cents/mile)......... 159

Table B.7 Cost Responsibility with Various LEF Values (cents/mile) ..................................... 161 


\section{LIST OF FIGURES}

\section{Figure Page}

Figure 2.1 Trends of Fuel Prices and Fuel Taxes (1960 2005, 2004 dollars) (VTPI, 2005a)........ 6

Figure 2.2 Trends of Average Cost and Tax Revenue per Vehicle-Mile (1960 2005, 2004 dollars) (VTPI, 2005a) ... 7

Figure 2.3 Vehicle Fuel Retail Prices for Selected Countries (Metschies, 2005) ........................... 8

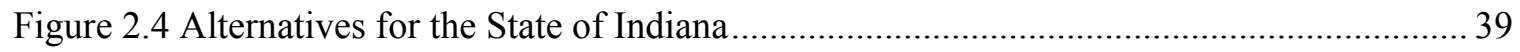

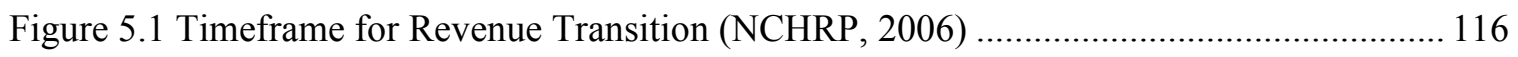

Figure A.1 Toll Impact on Demand (VMT) by Vehicle Type and Travel Time Value............... 144

Figure A.2 Toll Impact on Revenue by Vehicle Type and Travel Time Value........................... 144

Figure A.3 Arc Elasticity of Demand with Respect to Toll Rate................................................... 146

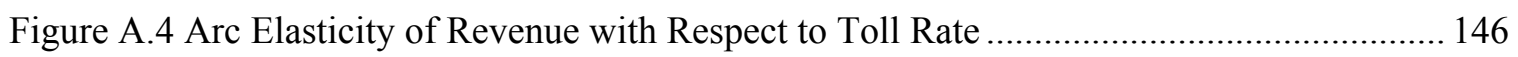

Figure B.1 Cost Responsibility with Various NLR Portion of Maintenance Cost ...................... 158

Figure B.2 Cost Responsibility with Various Minimum Pavement Thickness........................... 160

Figure B.3 Cost Responsibility with Various LEF Values ...................................................... 161 


\section{CHAPTER 1. INTRODUCTION}

\subsection{Background}

For decades, motor fuel taxes have been the major source of revenue for highway construction, maintenance, and operations at the state and local levels. However, compared to the budget needed to achieve the desired performance levels of highway systems, shortfalls in revenue are an increasing occurrence. According to AASHTO (2002), \$92.0 billion (in 2002 dollars) is needed by state and local governments annually for highways and bridges to maintain both the physical condition and the performance characteristics of the system between 2004 and 2009. The Conditions and Performance Report (FHWA, 2002), which is a similar needs study, predicts that the annual cost to maintain the current condition and performance of highways and bridges will be $\$ 75.9$ billion for 2010-2020 (in 2000 dollars). The current capital investment on highways and bridges made by all levels of governments is lower than the assessed needs, although it has been increased sharply since TEA-21 was enacted. For example, in 2000, the total capital investment on highways and bridges was $\$ 64.6$ billion across the all levels of governments, only about $85 \%$ of the assessed needs ( $\$ 75.9$ billion).

Consistent with the previous studies, the most recent need assessment conducted by the U.S. National Chamber Foundation (2005) also noted significant shortfalls in current revenue streams to both maintain and improve the U.S. highway and transit systems. According to the analysis results, in order to maintain just the current condition, current revenue streams will have a cumulative shortfall through 2015 of $\$ 0.5$ trillion. And if improvements are to be made to a level that benefits the national economy, the shortfall will amount to \$1.1 trillion in 2015.

The State of Indiana is no exception to this nationwide insufficiency in transportation

funding according to a 10-year highway financial forecast included in the recent business plan (2006-2007) for Indiana Department of Transportation (INDOT, 2005). In this document, future revenues were compared with the expected funding needs to complete projects that were planned to preserve the existing facilities and to build new facilities to improve mobility and accessibility. 
It was estimated that the annual funding gap would be gradually increasing each year, such as $\$ 152$ million in 2008 and $\$ 167$ million in 2010, until it reached \$405 million in 2015. The possibility of additional funding gap was indicated as the state highway system targets a higher level of mobility and accessibility, requiring completion of larger number of projects.

Highway needs and funding gap trajectory under several hypothetical scenarios were studied in the research conducted by the Joint Transportation Research Program (Sinha et al., 2005). Including all projects in INDOT's Long Range Plan and using HERS-ST model, the study estimated that the state highways would require \$29.8 - 30.2 billion during 2006-2020. On the contrary, Indiana's highway revenue was estimated to be $\$ 13.4$ - 16.9 billion during the same period based on the current trend. Consequently, the JTRP's 2005 need study concluded that an annual funding gap would be $\$ 860$ - 1,120 million, which is a more aggressive estimation than the INDOT's 2006-2007 business plan. However, regardless of aggressiveness of future scenarios that are hypothesized, it is expected that there will be a significant level of future funding needs that cannot be covered by the current revenue stream.

One of the major reasons for the projected deficit in transportation revenue is that while travel is increasing vehicle fuel economy is improving, thereby reducing fuel tax revenues for each mile of travel. Also, fuel taxes do not automatically increase with rising costs. Another factor in the revenue shortfall issue is the increasing use of hybrid vehicles and bio-fuels. The traditional fuel tax does not apply in these cases.

The growing financing gap indicates that a new financing mechanism is needed. A new financing mechanism should generally meet the following criteria (TRB, 2005; Whitty, 2003; Adams et al., 2001): First, the pricing scheme should be financially effective, that is, it needs to generate sufficient revenue not only to replace the fuel tax mechanism, but also to bridge the funding gap. Second, it should help the transportation system achieve its efficiency by charging users based on their road use, in a way that will support the entire network. Third, the program should be able to be implemented with low administrative and enforcement costs. Fourth and last, through the mechanism, fairness of the system should be attained in a way that is acceptable to the public. By reviewing the suggested criteria in earlier studies and examining the highway financing environment in Indiana, the present study develops its own evaluation framework, the details for which are discussed in Chapter 3.

There have been several studies conducted at the national level, as well as in other states in the U.S. to explore possible alternatives to fuel taxes. TRB Special Report 285 (2005) 
especially provided a comprehensive review of variable revenue sources including increases in current resources, debt financing, toll pricing, and mileage charging. State level research conducted, for example, in California (Adams et al., 2001) and South Carolina (SCDOT, 2003), has also presented approaches consistent with the national perspective. This report presents possible highway financing mechanisms from the perspective of Indiana, in terms of their background, implemented examples, issues, and evaluation results.

\subsection{Purpose and Scope of the Study}

This research explores possible alternative revenue sources for the State of Indiana. Financing tools such as fuel tax increases and several user-charging schemes, including toll pricing as well as distance-based fees, are considered. The evaluation criteria to select the best plan for Indiana are suggested and quantitative and qualitative analyses for each alternative are conducted based on the methodological framework developed. The analyses include estimation of fee/toll rates and revenue streams and a simulation model based on the Indiana Statewide Travel Demand Model (ISTDM). Data acquisition and the analyses are accomplished from the perspectives of the state government.

\subsection{Report Outline}

In Chapter 2, examples of several types of user charges are examined to understand the financing concepts, the impacts on users and transportation systems, the caveats in their implementations, and possible guidelines for several aspects, including pricing schemes, technological choices, institutional issues, and public acceptability. An overall scheme of alternatives is also provided for consideration for Indiana.

Chapter 3 provides a methodological background of the criteria for the evaluation of alternatives related to user charging schemes. Chapter 4 is a review of the current financing situation in Indiana, as well as future predictions. Based on the financing framework provided in 
Chapter 3, alternatives are developed and their implementation schemes are discussed in detail. Chapter 5 provides a multi-objective decision-making exercise to evaluate the alternatives. In Chapter 6, recommendations are made for future financing tools with considerations for the implementation issues and political concerns. Chapter 7 summarizes the study results and presents conclusions. 


\section{CHAPTER 2. EXPLORING ALTERNATIVES}

There are several possible financial tools to secure required revenue. First, the current fuel tax rates can be increased. Since fuel taxes have taken a traditional role as user fees, adjusting fuel taxes could be an easier policy to implement than introducing new methods. However, political reluctance to raise existing fuel taxes is widespread at all levels of government, which can be a major barrier of this approach.

For financing tools other than motor fuel taxes, this research makes the distinction between supplementary revenue sources and main revenue sources. In this context, supplementary sources are particular facilities or regions where tolls or fees are imposed and can act as offsets to budget shortfall. This category of alternatives includes various types of toll pricing, such as facility tolls and cordon tolls, which are often referred to as congestion pricing, value pricing, etc. This approach, however, cannot be considered a main alternative, not only because the revenue generated from individual facilities or particular areas cannot cover the financing needs of the entire state, but also because many implementations of this type are valued more for their role as demand management and congestion reduction measures rather than as a revenue source. To replace current fuel taxes in a more complete manner would require relatively innovative approaches such as distance-based charging systems.

In this chapter, the experiences of other U.S. states and other countries with each revenue source category are addressed, including analysis of surrounding conditions, which make the implementation of each alternative successful or infeasible.

\subsection{Motor Fuel Tax Increase}

Motor fuel taxes are the most important source of transportation funding. However, this taxation scheme has certain pitfalls as follows (Whitty, 2003): 
- Fuel taxes are not indexed for inflation, and it is not easy to raise the tax rate because of a general reluctance by the public and politicians.

- Fuel taxes may not be able to generate the necessary revenue to provide quality transportation services in future years as alternative energy sources and propulsion systems based on them become more common in the near future.

- Increased fuel efficiency will result in lower fuel tax receipts per mile traveled.

Shortfalls in fuel tax revenue are mainly due to the tax structure, which is not indexed for inflation and the overall increase in fuel efficiency. Figure 2.1 shows the trend of fuel prices and taxes (federal and states average) in 2004 constant dollars. While fuel prices have fluctuated and even increased since the late 1990s, fuel taxes have gradually decreased for that time period.

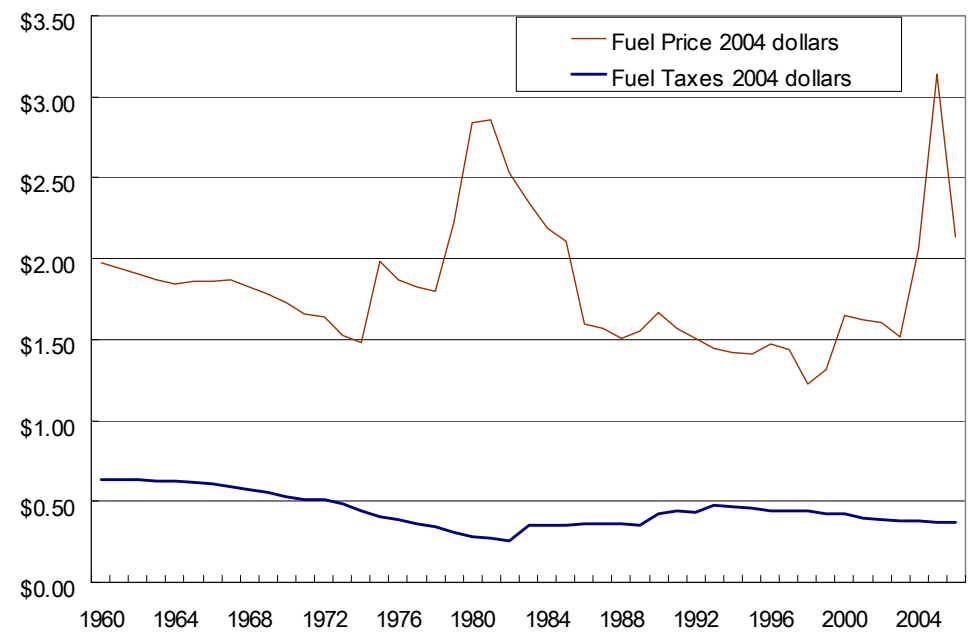

Figure 2.1 Trends of Fuel Prices and Fuel Taxes (1960 2005, 2004 dollars) (VTPI, 2005a)

Figure 2.2 depicts the trends for the average cost and revenue generated per vehicle-mile. The upper curve of the figure represents the average cost per vehicle-mile, obtained from the ratio of the fuel price to the average miles-traveled per gallon, and shows similar trends to the fuel price (the upper curve in Figure 2.1). The lower curve in Figure 2.2 clearly shows the decreasing trend of tax revenue per vehicle-mile. 


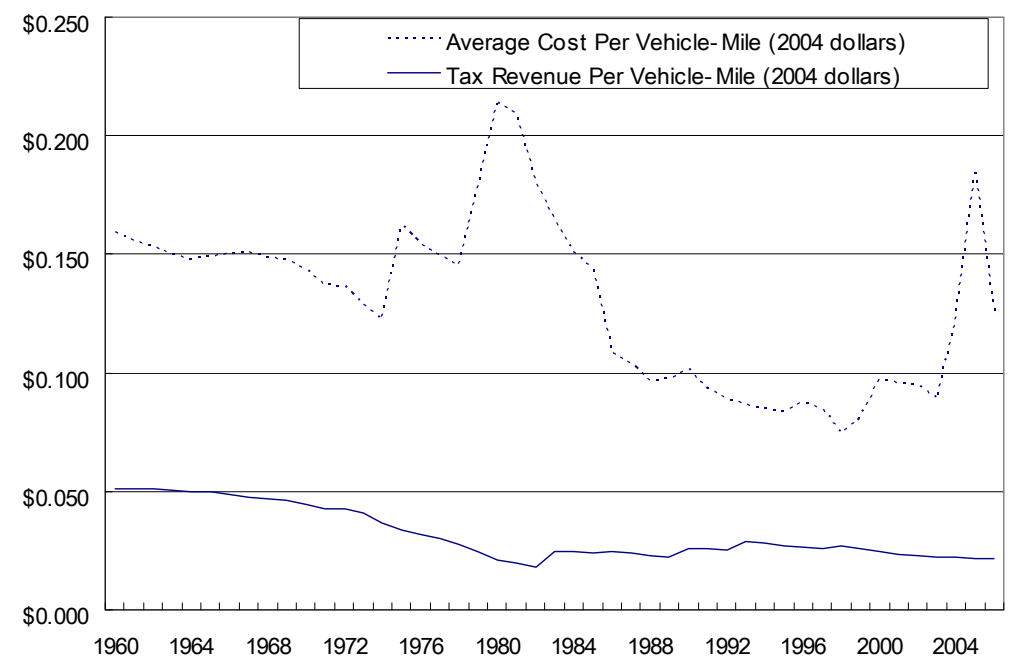

Figure 2.2 Trends of Average Cost and Tax Revenue per Vehicle-Mile (1960 2005, 2004 dollars) (VTPI, 2005a)

Elected officials are generally reluctant to raise fuel taxes in spite of increases in the cost of transportation programs. Instead, they have chosen other sources, especially borrowing and local sales taxes. However, many researchers, including Wachs (2003), insist that raising fuel taxes would be more effective, efficient, and equitable than other tools to raise revenue.

The common belief about fuel taxes is that they are well below their theoretical optimal levels, which conceivably can cover the all roadway costs, particularly if external costs are considered. Compared to motor fuel taxes in other developed countries, those in the U.S. are relatively low as illustrated in Figure 2.3. The 1997 Federal Highway Cost Allocation Study (FHWA, 1997) found that vehicle user fees, which include the sum of fuel taxes, vehicle registration fees, and road tolls, would need to increase by more than $43 \%$ to fund all roadway expenses. This study also noted that the increment would have to be even more if other externalities, such as congestion and environmental impacts, are to be internalized through fuel taxes. 


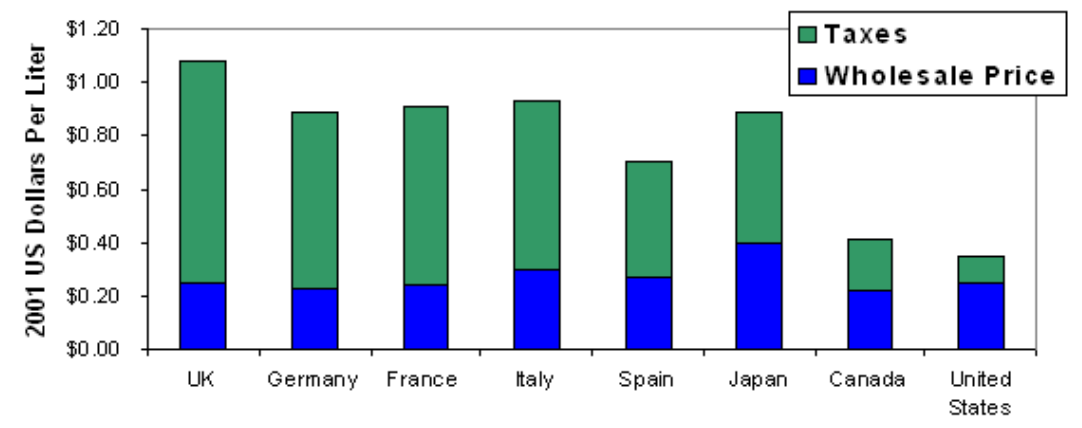

Figure 2.3 Vehicle Fuel Retail Prices for Selected Countries (Metschies, 2005)

Methods other than simply raising the overall taxes rates also have been suggested to augment fuel tax revenue (VTPI, 2005b):

- Impose a carbon tax, which reflects the amount of carbon emitted and can act as an incentive to reduce emissions.

- Apply a general sales tax to motor fuel, which is exempted by many jurisdictions currently.

- Index the fuel tax rates to inflation or roadway costs. 


\subsection{Value Pricing}

\subsubsection{Outline}

Toll pricing on transportation facilities comprises tolls on individual facilities and cordon tolls. The former are levied on a highway segment, bridge, or tunnel, while the latter are designated on a geographical area, such as central business districts.

The concept of toll pricing has been around for years with a great deal of experience available from all over the world, including the U.S. and European and Asian countries. Fixed tolls on roadways can act as service fees for those facilities, while tolls based on the congestion level can be used as a strategy to manage demand on a limited road network. Facilitated by recent developments in information and communication technologies, more innovative and strategic attempts have been made in road pricing. In the U.S. the Value Pricing Pilot Program (VPPP), authorized by the Intermodal Surface Transportation Efficiency Act of 1991 (ISTEA) and amended by TEA-21, was launched to encourage states to understand the feasibility of various road pricing schemes, obtain demonstrated results, or to implement them. A European program was also undertaken comparable to VPPP, which is called PRoGRESS (Pricing Road use for

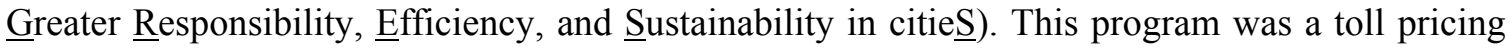
demonstration project in eight European cities, from 2000 to 2004, supported by the Directorate General for Energy and Transport of the European Commission. Illustrative implementations under these programs are discussed in the following sections. Other examples are also studied, including the most popular model of cordon tolls, with decades of implementation in Singapore, followed by its successors in European countries such as the United Kingdom, Italy, and Norway. Concepts of various types of tolling, including value pricing, are discussed below:

\section{Road Tolls}

A road toll is a very common and straightforward way to fund highway and bridge maintenance. This method is considered to be more equitable and economically efficient than other funding instruments since tolls from the users are dedicated to the costs of that particular facility and 
exclude contributions by non-users. Tolls on specific roadways are often associated with privatization of facilities, that is, private companies who built the roads or bridge collect the toll to fund construction and maintenance.

\section{Value Pricing (Congestion Pricing)}

Intended to mitigate peak hour congestion, the core idea of value pricing is to discriminate tolls based on the level of congestion. Tolls can vary based on a predetermined schedule or based on real-time congestion information. Generally, value pricing has two different objectives: 1) raise revenue and 2) manage demand. Some implementations impose tolls on only specific lanes rather than the entire road in order to provide choices for drivers to use either a congested toll-free lane or congestion-free toll lane.

\section{Cordon (Area) Tolls}

Cordon tolls can be interpreted as entrance fees for a designated area, often a congested center of urban areas. It is common to have different tolls according to the congestion level of the cordon area; namely, users are charged higher fees during peak hours.

\section{HOT (High Occupancy Toll) Lanes}

HOT lanes allow vehicles not meeting occupancy requirements on HOV lanes if they pay tolls. As one approach to a managed lane, HOT lanes give motivation for modal shift, enable more efficient use of HOV lanes, and can reduce general purpose lane occupancy.

\section{FAIR (Fast And Intertwined Regular) Lanes}

FAIR lanes divide currently free, general-purpose traffic lanes into two sections: fast lanes and regular lanes. Fast lanes would be electronically-tolled express lanes, with tolls set in real time to limit traffic to the free-flowing maximum. Under the FAIR lanes scenario, drivers using the regular lanes, which are more congested than fast lanes, during rush hour periods, would be compensated with credits that could be used as toll payments on days when they choose to use express lanes. The express-lane credits would compensate drivers for giving up their right to use lanes that they "have already paid for," and for any added delays that might result (ENO, 2002). 
As noted in the beginning of this chapter, toll pricing can only be supplementary revenue source, especially because of its current technological basis, which is not readily applicable to area-wide implementation. Although pricing schemes under this category are not quite suitable for substituting as a whole funding mechanism based on fuel tax, the richness of experience in toll pricing can offer insight to their implications on pricing scheme design, implementation policy, and public acceptability issues.

\subsubsection{Examples and Case Studies}

HOT Lanes on I-15 in San Diego (SDSU, 2001; FWHA, 2007)

HOV lanes on I-15, which opened in 1988 and experienced underutilization by the mid-1990s, were converted to HOT lanes in 1996. During the first phase through March 1998, a limited number of solo drivers were provided unlimited use of HOV lanes by paying a flat fee. In April 1998, the FasTrakTM pricing program, under which customers in single occupant vehicles pay tolls varying dynamically with the level of congestion in the HOV lanes, started its operation. Fees vary in 25 -cent increments as often as every six minutes to yield free-flow speed on the HOV lanes (LOS C). Variable message signs located in advance of the entry points inform motorists the toll rate, which varies between $\$ 0.50$ and $\$ 4.00$ normally. When the congestion level is too high, the toll can be as high as $\$ 8.00$.

The Phase II third-year evaluation report issued in 2001 concluded that this project was successful in that the traffic conditions and revenues balance improved since implementation. The post-project HOV volume was significantly higher than before, and the redistribution impact of volumes from the peak hours to the peak shoulder was apparent. Also, as the most conspicuous benefit, FasTrakTM users could save up to 20 minutes under the worst congestion conditions. At the end of the three-year evaluation, enough revenue was raised to fund a new express bus service, Inland Breeze. Overall public opinion of this policy was positive with relatively strong support from the carpoolers and express bus service users; and most of I-15 respondents agreed on the idea of imposing tolls on solo drivers in using HOV lanes.

However, the current pricing structure did not realize marginal cost since the price did not fluctuate in a truly dynamic manner in response to the real congestion level. Given the 
concern, the San Diego Association of Governments (SANDAG) is planning expansion of the current system to create a 20-mile managed lanes facility with dynamic tolling. The per-mile fees will fluctuate on the basis of the value of travel time saved between the managed lanes and general purpose lanes (FHWA, 2007).

HOT Lanes on Two Radial Corridors in Houston (I-10 and US 290) (FHWA, 2004b; FHWA, 2005b; and Burris and Appiah, 2003)

Houston's “QuickRide" pricing program was launched for the existing HOV lanes of I-10 in January 1998 and in November 2000 for US 290. The reversible HOV lanes are restricted to vehicles with three or more occupancy during the peak hours. The pricing program allows twoperson carpool vehicles to use the HOV lanes by paying $\$ 2.00$ toll per trip, while single-occupant vehicles are not allowed to use the HOV lanes. This project sustains only electronic transactions, and there is no cash on the facility. Results from surveys conducted on I-10 indicate that the primary source of QuickRide participants were persons who formerly traveled in single-occupant vehicles in the regular lanes. Toll revenues pay for all the operational costs of the program.

After five years in operation (three years on US 290), the QuickRide program receives comparatively lower patronage than the I-15 HOT lane project. The primary issue limiting QuickRide use appears to be the inconvenience of carpooling rather than cost.

Express Lanes on State Route 91 in Orange County (FHWA, 2004b; FHWA, 2005b; and OCTA, 2004)

Since December 1995, the S.R. 91 Express Lanes have been operated in a 10-mile section of that freeway, which is very congested during peak periods. According to the toll schedule effective August 2005, the tolls on the express lanes range between $\$ 1.10$ and $\$ 7.75$ based on the time of day to maintain free-flow traffic condition for the tolled lanes. Beginning in May 2003, vehicles with occupancy of three or more can receive a 50\% discount Monday through Friday between 4:00 pm and 6:00 pm, and can get an exemption on their tolls for the rest of those periods. A toll exemption is also applied for zero-emission vehicles and disabled person's license plates.

By the end of fiscal year 2005, it was reported that there were over 172,000 transponders circulating. During that fiscal year, about 12.7 million vehicles were served, averaging 35,000 vehicles per day, to yield $\$ 32.5$ million in gross revenue. Express lanes carry more than $40 \%$ of 
total demand on SR 91 during congested periods, which in turn results in a $33 \%$ higher throughput than the general purpose lanes.

\section{London Congestion Pricing (Litman, 2005)}

In February 2003, the city of London, England imposed a charge to drive into the city center, an eight-square-mile area, as a way to reduce traffic congestion and raise revenues for transport improvements. The charging zone was expanded in February, 2007 and the charge for entering the zone is about $\$ 15$ a day during working hours Monday through Friday. An automated system checks vehicles entering the charging zone against a database of motorists who have paid the fee. Despite considerable controversy, the program was implemented without major problems, and has substantially reduced traffic congestion, improved bus and taxi service, and is generating revenues. Vehicle traffic speeds have increased and bus transit service has improved, while accidents and air pollution have declined in the city center. Public acceptance has grown and the mayor was reelected in 2004 largely due to the success of the congestion pricing program. This was the first congestion pricing program in a major European city, and its success suggests that congestion pricing may become more politically feasible elsewhere.

\section{Highway 407 (www.407etr.com)}

Highway 407, the Express Toll Route (ETR), is a multi-lane, electronic highway running 69 kilometers across the top of the Greater Toronto Area, from Highway 403 in Oakville to Highway 48 in Markham. The first phase of the highway opened in 1997 and runs from Highway 410 in Brampton to Highway 404 in Markham. It was constructed in a partnership between Canadian Highways International Corporation, a private company specializing in highway development, and the Province of Ontario. It is now owned by 407-ETR International, Inc. Fees are $10 \notin$ per kilometer $(16.1 \phi / \mathrm{mi})$ during weekday peaks, $8 \notin$ per kilometer $(12.9 \notin / \mathrm{mi})$ during weekends and off-peak periods, and $4 \varnothing$ per kilometer $(6.4 \varnothing / \mathrm{mi})$ at night. About $70 \%$ of tolls are collected through the use of electronic transponder cards that deduct charges from prepaid accounts, and $30 \%$ using a license plate photography billing system. Speeds on Highway 407 are about double that of parallel free highways. Peak-hour traffic volumes average 11,000 to 12,000 vehicles. Surveys indicate a high level of user satisfaction. 


\section{Cordon Tolls in Rome (PRoGRESS, 2004a, 2004b)}

The central area of Rome, Italy, having about 42,000 residents and over 116,000 workers, was selected as the site for demonstration project for the Limited Traffic Zone (LTZ) — an example of the cordon toll. The access permits were adopted in a systematic way in 1994, and the automatic operation started in October 2001. The main objectives of this project were to control the number of vehicles entering the congested area and to promote public transport to the historic center. This demonstration project was undertaken to assess the impact of different road pricing schemes, based on both a per-trip and a time-based charging structure in the LTZ during operation times ranging from 6:30 am to 6:00 pm during the weekdays and from 2:00 to 6:00 pm on Saturday.

The major institutional background that supported road pricing in Rome includes national laws on land use and environmental protection, and regional and local regulations on parking time and car circulation, the purpose of which are to protect human health, public order, and environmental and cultural city heritage. According to a user survey on the acceptance of the system, the majority of residents and shop owners perceived the access control of Rome as a good idea. As a result of the implementation, considerable changes in trip mode from private to public transport have occurred. The area experienced a $10 \%$ decrease in traffic during the day with a larger reduction of $15 \%$ during the morning peak hour, a $10 \%$ increase of two-wheelers, and a $6 \%$ increase in public transport. After the demonstration that was conducted until 2004, access restriction to the central area of Rome is being implemented, combined with pricing scheme.

\section{Cordon Tolls in Trondheim (PRoGRESS, 2004a, 2004b)}

A full scale electronic cordon toll scheme in Trondheim, Norway was initiated in 1991 with a major upgrade in 1998 when the old toll ring was replaced by a zonal charging system for the whole urban area. A technological option based on the dedicated short range communication (DSRC) standard was introduced in 2001. The PRoGRESS demonstration in Trondheim consists of the long-term effect evaluation of existing tolling system, implementation of a new CBD ring, and a stated preference survey for a through-traffic charging system in the city center.

Evaluation results showed that since the first implementation in 1991, this strategy decreased car use for the hours and places where the toll system was operating. Thus, although there was not significant decrease in the total number of trips, there were significant changes in spatial and temporal travel patterns. 
In 2003, the toll system was revised to induce more reduction of congestion level. With the normal charge of 1.5 Euros (2.0 U.S. dollars), traffic level to/from the city center was declined by $10-15 \%$. According to the public opinion survey conducted in 2003, the attitudes were generally positive toward the pricing scheme.

\subsection{Distance-Based Fees}

\subsubsection{Outline}

Distance-Based Pricing (also called Pay-As-You-Drive and Mileage-Based) is based on how much a vehicle is driven. This approach could be the most appropriate alternative to ultimately replace the fuel tax and could become the principal revenue source for the nation's transportation system. There are several different funding tools in this category, which are discussed below.

\section{Weight-Distance Truck Tolls}

Weight-distance truck tolls impose fees on freight carriers for their use of the road based on the weight and distance traveled (Fwa and Sinha, 1987b). The measurement of weight varies depending upon specific programs (i.e., actual weight, maximum laden weight, or axle configuration). The intent of such tolls is to recover the full costs associated with the operation of heavy vehicles on the road network. As discussed later in Section 3.4.3, the unit costs per mile traveled vary drastically according to the vehicle classes and weight. Therefore, the weightdistance toll is a more equitable pricing method than fuel taxes because the roadway costs imposed by individual vehicles are more accurately reflected under this scheme. European countries recently began implementing this pricing scheme.

\section{Distance-Based Road User Fees (Vehicle-Mile-Traveled (VMT) Fees)}

Distance-based road user fees, called "VMT" fees, charge road users a fee that is proportional to the number of miles driven. Although traveled distances are reflected also in current fuel taxes, VMT fees are a more direct way to charge for road usage. In the long term, it may be possible to 
discriminate fees according to the jurisdiction of the highways and to distribute the revenue gained from each highway agency to the relevant governmental authority.

The following section reviews examples and case studies under these pricing schemes, including Heavy Vehicle Fees (HVF) in Europe, VMT pilot projects in the U.S., and incubating VMT studies in Europe.

\subsubsection{Examples and Case Studies}

Austria: “GO” Weight-Distance Truck Toll Program (Schwarz-Herda, 2004)

Launched in January 2004, the GO program charges a toll for all vehicles exceeding weight of 3.5 tons. Fee rates are determined depending on the weight class and the number of axles. The technological system is configured by an on-board unit on each vehicle and 420 gantries distributed throughout the network. On the basis of DSRC signals, on-board units communicate with gantries for distance and fee rates information. In order to prevent toll evasion, vehicles are flagged for investigation when they are not equipped with on-board units or simply when the

detection is failed. Truckers without equipments have to pay the tolls manually. The system is designed to be interoperable with the Swiss tolling program, by allowing automatic payment of Swiss drivers when they insert a chip in their on-board units.

\section{German "Toll Collect” Truck Toll (operational 2005) (PRoGRESS, 2004a, 2004b)}

Plans to introduce tolls on trucks beginning in 2003 were approved by the German cabinet in August 2001. Vehicles over 12 tons are charged 0.14-0.19 Euros per kilometers (0.31-0.42 U.S. dollars per mile), depending on the levels of emission and the number of axles. It was stated that the rationale of this plan is to transfer the financial burden to sustain roadway system from the general taxpayers to commercial heavy vehicles. The toll rates were designed to reflect road wear caused by incremental weights. The revenues generated from this toll project are dedicated to transportation programs that aim to mitigate congestion. 
Swiss “HVF” Truck Toll (PRoGRESS, 2004a, 2004b; Werder, 2004)

Heavy goods vehicle fee (HVF) of Switzerland charges all vehicles using any link of Swiss road network (not just highways) with a maximum laden weight exceeding 3.5 tons, since its launching in January 2001. The fees are calculated on the basis of distance traveled, maximum laden weight, and the emission class of the vehicle. Intending to motivate a freight modal shift from road to rail, the pricing structure is designed to reflect both the direct and external costs of truck travels. Fee calculation and collection are taken place by the technological configuration based on on-board units featuring GPS and DSRC signals, supported by vehicle's tachometer (including odometer information). Installment of on-board unit is mandatory for all Swiss vehicles and optional but encouraged for foreign vehicles. The DSRC signals are used for communication on the primary arterial network, while communication on the minor network is based on the GPS signals. In both cases, odometer information is used to meter the distance traveled on Swiss roads. Truck traffic, which had increased by 5-6\% annually before introduction of the toll, is now significantly decreasing (e.g., an average reduction was $5 \%$ in each of the first two years).

\section{RUFTF (Road User Fee Task Force) in Oregon (Whitty, 2003; FHWA, 2007)}

Under a mandate from the state legislature, the Oregon Department of Transportation has organized a Road User Fee Task Force conducting a pilot study of mileage-based user fees and area-wide congestion tolls, facilitated by on-board units featuring GPS receivers and short wave radio communications. The technology platform was demonstrated successfully in May 2004. In the fall of 2005, 20 trial vehicles were equipped with the on-board technology for an initial trial run of six months. After the verification of technological functionality, 260 trial vehicles in Portland were equipped with on-board units to participate in a one-year period demonstration. During the period, participants paid distance charges instead of the fuel tax by receiving rebates on the standard fuel tax at gas stations where they are charged mileage fees. The demonstration was completed in summer 2007. Depending on the evaluation of study results, legislation to enact the mileage fee (and potentially introduce congestion tolls) on a statewide basis may be considered. 
GPS Based Pricing in the Puget Sound Region, Washington (FHWA, 2005b; FHWA, 2007)

The Puget Sound Regional Council is conducting a test of congestion tolls at network level. Approximately 350 households, collectively owning close to 500 vehicles, participated in the study. Each vehicle owned by a participating household was equipped with an on-board unit, complete with cellular communications and a GPS receiver. The proposed technological configuration enables detection of vehicle location, calculation of the ensuring charge, and periodic uploading of the data to a central computer center. The study does not include timedependent distance-based user fees, but instead is designed to evaluate the behavioral response of drivers to congestion-adjusted distance pricing (the study includes a built-in mechanism to provide a financial reward for drivers who reduce their level of travel during peak congestion periods). A prototype for the on-board unit was demonstrated successfully during the summer of 2004 , and the operational portion of the project was completed in the spring of 2006. As a result of the demonstration, drivers' behavioral data was collected and analyzed to obtain demand elasticity with respect to distance-based charging. It was found that such a toll system could reduce vehicle use during peak travel times by approximately $10 \%$.

ARMAS Pan European Tolling Project (Gomes et al., 2004; Sorensen and Taylor, 2005)

On behalf of the European Union, the European Space Agency has initiated the Active Road Management Assisted by Satellite (ARMAS) program. ARMAS involves the use of on-board vehicle equipment incorporating satellite-based positioning information and cellular communications. Initial trial applications focus on electronic road tolling, which may be implemented across all of Europe as early as 2010. Additional applications envisioned for the technology include improved safety (obstacle detection and avoidance, incident warnings, etc.), increased traffic management capabilities (e.g., electronic speed advisory and enforcement), fleet management support, and dynamic route guidance services. The preliminary feasibility study for ARMAS was completed successfully in November 2003. Upon the completion of trial projects in October 2006, architecture definition, feasibility assessment, and the demonstration of a test-bed focused on electronic fee collection were covered. In the next phase of the project, extensive trials with a larger number of vehicles will be performed, supported by engagement of several stakeholders both from public and private sectors in Portugal, Netherlands, and Ireland. This stage of demonstration started in October 2006 with duration of 17 months. 


\subsection{Toll Roads and Privatization}

\subsubsection{Outline}

Privatization offers the potential to increase governmental revenue through lease arrangements for right-of-way access along interstates or other highway access points. Public-private partnerships and private infrastructure investments are most likely to result in toll roads to recover investments that may also tackle congestion problem (SCDOT, 2003). In this section, examples are discussed to identify possible directions for implementation.

\subsubsection{Examples and Case Studies}

The Dulles Greenway (Samuel, 2005)

A 14-mile toll road in Loudoun County, Virginia between VA-28 near the entrance of Washington Dulles International Airport and US 15 in Leesburg was sold to a private company. Designated as State Route VA-267, the Greenway toll road and the land on which it is built are owned by TRIP-II, a company owned by local investors. In the Greenway's early years, traffic was well below projections, leading to a financial restructuring. But over the past five years, as development has boomed in Loudon County, traffic has increased to such an extent that the Greenway is being widened.

\section{The 91 Express Lanes (Samuel, 2005)}

The 91 Express Lanes project is a 10-mile long toll road within a freeway built by the California Private Transportation Company (CPTC) in the median of SR 91 (the Riverside Freeway). CPTC was successful financially but ran into heavy political trouble over a non-compete clause in its contract with the state of California. The Express Lanes were purchased by the Orange County Transportation Authority by negotiation in January 2003 for $\$ 207$ million, so the project is now 
publicly owned. The toll road has received awards and other recognition for excellence in customer service.

The Camino-Colombia Toll Road (Samuel, 2005)

The Camino-Colombia Toll Road (CCTR) near Laredo, Texas is 22 miles long and extends from I-35 to the Colombia Solidarity Bridge on the Rio Grande River, one of four Mexico-U.S. toll bridges in the Laredo-Nuevo Laredo area. The bridge was built for $\$ 90$ million by a company formed by large landowners along its route led by a businessman from a long-established local family. It opened in October 2000 hoping to attract significant truck traffic at a $\$ 16$ toll for 18 wheelers. The project was a dismal financial failure. The borrowers foreclosed and Camino Colombia is now owned by the Texas Department of Transportation for the price of $\$ 20$ million. The state has a brand new toll road for the cost of 22 cents on the dollar.

SR 125-South (Samuel, 2005)

SR 125-South is a 9.3-mile north-south toll road under construction along the eastern fringe of the San Diego, California metro area. As well as providing connectivity to the area freeways for residents, the toll road will provide an alternative for international traffic using the well-equipped Otay Mesa border crossing to Mexico. Owned by the Sydney, Australia-based Macquarie Infrastructure Group, SR 125-South is expected to cost about $\$ 650$ million.

Chicago Skyway (SCC, 2005; MIG, 2007)

The Chicago Skyway in Illinois is a 7.8-mile toll road connecting Interstate 90 at the Dan Ryan Expressway on the west end, and the Indiana Toll Road on the east end. Previously a publiclyowned toll road, which served 17.4 million motorists to yield $\$ 39.7$ million dollars in 2003, was leased to a private operator in 2005. The Skyway Concession Company (SCC), a joint-venture between Australian Macquarie Infrastructure Group and Spanish Cintra Concesiones de Infraestructuras de Transporte S.A., paid $\$ 1.83$ billion to the City of Chicago for a 99-year operating lease. This agreement is the first privatization of an existing toll road in the U.S. The toll is $\$ 2.50$ for passenger cars and other two-axle vehicles with higher rates for vehicles, with multiple axles. A discount is given during the overnight hours for vehicles with three or more axles. 
Indiana Toll Road (MIG, 2007)

The Indiana Toll Road is a tolled freeway which runs the full length (157 miles) of the northern part of Indiana and is a part of the New York-Chicago toll road system. Carrying 145,000 transactions on an average day and having been operated by the Indiana Department of Transportation for the past two decades, the toll road is now owned by the Indiana Finance Authority and operated by the Indiana Toll Road Concession Company. The Concession Company, a joint-venture between Spanish Cintra Concesiones de Infraestructuras de Transporte S.A. and Australian Macquarie Infrastructure Group offered $\$ 3.85$ billion for a 75 -year lease. The concessionaire agreement includes implementation of over $\$ 770$ million in planned upgrades to the expressway. Standard passenger cars are charged a toll of $\$ 4.15$ along the section from Portage to Eastpoint, with an extra $\$ 0.50$ at the Westpoint barrier. 


\subsection{Possible Guidelines for Implementation}

Guidelines for implementation can be drawn by observing experiences of other states and countries. The following sections synthesize considerations and suggestions that could lead to successful implementation of pricing schemes, including their design, technology used, legal and institutional issues, and public acceptability.

\subsubsection{Design of Pricing Schemes}

\section{Congestion Pricing}

1. The optimal pricing:

In order to pursue efficiency of the transportation sector and to maximize social welfare, toll/fee rates should reflect as closely as possible the marginal cost of each trip taking into account its impact on others. Charges may be set to exceed marginal costs as a means of obtaining additional revenues at a slightly excess burden, justified possibly in naive terms as a surcharge. However, there is no excuse for charges below the marginal social cost as it would obstruct efficient allocation of resources (Vickrey, 1994).

\section{Dynamic structure of tolls:}

Tolls should be time-variable and should vary smoothly over time in a way that users can predict the changes. Only in this way can all travelers be given an incentive to shift the time of travel, if only by small amounts, away from the peak. If charges vary drastically over periods, it is likely that there will be spikes in demand before and after the period during which the fee is high (Vickrey, 1994). Consequently, it can hardly be expected that peak period travelers would be willing to make substantial shift in departure time to pay a lower toll. On the contrary, when tolls are designed to vary smoothly, more travelers would consider change in departure time (small amount in this case, e.g., 10 minutes), and eventually travel demand would be more evenly distributed and congestion could be reduced. 


\section{Selection of congestion-pricing-applicable corridors:}

Applicability of congestion pricing scheme is determined by several factors. First of all, it is applicable to roadways where there exists a certain level of congestion. In understanding levels of congestion, the Travel Time Index (TTI), which measures the ratio of the average travel time to the free flow travel time, can be referred to. Table 2.1 provides comparison of TTI values between major corridors of Indiana (I-65 and I-70) and I-10. It is noted that congestion level of I70 is higher than that of I-10, where congestion pricing is being successfully implemented.

Table 2.1 TTI for Selected Corridors, April-June 2004

\begin{tabular}{|c|c|}
\hline Corridor (miles per hour) & Travel Time Index (TTI) \\
\hline I-10 & 1.11 \\
\hline I-65 & 1.08 \\
\hline I-70 & 1.14 \\
\hline
\end{tabular}

Source: FHWA (2004a)

A level of highway congestion cannot act as a sole determining factor, however, as there are several other aspects that influence outcome of pricing. FHWA (2003) notes that congestion pricing schemes that include HOT lanes work best in large metropolitan areas in high density corridors where there are limited travel options. The lack of free-flowing parallel routes, together with limited transit options, makes toll lane options more attractive when revenue generation is the major objective of pricing. More importantly, it should be noted that the notion of successful implementation should be used carefully, considering all the objectives of pricing projects. Tolling may return a great deal of revenue but may not have a significant impact on congestion mitigation due to excessive restrictions on travel alternatives to avoid the tolls.

\section{Demand impact outlook:}

Changes in the prices of transportation options will cause changes in their demand. Different types of pricing will cause different types of travel changes. Road pricing in general would shift traffic to alternative non-tolled roads, while time-variable congestion pricing could also cause changes in departure time. If travel alternatives such as public transits are attractive to the current highway users, then pricing would cause significant modal shifts. In addition, if revenues from 
pricing are used to expand roadway capacity that would otherwise not occur, it may increase total demand (rebound effect) (VTPI, 2005a).

In short, the travel impacts of pricing depend on many factors, including the price structure, the quality of the alternatives (competing routes, destinations, and modes), and allocation of the toll/fee revenues. Demand elasticity values with respect to travel cost (including gas price and road tolls) under various circumstances are reviewed in Section 3.2.3.

\section{Support of public transit:}

In most cases, where the tolled section of highway is acting as a major commuting route, agencies usually provide a public transit system with appropriate toll charging. Most recent cases have introduced a new rapid/express service, adding express options to the current service structure or changing the existing services to express level. Basically, this approach is about providing a higher level of service for alternative modes, even with new tolls to pay. This is also one of the key challenges of the public acceptability issue.

\section{Weight-Distance Truck Tolls}

\section{Determining toll levels by looking at cost study:}

The fundamental reasons to have this type of pricing scheme are to control truck demand and to realize the full user costs of heavy vehicles including the externalities they are imposing on the system. In order to set up accurate bases of tolling, the costs per vehicle weights and types should be established based on a cost study of each vehicle class. A cost allocation study by FHWA (1997, 2000a) calculated the equity ratio for each vehicle class by comparing the revenue generated from and cost introduced to the system by each vehicle class. For example, in Table 2.2 , single unit trucks that weigh more than 50,000 pounds pay only $40 \%$ of the costs they are bringing to the system. Pickups, single unit trucks smaller than 25,000 pounds, and combination trucks smaller than 50,000 pounds are classes that yield more revenue than the costs imposed. 
Table 2.2 Highway Costs and Equity Ratios by Vehicle Classes

\begin{tabular}{|l|c|c|}
\hline \multicolumn{1}{|c|}{ Vehicle Class/ Registered Weight } & Cents per Mile & Equity Ratio \\
\hline Passenger Vehicles & 0.81 & 1.0 \\
\hline Autos & 1.11 & 1.5 \\
Pickups/Vans & 0.67 & 0.2 \\
Buses & 0.89 & 1.1 \\
\hline All Passenger Vehicles & 3.28 & 1.5 \\
\hline Single Unit Trucks & 3.88 & 0.7 \\
\hline$\leq 25,000$ pounds & 7.32 & 0.4 \\
25,001 - 50,000 pounds & 3.78 & 0.9 \\
>50,000 pounds & 4.92 & 1.4 \\
\hline All Single Unit Trucks & 5.25 & 1.0 \\
\hline Combination Trucks & 6.78 & 0.9 \\
\hline$\leq 50,000$ pounds & 6.97 & 0.8 \\
50,001 - 70,000 pounds & 7.74 & 0.5 \\
70,001 - 75,000 pounds & 9.01 & 0.4 \\
75,001 - 80,000 pounds & 6.75 & 0.8 \\
80,001 - 100,000 pounds & 1.23 & 1.0 \\
>100,001 pounds &
\end{tabular}

Source: FHWA (2000a)

\section{Alternative freight modes:}

Once truck tolls are implemented, a certain portion of freight demand might seek some other mode to be shipped. This parallels providing public transit to toll pricing schemes. It is easily expected that other modes, such as railways, waterways, etc. will see increased demand.

\section{Distance-Based Fees}

8. Determining toll levels through a pilot study:

The Road User Fee Task Force of Oregon set up a fee rate of passenger cars to be 1.2 cents per mile (in 2004 dollars) for its pilot study on VMT fees (Whitty et al., 2006). The unit rate was calculated by dividing the Oregon's current state fuel tax of 24 cents per gallon by the 2004 average fuel efficiency of 20 miles per gallon. 
Given that the objective of the VMT fees is to bridge the revenue deficit gap of current fuel taxes, the fee rates based on the revenue needed and the vehicle-miles driven could be higher than the current fuel taxes. However, during the phase-in period, 20 years in Oregon's case, it would be necessary for the state to operate both the fuel tax and the mileage fee. Therefore, if the VMT rate is a great deal higher than the fuel tax, it would be difficult to induce users to pay the new fees replacing fuel taxes.

\section{Privatizing Toll Roads}

\section{Determining franchising price:}

The ratio of price to current revenue for the Chicago Skyway and Indiana Toll Road, which were recently franchised for a 99-year and 75-year concession period respectively, can provide guidance on the franchise purchase price. The franchise price for the Chicago Skyway, of which the annual revenue was $\$ 43$ million in 2004 , was $\$ 1.8$ billion, while the Indiana Toll Road that collected $\$ 85$ million in 2004 was contracted out for $\$ 3.8$ billion. Assuming $4 \%$ of interest rate, the ratios of the annuity of the franchise price to the annual revenue can be calculated and compared as exhibited in Table 2.3. The ratios of the two highways are comparable with each other and could be referred to as guidelines.

Table 2.3 Comparison of Ratios of Franchise Prices to Annual Revenues

\begin{tabular}{|c|c|c|c|c|}
\hline & a. Franchise Price & b. Annuity & c. Annual Revenue & d. Ratio b/c \\
\hline Chicago Skyway & $\$ 1.8 \mathrm{~B}(99$ years) & $\$ 73.5 \mathrm{M}$ & $\$ 43 \mathrm{M}$ in 2004 & 1.71 \\
Indiana Toll Road & $\$ 3.8 \mathrm{~B}(75$ years) & $\$ 160.5 \mathrm{M}$ & $\$ 85 \mathrm{M}$ in 2004 & 1.89 \\
\hline
\end{tabular}

\subsubsection{Technological Concerns}

The processing within an electronic charging system comprises several technological components. In the case of distance-based fees, the system needs to measure the traveled distance for each vehicle. Then, the gathered distance information must be consolidated as billing data 
with considerable concerns for privacy protection. As far as toll charging for individual facilities, necessary instant detection and payment processes have been successfully implemented in many real applications. The system also needs to be equipped with sufficient tools to deter users from avoiding payment. Following are the most commonly embedded technologies for these tasks (Sorensen and Taylor, 2005):

- On-Board Unit (OBU): The OBU is a computer module that is used for storing vehiclespecific information, recording distances driven, and calculating user charges. It can be designed to cooperate with other technologies such as DSRC or GPS.

- Dedicated Short-Range Communications (DSRC): DSRC is a microwave-based shortdistance communication between receivers installed in vehicles and roadside transponders. This technology is commonly used to identify vehicles entering or exiting road sections or geographical areas and to charge user fees on the basis of the pre-coded rates.

- Global System for Mobile Communications (GSM): GSM is a satellite-based cellular communication that may be used to replace DSRC. It is commonly known that GSM costs more than DSRC, but it does not require construction of roadside gantries. Advantages of this technology include multi-purpose usage, real-time communication, and flexibility for potential system expansion.

- Global Positioning System (GPS): GPS is a satellite-based location technology. When integrated with the OBU, it can be used to collect vehicle location and travel information such as distance and speed.

- Odometer: Odometers installed in individual vehicle may be useful in distance-based pricing as they record distance information. Some see its potential to be paired with the GPS system.

- Automated License Plate Recognition (ALPR): Based on digital photography and optical character recognition (OCR) algorithm, the ALPR system identifies vehicle on roads.

- Internet and On-Line Billing: These technologies often are used to automate the billing and collections process. 


\section{Guidelines on DSRC Application}

\section{Applicability of DSRC system:}

DSRC can be used to measure the distance traveled across a limited part of road network, which is equipped with gantries or road-side beacons; to toggle the status of the on-board unit between when entering or leaving a particular area (in case of cordon pricing); to verify that an on-board unit is functioning as required; or to communicate billing data (Sorensen and Taylor, 2005).

\section{Reliability of DSRC system:}

DSRC has been used successfully in I-15 HOT lanes in San Diego, cordon tolls in Singapore, and in weight-distance truck tolls in Austria and Switzerland. Also in Europe, both Trondheim and Rome have implemented tag-based DSRC systems, which have proven to be very reliable. The capture rate of the DSRC and on-board unit suite in the Trondheim implementation is better than $99.5 \%$, which satisfies the specification requirements. In spite of some remaining issues including signals distortion with metalized windshield and the limited battery life, it was shown that DSRC systems generally provide a robust and well-tested technology (PRoGRESS, 2004b).

\section{Guidelines on ALPR Application}

\section{Accuracy of ALPR system:}

ALPR system is advantageous in that it does not require equipment of on-board units at each individual vehicle. However, ALPR system can have unresolved problems caused by different shapes and sizes of license plate numbers, plates which are not retro-reflective, difficulties in reading under poor weather condition, non-standardized fonts, similarities between some letters/numbers, and insufficient control of ambient light at camera positions.

In Rome, the overall reliability of the system was such that $73.6 \%$ of license plate numbers were identified successfully. Of the remainder, $6.9 \%$ were captured by the camera but could not be identified by the optical character recognition system, and $19.5 \%$ of the data were not useable (PRoGRESS, 2004b).

\section{Suitability of ALPR system for enforcement purposes:}

Given the limited accuracy of the ALPR system, its primary applicability is as an enforcement tool, targeting those who are trying to avoid a charge or who have forgotten to register. As in the cordon pricing scheme operated in Rome, the ALPR system can be used as the main monitoring 
system for incoming vehicles (PRoGRESS, 2004b). This approach is also used in the London cordon toll and for enforcement on the SR-91 HOT lanes near Los Angeles, California. On the other hand, applicability of ALPR for distance-based pricing schemes is limited due to its incapability to communicate with a vehicle's on-board unit (Sorensen and Taylor, 2005).

\section{Guidelines on GSM Application}

\section{Communication capability of GSM system:}

Unlike DSRC or chip cards, communications with GSM can occur at any time from any location on the road network. This GSM feature can be used in real-time routing and for emergency distress signals (Sorensen and Taylor, 2005). Gothenburg and Copenhagen experienced success in their cordon pricing demonstrations with GSM (PRoGRESS, 2003). Yet, a GSM system usually has higher costs than other simpler communication technology options; also, due to its longer distance of information transmission, the probability of unauthorized interception could be higher.

\section{Guidelines on GPS Application}

\section{Applicability of GPS system:}

GPS is essential to large-scale road pricing schemes especially when it is required to distinguish regions or road types with different toll/fee rates. Generally, GPS works well in a wide-area pricing scheme, especially when there is a need to track vehicles, as in Oregon's VMT pilot study (Whitty, 2003). Other systems, where GPS is employed or tested, including Swiss truck tolls (Balmer, 2004) and Bristol, Copenhagen, and Gothenburg (PRoGRESS, 2004b), proved that GPS can work well in region-wide pricing schemes.

Although stand alone GPS can be used in usage metering, experience in the Oregon pilot study suggests that systems having a backup of an odometer toggle perform better in terms of measurement accuracy. Actually, GPS system can lose signal intermittently with the presence of tall obstacles such as trees and buildings. Therefore, a technological suite that uses an odometer toggle as a tool to meter the distance according to the location information sent through GPS was suggested (Whitty et al., 2006) 


\section{Resolution of GPS system:}

At the broadest level, GPS can be used to measure whether a vehicle is within or without a given geographic region, as in the Swiss truck toll (Balmer, 2004). At the intermediate level, it can be used to identify whether a vehicle is on a specific link (or, by extension, on a particular class of road), such as in the German truck toll (Rothengatter and Doll, 2002). Finally, at the most refined level, GPS potentially can be used to detect the presence of vehicles within specific lanes on a given road (for example, to implement HOT lane pricing (Sorensen and Taylor, 2005).

\section{Guidelines for General Technology Issues}

In choosing technological solution to road pricing, it should be considered cost-effectiveness, user convenience, and accuracy (Vickrey, 1994). Critical issues are as the following:

\section{Initial stage system design:}

It is often observed that technological complexity can adversely affect punctuality and financial efficiency of a project delivery. For example, several projects that sought integration of GPS and GSM systems, such as German truck toll project and field trials of road pricing scheme in Copenhagen and Gothenburg, technical difficulties resulted in significant delay of the projects and cost overrun (PRoGRESS, 2003).

\section{Cost of system deployment:}

The larger the boundary to apply electronic toll collection technologies, the greater will be the initial costs. It is inevitable that governments will pass on the costs to deploy the system to the public as they will equip individual vehicles with devices such as OBU free of charge.

\section{Enforcement accuracy vs. costs:}

The ways to enforce a system efficiently can be one of the most critical issues in implementation. Costs can be prohibitive if the accuracy desired is very high. The experience with the existing systems indicates that there is no need to have a perfect enforcement system with $100 \%$ violation detection. After achieving a certain level of accuracy, that is, after people recognize that there is a high probability of being caught, there will be high voluntary compliance. 


\section{Flexibility of future expansion:}

Although the current effect on VMT fees is limited to measuring and charging the distance traveled, the system may need to be enhanced in the future to distinguish travel by jurisdiction in order to distribute revenues to the relevant authorities for the facilities utilized. Preparation is therefore required to guarantee sufficient flexibility within the system so that it can be expanded without major alterations or expenditures.

\subsubsection{Legal and Institutional Issues}

\section{Federal Level Legal Background of Pricing and Tolling}

The Safe, Accountable, Flexible, and Efficient Transportation Equity Act - A Legacy for Users (SAFETEA-LU) has provided increased flexibility to use tolling in a way not only to manage congestion, but also to finance infrastructure improvements. SAFETEA-LU specifies the following programs under which pilot or demonstration of toll projects are available (FHWA, 2005a):

- Under the new Interstate System Construction Toll Pilot Program, the Secretary may permit a State or compact of States to collect tolls on an Interstate highway, bridge, or tunnel for the purpose of constructing Interstate highways. This program is limited to 3 projects in total (nationwide), and prohibits a participating State from entering into an agreement with a private entity which would prevent the State from improving adjacent public roads to accommodate diverted traffic.

- The Interstate System Reconstruction and Rehabilitation Toll Pilot Program was established in TEA-21 to allow up to 3 Interstate tolling projects for the purpose of reconstructing or rehabilitating Interstate highway corridors that could not be adequately maintained or improved without the collection of tolls. SAFETEA-LU makes no revisions to the program, therefore it continues without change, as it was authorized for "a term to be determined by the Secretary, but not less than 10 years."

- The Value Pricing Pilot Program, which was authorized by the Transportation Equity Act for the $21^{\text {st }}$ Century (TEA-21), is continued, funded at $\$ 59$ million through 2009, to support the costs of implementing up to 15 variable pricing pilot programs nationwide to 
manage congestion and benefit air quality, energy use, and efficiency. A new set-aside totaling \$12 million through 2009 must be used for projects not involving highway tolls.

- The new Express Lanes Demonstration Program will allow a total of 15 demonstration projects through 2009 to permit tolling to manage high levels of congestion, reduce emissions in a nonattainment or maintenance area, or finance added Interstate lanes for the purpose of reducing congestion. A State, public authority, or public or private entity designated by a State may apply. Eligible toll facilities include existing toll facilities, existing HOV facilities, and a newly created toll lane. Tolls charged on HOV facilities under this program must use pricing that varies according to time of day or level of traffic; for non-HOV, variable pricing is optional. Automatic toll collection is required, and the Secretary must promulgate a final rule specifying requirements, standards, or performance specifications to ensure interoperability within 180 days.

\section{Federal Level Support for Seeking Innovative Funding Source}

A long-term strategy to finance highway and public transportation has been outlined by the Transportation Research Board (TRB, 2005) and the National Chamber Foundation (NCF, 2005). As discussed in detail in Sections 3.7 and 5.5, the long-term federal strategy for transportation funding is to eventually replace the current fuel tax with a federal VMT tax.

In SAFETEA-LU, institutional efforts to help close the gap between highway infrastructure investment needs and resources available from traditional sources are encouraged. In addition to the tolling options addressed above, SAFETEA-LU includes the following provisions that would lead to development of innovative financing tools including ones through private sector participation (FHWA, 2005a):

- Private Activity Bonds - SAFETEA-LU expands opportunity for new capital sources to finance nation's transportation infrastructure system, especially bonding authority for private activity bonds, by adding highway facility and surface freight transfer facilities to a list of activities eligible for exempt facility bonds. Qualified projects, which must already be receiving Federal assistance, include surface transportation projects eligible under Title 23, international bridge or tunnel projects for which an international entity authorized under Federal or State law is responsible, and facilities for the transfer of freight from truck to rail or rail to truck (including any temporary storage facilities related to the transfers). These bonds are not subject to the general annual volume cap for private 
activity bonds for State agencies and other issuers, but are subject to a separate National cap of $\$ 15$ billion.

- Transportation Infrastructure Finance and Innovation Act (TIFIA) - The TIFIA program provides Federal credit assistance to nationally or regionally significant surface transportation projects, including highway, transit and rail. This program was established in TEA-21 to fill market gaps and leverage substantial private co- investment by providing projects with supplemental or subordinate debt. SAFETEA-LU authorizes a total of $\$ 610$ million through 2009 to pay the subsidy cost (similar to a commercial bank's loan reserve requirement) of supporting Federal credit under TIFIA. To encourage broader use of TIFIA financing, the threshold required for total project cost is lowered to $\$ 50$ million ( $\$ 15$ million for ITS projects), and eligibility is expanded to include public freight rail facilities or private facilities providing public benefit for highway users, intermodal freight transfer facilities, access to such freight facilities and service improvements to such facilities including capital investment for intelligent transportation systems.

- State Infrastructure Banks (SIBS) - SAFETEA-LU establishes a new SIB program which allows all States to enter into cooperative agreements with the Secretary to establish infrastructure revolving funds eligible to be capitalized with Federal transportation funds authorized for fiscal years 2005-2009. This program gives States the capacity to increase the efficiency of their transportation investment and significantly leverage Federal resources by attracting non-Federal public and private investment.

\section{Guidelines for Institutional Issues}

\section{Establishment of policy goals:}

Design of a road pricing scheme varies depending on policy goals such as revenue generation, congestion management, emission reduction, and so forth. In defining goals of road pricing projects, it is crucial to get key stakeholders involved in the process. It is observed that, at often times, congestion pricing projects have local advisory committees, which are made up of critical stakeholders from public, private, and nonprofit sectors, participate in goal establishment process. These committees worked to build consensus on issues related to business development, 
environmental impacts, public-private partnerships, and land use and equity impacts (Haltum and Zimmerman, 1996).

\section{Concerns at the initial stage of implementation:}

Generally, it is recommended that changes in public policy should be made in an incremental fashion. As a road pricing scheme is still a relatively innovative concept to the majority of the population, an incremental approach is best applied for it. Usually, actions involved with an incremental approach include small-scale demonstration or pilot study, pre-implementation analysis of traffic and revenue impacts, and public hearings or similar consensus building process.

In procuring necessary pricing technologies, several contracting techniques can be considered. A single provider can be selected and assigned contractual obligation to deliver. Alternatively, when a pricing project can provide sufficient incentives for multiple companies to enter the market and compete with each other, free market provisions can be considered (Haltum and Zimmerman, 1996; Sorensen and Taylor, 2005).

\section{Interoperability between jurisdictions:}

Implementation of road pricing schemes entails more complicated issues when multiple jurisdictions involved than single one. It is therefore required to allow flexibility when initially designing a pricing project within the boundary of a single jurisdiction, expecting future expansion of the programs to adjacent jurisdictions. For example, a distance-based pricing scheme in Indiana, discussed later in the Section 4.3, may begin with the Indianapolis metropolitan area, then expanded to the entire state, and, in the long-term, to adjacent states.

\subsubsection{Public Acceptability}

Inherently, tax policies, as well as road user charging schemes, often face public reluctance in their implementation. In a democratic society, common consensus and public support is essential for policy-making; therefore, it is necessary to understand which factors affect public acceptability, the extent of the influence, and how to pursue a better consensus policy. 
It is widely perceived that two of the major concerns in obtaining public acceptance are equity and privacy issues. For each of these issues, critical lessons were drawn from the pricing implementation cases described in Sections 2.2 through 2.4.

\section{Equity Concerns}

1. Equity concerns as a key factor to win public acceptance:

It is advised that equity concerns should be paid attention as a key factor to gain public support for pricing projects. Relevant actions thus should be conducted in ways to ensure that all groups receive benefits, either through financial compensation or improved travel choices (Vickrey, 1994).

\section{Equity impacts of revenue allocation:}

It is often argued that road pricing concepts are regressive, rather than progressive, since users are charged the same fees regardless of their income level. Decisions on toll revenue allocation, however, would have significant impacts on equity between users. For example, by returning the revenues to projects that could provide more and better travel options to low income groups, the regressiveness of the pricing structure could be offset. This approach is observed in several projects, including I-15 HOT lanes (SDSU, 2001) and London congestion toll (Litman, 2005) where public transportation systems are invested in. Alternatively, as proposed in the Fast And Intertwined Regular (FAIR) lanes approach, a portion of revenue can be allocated to offer credits for frequent users of general-purpose lanes so they can get benefits of using other transportation services such as public transits or parking facilities (Kockelman and Kalmanje, 2005).

\section{Suggestions on Revenue Allocation:}

The "rule of three," as noted by Goodwin (1989) and reiterated by Farrell and Saleh (2005), allocates $1 / 3$ of the revenues as a general tax revenue to decrease existing taxes or increase social spending; $1 / 3$ for funding new road infrastructure and its maintenance (both according to national and local priorities); and the remaining $1 / 3$ for improving the effectiveness of public transportation, through a combination of fare and service level improvements.

Comparably, Small (1992) suggested tripartite divisions: 1/3 to reimburse to travelers as a group; $1 / 3$ as a substitution for general taxes which are currently used to pay for transport services; and $1 / 3$ to fund new transportation services. By doing so, the benefits would be 
widespread and thus alleviate the negative impacts. Small also asserted that this rule needs to be associated with other measures to achieve equity in financing. Those measures are: 1) to finance an employee commuting allowance program; 2) to remove all or part of any dedicated (to transportation) sales-tax that may apply in the region; 3) to rebate a portion of property taxes; 4) to finance new road capacity; 5) to finance public transportation improvements; and 6) to finance improvements in transportation-related facilities and services in business areas (Farrell and Saleh, 2005).

In spite of the general rules suggested, revenue portfolios can be differently designed depending on the primary purpose of a pricing project. When a pricing scheme mainly aims to generate revenue, the revenue can be allocated to transportation projects that are not directly related to the priced roadway. On the other hand, when the main goal of pricing is to manage congestion, the probability to achieve the goal would be high if the revenue is allocated to investments in alternative travel options.

\section{Privacy Issue}

As noted in the guidelines for technology, some of the technologies that collect individual travel information may infringe on a user's right to privacy. Issues and suggested solutions are summarized below.

\section{Public attitude toward the privacy issue:}

In the initial stage of pricing projects, users are reluctant in revealing their travel pattern information. It is leant from the recent implementations, however, that users show reduced reluctance as they are more accustomed to the technologies that gather individual activity information, such as credit cards and cell phones. For example, in road pricing projects including SR-91 Express Lanes (Orange County, California) and Highway 407 Toll Road (Toronto, Canada), majority of the users (about 99\%) used the transponders system that keeps the travel records (Poole, 2005). Also, in the Copenhagen and Gothenburg distance-pricing demonstration projects, surveillance was not considered by participants to be a major issue (PRoGRESS, 2004b).

\section{Technological and legal protection of user's privacy:}

Two complimentary approaches, technological solution and legal support, were suggested to protect personal travel records in Oregon's VMT demonstration. First, the selected standard 
technological configuration was designed to have an on-board unit store the toll rate information and calculate charges and only transmits the final bill to the concerned authorities. Under this technological specification, intermediate travel data are purged from the memory after being used in fee calculation and bill submission, never leaving the vehicle (Whitty, 2003). As an additional protection, it can be considered contract provisions with the concerned agents that guarantee the data will never be released or used for any purposes other than billing without a court order (Sorensen and Taylor, 2005).

\section{Building a Public Support}

\section{Public outreach:}

It is necessary to insure that road pricing decisions are transparent and built on public participation and trust to avoid political interference (Vickrey, 1994). For public outreach, three important groups need to be targeted: citizens, elected officials, and institutional leaders from the transportation and planning professions and business and community organizations. These groups should be dealt with having different focuses: outreach to citizens should focus on understanding and involvement; communication with elected officials should aim to get leadership support from them; leadership coalition should be discussed with institutional leaders (Haltum and Zimmerman, 1996).

At often times, pricing projects need the help of the media, especially at the early stage of implementations. It is critical to inform the media beforehand so distortion or inaccuracy of coverage could be avoided (Haltum and Zimmerman, 1996). Furthermore, the media can be used as a vehicle to educate the public about relevant topics including true costs imposed on the society due to congestion and high and increasing trend of costs to construct and maintain transportation infrastructure.

\section{Use of referendum:}

Referendum can be an effective means to gain public support as evidenced most recently. In 2004, voters were asked to vote on 56 state and local transportation related ballots in the U.S., $80 \%$ of which were approved by the voters. Especially in California at the 2004 elections, 9 of 12 county measures approved even with the state-mandated $2 / 3$ supermajority that is required to pass a dedicated sales tax (BTS, 2005b). 


\subsection{Development of Alternative Strategies}

Based on the information gathered, we can construct a system of alternatives to analyze and compare. The financing tools we have examined in this chapter, summarized in Table 2.4, can either complement or replace the current fuel tax system.

Table 2.4 Road Pricing Categories

\begin{tabular}{|l|l|l|}
\hline \multicolumn{1}{|c|}{ Category } & \multicolumn{1}{|c|}{ Definition } & \multicolumn{1}{c|}{ Primary Objectives } \\
\hline Road toll (fixed) & $\begin{array}{l}\text { Fixed fees imposed on particular } \\
\text { road sections or bridges }\end{array}$ & $\begin{array}{l}\text { To generate revenue; to recover } \\
\text { construction cost of new facilities }\end{array}$ \\
\hline $\begin{array}{l}\text { Road toll } \\
\text { (time-variable) }\end{array}$ & $\begin{array}{l}\text { Fees imposed on road sections or } \\
\text { bridges in a manner that varies over } \\
\text { time; variations could be pre-timed } \\
\text { or responsive to congestion level }\end{array}$ & $\begin{array}{l}\text { To generate revenue; to manage } \\
\text { congestion by shifting traffic to other } \\
\text { routes, time periods, or modes }\end{array}$ \\
\hline $\begin{array}{l}\text { Lane-specific pricing } \\
\text { (HOT lanes, Express } \\
\text { lanes) }\end{array}$ & $\begin{array}{l}\text { Fees differentiated by lanes of } \\
\text { particular road sections }\end{array}$ & $\begin{array}{l}\text { To generate revenue; to maximize } \\
\text { utilization of the road capacity both on } \\
\text { priced lanes and general-purpose (GP) } \\
\text { lanes; to manage congestion on GP lanes }\end{array}$ \\
\hline Area licensing & $\begin{array}{l}\text { Fees imposed for entering particular } \\
\text { areas }\end{array}$ & $\begin{array}{l}\text { To manage congestion in major urban } \\
\text { areas; to reduce parking demand }\end{array}$ \\
\hline Weight-distance fees & $\begin{array}{l}\text { Fees particularly associated with } \\
\text { commercial heavy vehicles and } \\
\text { imposed on the basis of combined } \\
\text { measurement of weight and distance }\end{array}$ & $\begin{array}{l}\text { To generate revenue; to realize true } \\
\text { highway cost incurred by heavy vehicles }\end{array}$ \\
\hline Distance-based fees & $\begin{array}{l}\text { Fees that directly charge the amount } \\
\text { of highway usage on the basis of } \\
\text { distance driven }\end{array}$ & $\begin{array}{l}\text { To generate revenue; to correct inequity } \\
\text { between vehicles with different levels of } \\
\text { fuel economy under the current fuel tax } \\
\text { system }\end{array}$ \\
\hline
\end{tabular}

The present study proposes three approaches. First, the current tax system, including fuel taxes, vehicle registration fees, and other general purpose taxes, is adjusted to meet funding needs. Second, the current fuel tax system is maintained and other revenue sources are considered to meet the expected deficit. With this approach, two types of user fees are considered: toll roads (by the public sector and by private concessionaires) and VMT fees. Third, the complete replacement of the fuel tax system is considered. In this approach, given that the state no longer has fuel taxes, a highway funding mechanism based on a distance-based (VMT) fee is developed. 
Also, as a more elaborated version of the VMT fee scheme, a statewide comprehensive usagebased pricing strategy is proposed. The structure of the alternatives is schematically depicted in Figure 2.4 .

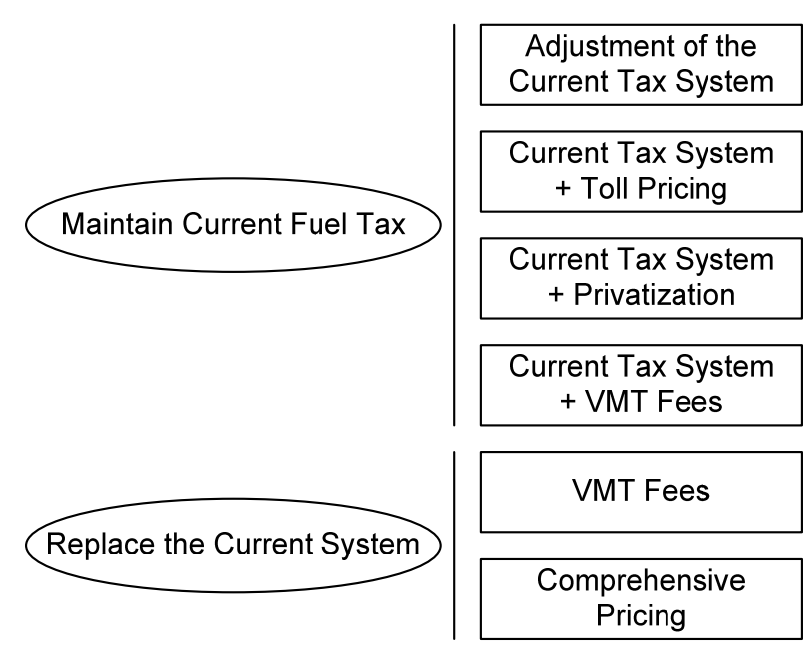

Figure 2.4 Alternatives for the State of Indiana

In the following chapters, an evaluation framework is designed and alternatives are developed with detailed descriptions of their features. Also, each developed alternative is evaluated based on the framework suggested. 


\section{CHAPTER 3. FRAMEWORK FOR THE EVALUATION OF ALTERNATIVES}

\subsection{Methodological Framework for Evaluation}

The present study identified the major evaluation categories and their criteria, upon which both quantitative and qualitative analyses for each alternative can be based. In measuring quantifiable factors, suitable computing tools are used. To understand the underlying features of the problem that are not easily quantified, results from qualitative analyses that include surveys or interviews are referred to. Evaluations on all the criteria are integrated to determine the desirable alternatives.

\subsubsection{Developing Evaluation Criteria}

Five major goals of a pricing and funding system were selected in the present study, as shown in Table 3.1. The first goal would be to yield the targeted revenue in a predictable way. Therefore, the sufficiency, stability, and accountability of revenue should be assessed from the agency's perspective.

The second goal of a funding system is to allocate resources in an efficient way. Theoretically and ideally, the efficiency of a system can be quantified by measuring the social welfare based on the consumer surplus theory. As discussed in Section 3.3, selection of optimal fees and attainment of system efficiency are intertwined and can be addressed under the same framework.

In addition, the present study provides a methodological framework to evaluate equity implication of pricing schemes. Equity between users is evaluated by breaking down highway users into groups and applying efficiency problem separately for each group. Highway Cost 
Allocation Study can be used as an analysis tool to allocate highway cost responsibility between various user groups and to establish equitable pricing structure.

Usually, innovative approaches associated with new technologies require additional costs for initial installation, deployment, operation, and administration. If a funding scheme requires prohibitive system costs, then it will considerably lose its value as a revenue-generating tool. Therefore, the costs of a system need to be considered in selecting the best option from the agency's perspective. Public acceptability and policy alignment with federal policies are both important aspects and should be considered, although development of rigorous methods to assess these criteria is lacking.

The goals, criteria, and broad possible outcomes for each of the alternatives are shown in Table 3.1. This chapter presented an information search to find methodologies to fill up each cell in this table, and the present study will conclude in Chapter 5 with a completed table addressing all possible alternatives.

Table 3.1 System of Alternatives Evaluation: Possible Format of Outcome

\begin{tabular}{|c|c|c|c|c|}
\hline \multirow[b]{2}{*}{ Goals } & \multirow[b]{2}{*}{ Criteria } & \multicolumn{3}{|l|}{ Alternatives } \\
\hline & & Do-nothing & $\begin{array}{l}\text { Tax increase (fuel taxes, } \\
\text { vehicle registration fees, } \\
\text { etc.) }\end{array}$ & $\begin{array}{l}\text { Alternatives to replace } \\
\text { current system (VMT } \\
\text { fees) (partly or fully) }\end{array}$ \\
\hline \multirow{3}{*}{ Revenue } & Sufficiency & Less achievable & Achievable & Achievable \\
\hline & Stability & Less achievable & Need analysis & Depends on fee rates \\
\hline & Accountability & Less achievable & Less achievable & More achievable \\
\hline Efficiency & $\begin{array}{l}\text { Total social } \\
\text { welfare }\end{array}$ & Less efficiency & $\begin{array}{l}\text { Less efficiency can be } \\
\text { expected }\end{array}$ & $\begin{array}{l}\text { More efficiency can be } \\
\text { expected }\end{array}$ \\
\hline Equity & User-pay principle & $\begin{array}{l}\text { Not fully } \\
\text { addressed }\end{array}$ & Not fully addressed & Fully addressed \\
\hline \multirow{2}{*}{$\begin{array}{l}\text { Implementation } \\
\text { Costs }\end{array}$} & $\begin{array}{l}\text { Physical costs of } \\
\text { system }\end{array}$ & None & Little & High \\
\hline & $\begin{array}{l}\text { Cost of } \\
\text { administration }\end{array}$ & None & Modest & High \\
\hline $\begin{array}{l}\text { Public } \\
\text { Acceptability }\end{array}$ & Public reluctance & None & $\begin{array}{l}\text { Will depend on the tax } \\
\text { increase rate, and public } \\
\text { awareness/sensitivity }\end{array}$ & $\begin{array}{l}\text { Will vary according to } \\
\text { the implementation } \\
\text { strategy }\end{array}$ \\
\hline $\begin{array}{l}\text { Policy } \\
\text { Alignment }\end{array}$ & $\begin{array}{l}\text { Compatibility with } \\
\text { federal policy }\end{array}$ & $\begin{array}{l}\text { Not fully } \\
\text { achievable }\end{array}$ & Partly achievable & Considerably achievable \\
\hline
\end{tabular}




\subsection{Adequacy of a Funding Mechanism}

\subsubsection{Revenue Sufficiency and Stability}

As need studies at federal and state levels have shown, a budget is required that provides an optimal level of transportation facilities and services. By projecting revenues generated from each of the alternatives and comparing them with need study results, the revenue sufficiency of alternatives can be appraised.

There is common doubt regarding the stability of motor fuel tax revenues because of the way the tax is levied. The number of gallons consumed, which is the basis of fuel tax revenue, continues to grow since VMTs have increased more than fuel economy enhancements in recent years. Along with the fuel consumption increase, current dollar receipts from the state motor fuel tax have increased steadily in recent years, but at a much lower rate compared to road construction prices (SCDOT, 2003). Furthermore, because the motor fuel tax rate has not changed much since the mid-1980s, revenues in constant dollars have even decreased for the last decade.

To secure stability of the revenue streams, competition between jurisdictions also needs to be considered. For example, if the motor fuel tax of a state, and thus the fuel price, is significantly higher than adjacent jurisdictions, then it is highly probably that the residents on the border might fuel their vehicles in neighboring states with lower prices, even though they mainly use facilities within their state of residence. In this situation, neither the revenue aimed nor the stability of the revenue stream will ever be attained.

\subsubsection{Accountability}

Accountability is defined as the ability to ensure the degree to which taxpayers are able to get their money's worth from the government. In this respect, it needs to be asked whether transportation policy is addressing the perceived need, and whether transportation funds are being 
targeted to priority transportation needs. For transportation funding alternatives to enhance accountability, a clear connection between revenue sources and program expenditures is required. That is, an increase in transportation taxes or fees should be earmarked specifically for transportation system improvements that are deemed to be priority issues (Goldman et el., 2001; SCDOT, 2003).

From this perspective, income and other general taxes are not preferred since those taxes are not solely dedicated to transportation purposes. Very often the transportation sector faces competition with other sectors for general tax revenues, such as education, medical service, etc. On the other hand, a pricing scheme that is designed to adhere to the user-pay-principle more strictly will secure better accountability. The revenue distribution strategy also influences the level of accountability attained by a pricing scheme. Usually, if a certain charging scheme can distinguish users based on their use intensity and the revenues generated are assigned to relevant sub-systems in the transportation sector, then the system is considered a very accountable one.

\subsubsection{Impacts on Demand}

In the market economy, prices can have significant impacts on demand, or particularly, travel behavior in the context of the present study. Therefore, in order to assess revenue impact of a pricing scheme, demand elasticity values obtained from other pricing implementations can to be referred to. It should be noted that pricing impact on demand may vary according to projectspecific factors such as alternatives other than tolled roads, travel time of competing modes, demographic characteristics, and so on. In this regard, demand elasticity values with respect to tolls are reviewed under various circumstances as the following.

Table 3.2 indicates the elasticity values for US toll roads from the review made by Matas and Raymond (2003), most of which were calibrated with short-run analyses. The values show that the elasticity ranges from -0.03 to -0.5 overall, provided that it is lower for monopolistic cases. It is commonly know that long-run elasticity tends to be greater than short-run. 
Table 3.2 Elasticity of Traffic Demand with respect to Tolls

\begin{tabular}{|c|c|c|}
\hline Authors & Results & Context \\
\hline $\begin{array}{l}\text { Wuestefeld and Regan } \\
\text { (1981) }\end{array}$ & $\begin{array}{l}\text { Roads between }-0.03 \text { and }-0.31 \\
\text { Bridges between }-0.15 \text { and }-0.31 \\
\text { Average value }=-0.21\end{array}$ & $\begin{array}{l}16 \text { tolled infrastructures in the } \\
\text { U.S. (roads, bridges, and tunnels) }\end{array}$ \\
\hline Harvey (1994) & $\begin{array}{l}\text { Bridges between }-0.05 \text { and }-0.15 \\
\text { Roads }-0.10\end{array}$ & $\begin{array}{l}\text { Golden Gate Bridge, San } \\
\text { Francisco Bay Bridge, and Everett } \\
\text { Turnpike in New Hampshire } \\
\text { (U.S.). }\end{array}$ \\
\hline $\begin{array}{l}\text { Hirschman, McNight, } \\
\text { Paaswell, Pucher, and } \\
\text { Berechman (1995) }\end{array}$ & $\begin{array}{l}\text { Between }-0.09 \text { and }-0.50 \text { Average } \\
\text { value }-0.25 \text { (only significant values } \\
\text { quoted) }\end{array}$ & $\begin{array}{l}\text { Six bridges and two tunnels in the } \\
\text { New York City area, U.S. }\end{array}$ \\
\hline $\begin{array}{l}\text { Gifford and Talkington } \\
\text { (1996) }\end{array}$ & $\begin{array}{l}\text { Own-elasticity of Friday-Saturday } \\
\text { traffic }-0.18 \text { Cross-elasticity of } \\
\text { Monday-Thursday traffic with } \\
\text { respect to Friday toll }-0.09\end{array}$ & $\begin{array}{l}\text { Golden Gate Bridge, San } \\
\text { Francisco, U.S. }\end{array}$ \\
\hline $\begin{array}{l}\text { Lawley Publications } \\
(2000)\end{array}$ & -0.20 & New Jersey Turnpike, U.S. \\
\hline $\begin{array}{l}\text { Burris, Cain, and } \\
\text { Pendyala (2001) }\end{array}$ & $\begin{array}{l}\text { Off-peak period elasticity with } \\
\text { respect to off-peak toll discount } \\
\text { between }-0.03 \text { and }-0.36\end{array}$ & Lee County, Florida, U.S. \\
\hline
\end{tabular}

Source: Matas and Raymond (2003)

Table 3.3 shows traffic demand elasticity with respect to fuel prices (Goodwin et al., 2004). For example, $1 \%$ of the increase in fuel prices would yield a $0.1 \%$ decrease in traffic demand in the short-run, $0.3 \%$ in the long-run. Although the impacts of tolls cannot be identical to those of fuel prices since tolls are more site-specific, congestion-sensitive, and straightforward, they can be referred to in understanding the demand shifts with respect to cost changes because fuel prices represent the greatest part of vehicle operating costs.

Table 3.3 Elasticity of Traffic Demand with respect to Fuel Prices

\begin{tabular}{|c|c|c|}
\hline Elasticities & Short-term & Long-term \\
\hline Vehicle-km (total) & -0.10 & -0.29 \\
\hline Vehicle-km (per vehicle) & -0.10 & -0.30 \\
\hline
\end{tabular}

Source: Goodwin et al. (2004) 
Harvey and Deakin (1998) studied California toll roads and estimated that two cents of increment in toll per mile would cause an average of a $4 \%$ reduction in the number of trips, as in Table 3.4.

Table 3.4 Impacts of $2 \varnothing$ per mile Fee in Year 2010

\begin{tabular}{|c|c|c|c|c|c|}
\hline Region & VMT & Trips & Delay & Fuel & VOC \\
\hline Bay Area & $-3.9 \%$ & $-3.7 \%$ & $-9.0 \%$ & $-4.1 \%$ & $-3.8 \%$ \\
\hline Sacramento & $-4.4 \%$ & $-4.1 \%$ & $-7.5 \%$ & $-4.4 \%$ & $-4.3 \%$ \\
\hline San Diego & $-4.2 \%$ & $-4.0 \%$ & $-8.5 \%$ & $-4.2 \%$ & $-4.1 \%$ \\
\hline South Coast & $-4.3 \%$ & $-4.1 \%$ & $-10.5 \%$ & $-5.2 \%$ & $-4.2 \%$ \\
\hline Average & $-4.2 \%$ & $-4.0 \%$ & $-8.9 \%$ & $-4.5 \%$ & $-4.1 \%$ \\
\hline
\end{tabular}

Source: Harvey and Deakin (1998)

Table 3.5 provides demand reduction impacts with respect to VMT fees by each income group. It is clear that, even with the same amount of fees, the demand reduction impact is significantly larger in lower income groups. Also, the gap between income groups expands as the unit charge increases.

Table 3.5 Vehicle Travel Reduction of VMT Fee by Income Quintile (\%)

\begin{tabular}{|c|c|c|c|c|c|c|c|}
\hline VMT Fees & Q1 & Q2 & Q3 & Q4 & Q5 & Overall & 2001 \\
\hline $1 \varnothing$ & -7.0 & -4.2 & -2.6 & -1.5 & -0.5 & -2.3 & -1.8 \\
\hline $2 \varnothing$ & -13.3 & -8.2 & -5.1 & -3.1 & -1.0 & -4.5 & -3.5 \\
\hline $3 \phi$ & -19.1 & -12.0 & -7.5 & -4.6 & -1.6 & -6.6 & -5.1 \\
\hline $4 \varnothing$ & -24.3 & -15.6 & -10.0 & -6.2 & -2.2 & -8.7 & -6.7 \\
\hline $5 \varnothing$ & -29.1 & -19.1 & -12.4 & -7.7 & -2.8 & -10.7 & -8.2 \\
\hline $6 \varnothing$ & -33.5 & -22.4 & -14.7 & -9.3 & -3.5 & -12.6 & -9.7 \\
\hline $7 \varnothing$ & -37.4 & -25.6 & -17.0 & -10.8 & -4.1 & -14.5 & -11.2 \\
\hline $8 \varnothing$ & -41.0 & -28.7 & -19.2 & -12.4 & -4.8 & -16.3 & -12.5 \\
\hline $9 \phi$ & -44.2 & -31.5 & -21.4 & -13.9 & -5.5 & -18.0 & -13.8 \\
\hline $10 \varnothing$ & -47.2 & -34.3 & -23.5 & -15.4 & -6.3 & -19.7 & -15.2 \\
\hline
\end{tabular}

Source: Rennacker (2004) 
A quintile is one-fifth of the population. Values are based on 1991 dollars, except the last column, labeled 2001, which indicates travel reductions taking into account $30 \%$ inflation between 1991 and 2001.

Different demand elasticity ranges under different circumstances and pricing schemes have been observed. However, more detailed analysis is needed to understand the demand shifts from peak periods to adjacent time periods after and before peaks and shifts between modes.

\subsection{Efficiency of Resource Allocation}

\subsubsection{Definition of Economic Efficiency}

Economic efficiency refers to the net benefit of the society, which is the result of resource allocation. Thus, maximizing efficiency is equivalent to maximizing the total welfare of all the inhabitants within that society.

A competitive market (e.g., the private sector) achieves its efficiency through market transactions with prices at the equilibrium. Prices convey signals to both the demand and supply sides about resource shortages, technological change, and consumer demand. Similarly, transportation market operated by the public sector mimic the competitive market by having user fees as proxies of market prices. Fuel taxes, road tolls, and other related fees are user fees that charge for transportation system use.

The key to achieving efficiency in the public sector is to set the right prices to reflect the true costs. When true costs are not reflected in a pricing scheme, facilities and services that are underpriced are often overused and deteriorate more rapidly. Especially in transportation systems, the current market price structure does not include costs related to externalities such as safety, the environment, and congestion. For example, under congestion, when traffic demand exceeds road capacity, marginal costs are higher than average costs, indicating system inefficiency. The notion of value pricing is to address this inefficiency.

Economic efficiency has two aspects. First, optimal tolls/fees should be determined considering system costs. Second, market equilibrium works in a way that price changes cause 
changes in demand, thus the impacts of tolls/fees on demand are to be studied. Replicating the market mechanism, welfare changes in the system can be analyzed based on consumer surplus theory.

\subsubsection{Costs in Consideration}

In the previous section, it was indicated that efficiency is attainable when market prices are adequately set to reflect true system costs. Yet, exactly which components of costs should be considered as true costs can vary depending on objectives of pricing: allocative efficiency, cost recovery, adherence to the user-pays-principle, or income redistribution. Much debate has taken place among economists about short-run marginal cost (SRMC), long-run marginal cost (LRMC), and fully allocated cost (FAC).

Many economists have defended SRMC, which would require price differentiation with respect to space, time, and vehicle characteristics, for its best potential to achieve allocative efficiency (Lindsey, 2006). As Rannaker (2004) noted, the full cost of an individual trip down a congested highway includes the personal cost of the traveler's own time, cost of the vehicle operation, and the impacted costs to other travelers trying to use the highway at the same time (external cost). From that perspective, SRMC-based pricing scheme would resemble the competitive market economy with the most similarity. However, it should be noted that SRMCbased pricing does not always guarantee recovery of cost for highway construction and maintenance. In this regard, LRMC or FAC, which takes into account capital costs, are favored. These various perspectives and charging concepts are compared in Table 3.6.

In the next section, suggestion on pricing scheme by Mohring and Harwitz (1962) that can be interpreted as hybrid of LRMC and FAC pricing is introduced and discussed. 
Table 3.6 Comparison of Costs and Charge Concepts

\begin{tabular}{|c|c|c|c|}
\hline Category & SRMC & LRMC & FAC \\
\hline \multicolumn{4}{|l|}{ Costs } \\
\hline Return on capital & Not relevant & Not relevant & Return on capital employed \\
\hline Infrastructure costs & $\begin{array}{l}\text { Facility wear caused by } \\
\text { use }\end{array}$ & $\begin{array}{l}\text { Facility wear caused by use, } \\
\text { and capital costs to increase } \\
\text { capacity to accommodate } \\
\text { growing demand }\end{array}$ & $\begin{array}{l}\text { All ongoing infrastructure } \\
\text { costs (operation, maintenance, } \\
\text { and depreciation) }\end{array}$ \\
\hline $\begin{array}{l}\text { Service provider } \\
\text { operating costs }\end{array}$ & $\begin{array}{l}\text { Cost of an additional } \\
\text { vehicle mile }\end{array}$ & $\begin{array}{l}\text { Cost of an additional vehicle } \\
\text { mile }\end{array}$ & $\begin{array}{l}\text { All costs associated with } \\
\text { providing services }\end{array}$ \\
\hline Congestion & $\begin{array}{l}\text { Costs imposed by one user } \\
\text { on other transport system } \\
\text { users }\end{array}$ & $\begin{array}{l}\text { Not included if capacity } \\
\text { expansion leaves existing } \\
\text { traffic unaffected }\end{array}$ & $\begin{array}{l}\text { Not relevant, since this cost is } \\
\text { imposed and borne by } \\
\text { infrastructure users as a group }\end{array}$ \\
\hline Mohring effect & \begin{tabular}{|l|} 
Benefits of increased \\
public transport service \\
frequencies due to \\
additional demand \\
\end{tabular} & $\begin{array}{l}\text { Benefits of increased public } \\
\text { transport service frequencies } \\
\text { due to additional demand }\end{array}$ & $\begin{array}{l}\text { Not relevant, since this impact } \\
\text { is imposed and borne by } \\
\text { infrastructure users as a group }\end{array}$ \\
\hline Accidents & $\begin{array}{l}\text { External crash risk costs } \\
\text { of an additional unit of } \\
\text { travel }\end{array}$ & $\begin{array}{l}\text { External crash risk costs of an } \\
\text { additional unit of travel }\end{array}$ & $\begin{array}{l}\text { External costs attributed to } \\
\text { user groups on the basis of } \\
\text { responsibility }\end{array}$ \\
\hline $\begin{array}{l}\text { Environmental } \\
\text { Costs }\end{array}$ & $\begin{array}{l}\text { Cost of an additional unit } \\
\text { of travel }\end{array}$ & $\begin{array}{l}\text { Cost of an additional unit of } \\
\text { travel }\end{array}$ & Costs of total vehicle travel \\
\hline \multicolumn{4}{|l|}{ Charges } \\
\hline $\begin{array}{l}\text { Fuel excise tax and } \\
\text { road user charges }\end{array}$ & $\begin{array}{l}\text { Revenue associated with } \\
\text { an additional vehicle mile }\end{array}$ & $\begin{array}{l}\text { Revenue associated with an } \\
\text { additional vehicle mile }\end{array}$ & $\begin{array}{l}\text { Total revenue from fuel taxes } \\
\text { and road user charges }\end{array}$ \\
\hline $\begin{array}{l}\text { Motor vehicle } \\
\text { registration and } \\
\text { licensing }\end{array}$ & $\begin{array}{l}\text { If related to additional } \\
\text { vehicle travel }\end{array}$ & $\begin{array}{l}\text { If related to additional vehicle } \\
\text { travel }\end{array}$ & $\begin{array}{l}\text { All motor vehicle registration } \\
\text { charges }\end{array}$ \\
\hline $\begin{array}{l}\text { Goods and Services } \\
\text { Tax (GST) }\end{array}$ & On all costs & On all costs & On all costs \\
\hline $\begin{array}{l}\text { Fares, freight tariffs } \\
\text { and traffic fines }\end{array}$ & $\begin{array}{l}\text { Associated with an } \\
\text { additional unit of travel }\end{array}$ & $\begin{array}{l}\text { Associated with an additional } \\
\text { unit of travel }\end{array}$ & All fares, taxes \\
\hline
\end{tabular}

Source: VTPI (2005d)

\subsubsection{Optimal Pricing - Concept of Self-Financing}

Mohring and Harwitz (1962) established an important relationship between demand management and capacity policies which evolved into the self-financing theorem. The theorem states that revenue from optimal congestion pricing is equal to the cost of supplying the optimal road capacity under the following conditions: (i) capacity is adjustable in continuous increments; (ii) 
capacity can be expanded at constant marginal cost; and (iii) trip costs are homogenous of degree zero in usage and capacity. Past literature suggest that the second and third conditions may generally hold when the ratio of long-run average and marginal costs are often relatively close to unity, in a range of circumstances. The first condition also holds if the analysis is not for a single road segment but for a large-scale road network because capacity is considered divisible in a large network (Verhoef and Rouwendal, 2004).

While the theorem may seem somewhat pedantic, it actually is conceptually simple. When it is carefully applied to a realistically represented transportation network, the resulting pricing scheme and capacity provision can yield a market equilibrium that ensures maximum efficiency. Furthermore, any concept that involves self-financing of a highway system lends increased transparency to the highway financing process. Therefore, transportation finance, when based on self-financing strategy, can be expected to receive greater support from the general public. The overall concept has often been referred to as the user-pay-principle. The critical first step of the transportation network representation is discussed below.

Several studies have investigated the application of social welfare maximization to systems susceptible to congestion, for example, highways. These studies represent social welfare as a function of benefits from the use of highways and cost of its provision, and the maximization problem is solved for pricing and capacity choice of road networks.

Arnott and Kraus (1995) constructed a social surplus maximization problem formulation for public goods such as highways, as follows:

The price of using highways, including the user cost and any imposed toll, or "VMT fee" in this context, is denoted as $p$. The demand function and user cost function are written as $N(p)$ and $c(N, K)$, respectively. The user cost function increases with demand: $N$ (i.e., $\partial c / \partial N$, written as $c_{N}$, is greater than 0 ); and decreases with capacity: $K$ (i.e., $\partial c / \partial K$, written as $c_{K}$, is less than 0 ). It is noted that $c_{N}>0$ captures the impact of road congestion. On the supply side, $F(K)$ denotes the cost function for construction and operation. The social surplus is equal to the consumers' surplus plus toll revenue less construction/operation costs. The objective of this problem is to maximize the social surplus associated with the facility, as shown below:

$$
\text { Maximize } S=\int_{p}^{\infty} N\left(p^{\prime}\right) d p^{\prime}+(p-c(N(p), K)) N(p)-F(K)
$$

The first-order condition gives:

$$
p:\left(p-c+N \cdot c_{B}\right) N_{p}=0 ; \quad K:-c_{K} N-F^{\prime}=0
$$


where $N_{p}=\partial N / \partial p$ and $F^{\prime}=\partial F / \partial K$.

Assuming that the total cost function, $\varphi(N, K)=c(N, K) \cdot N+F(K)$, which is the sum of the costs of all users and of the agency (construction and maintenance costs), is homogenous with degree one in $N$ and $K$, then it is deduced from Euler's Theorem that,

$$
c N+c_{N} N^{2}+c_{K} K N+F^{\prime} N=\varphi ;
$$

Combining this with the first-order condition, the revenue at equilibrium is:

$$
R^{*}=\left(p^{*}-c^{*}\right) N=\varphi\left(N^{*}, K^{*}\right)-c^{*} N^{*}=F\left(K^{*}\right)
$$

In other words, with the optimal toll $\tau^{*}=p^{*}-c^{*}$ and optimal capacity $K^{*}$, with which the total revenue is equal to the total construction/operation costs, social surplus is maximized.

Yang and Meng $(2000,2002)$ suggested an alternative approach that tailored the problem to a highway network. Their approach, which incorporates the concept of social net benefit maximization in a fundamentally similar manner to the Arnott and Kraus model, is described as follows:

Consider a highway network with a set of directed links, $A$, a set of origin-destination pairs $W$ and given link capacities $y_{a}$. In this network, the demand function $D_{w}$ maps the generalized cost of any given O-D pair, $c_{w}$, onto its demand, $d_{w}$; that is, $d_{w}=D_{w}\left(c_{w}\right)$. Also, travel time on a link $t_{a}$ is determined by link volume $v_{a}$ and capacity $y_{a}$, in turn, the total link travel time is denoted as $v_{a} t_{a}\left(v_{a}, y_{a}\right)$. It is worth noting that link volume is the sum of all flows, as follows: $v_{a}=\sum_{w \in W} \sum_{r \in R} \delta_{a r}^{w} f_{r}^{w}$, where $\delta_{a r}^{w}$ is 1 , if route $r$ is between O-D pair $w$, and 0 otherwise. The link construction and operation cost, whose principal determinant is link capacity, is represented by the function $I_{a}\left(y_{a}\right)$.

On the basis of the notations above, the social net benefit function $S S(f, y)$, similar to Eq 3.1 , is formulated as the consumer surplus plus toll revenue less the cost of providing the system. Thus, the maximization problem is represented as follows:

$$
\begin{aligned}
& \text { Maximize } S S(f, y)=\sum_{w \in W} \int_{0}^{d_{w}} D_{w}^{-1}(w) d w+\sum_{a \in A} v_{a} t_{a}\left(v_{a}, y_{a}\right)-\sum_{a \in A} I_{a}\left(y_{a}\right) \\
& \text { subject to } \quad \sum_{r \in R_{w}} f_{r}^{w}=d_{w}, v_{a}=\sum_{w \in W} \sum_{r \in R_{w}} \delta_{a r}^{w} f_{r}^{w}, f_{r}^{w} \geq 0, r \in R_{w}, w \in W
\end{aligned}
$$

Solving the first-order condition with respect to $y_{a}$, we get: 


$$
v_{a} \frac{\partial t_{a}\left(v_{a}, y_{a}\right)}{\partial v_{a}}+\frac{d l_{a}\left(y_{a}\right)}{d y_{a}}=0, a \in A
$$

Assuming a "fee" on a link $\tau_{a}$, the generalized user cost $\bar{t}_{a}$ can be written as $\bar{t}_{a}\left(v_{a}, y_{a}\right)=t_{a}\left(v_{a}, y_{a}\right)+\tau_{a}$, where $\tau_{a}=v_{a} \frac{\partial t_{a}\left(v_{a}, y_{a}\right)}{\partial v_{a}}$. If $t_{a}\left(v_{a}, y_{a}\right)$, the link cost function, is homogenous of degree zero and the construction cost is a linear function with respect to capacity, that is, $I_{a}\left(y_{a}\right)=\kappa_{a} y_{a}$, where $\kappa_{a}$ is a constant, then we obtain:

$$
y_{a} \frac{\partial t_{a}\left(v_{a}, y_{a}\right)}{\partial y_{a}}=-v_{a} \frac{\partial t_{a}\left(v_{a}, y_{a}\right)}{\partial v_{a}} \text { and } \frac{d l_{a}\left(y_{a}\right)}{d y_{a}}=\kappa_{a}, a \in A
$$

Eq 3.4 and Eq 3.5 yield:

$$
\tau_{a} v_{a}=\kappa_{a} y_{a}, a \in A
$$

This conclusion implies that the revenue from the optimal user fee is equal to the agency cost (of preservation, operations, and maintenance). This holds for each link in the network.

\section{Computation of Optimal Pricing}

From the above discussion, and given a set of technical assumptions regarding the functional form of user demand (utility) and costs, the maximum social surplus is attained at the highwayusage price at which total revenue equals the total cost. This is the core philosophy of selffinancing highway system. Furthermore, as concluded by Yang and Meng's approach (2000, 2002), if each link of highway system is assigned an adequate "fee" to cover the facility agency costs, in other words, if every link is self-financed, then the system attains the maximum efficiency.

It can be noted that extensions of the maximization problem, which consider pricing differentiation between modes and continuously-incurred costs such as maintenance and operation expenses, are also possible. At the current time, however, this analytical tool has been usually applied for small and/or hypothetical networks where this complicated formulation of optimization problem can be solved in a closed form. The present study adopts the conclusion drawn from the problem formulations above and applies it to establish the optimum price of using Indiana's state highway system. 
Applying this concept, the unit rate of optimal pricing can be calculated based on expenditure and demand data. It is equivalent to the calculation of $\tau_{a}$, when we know $v_{a}$ (demand) and $\kappa_{a} y_{a}$ (capital cost). Calculation results using expenditure and demand data available for Indiana are presented in Section 4.3 for several scenarios.

One important issue that remains, as discussed in Section 3.3.2, is the determination of whether a particular pricing scheme is optimal or not and depends on the scope of the cost that needs to be covered by the revenue, such as short-term marginal costs, long-term marginal costs, and fully allocated costs. At the current stage, an optimal pricing scheme will be sought for fully allocated costs, as such data are readily available.

\subsection{Equity Impacts}

\subsubsection{Definition of Equity}

Unlike efficiency, which deals with impacts of pricing on the system as a whole, equity-also called distributional - effect is considered in terms of specific user groups. A particular pricing strategy may work in a way to improve certain groups of people at the cost of others. It is alternatively also possible that even when a policy benefits every user in the system, the amount of benefit distributed to each user group may not be equitable. Pricing strategies often succeed or fail based on how the equity impacts are perceived by the stakeholders, and how well the equity concerns are addressed in the planning process (VTPI, 2005a).

In order to address the equity issue related to a pricing scheme, it is required first to classify user groups to well represent the heterogeneity and homogeneity of the users, and then a measurement of the distributional impacts can be selected. There are three dimensions of equity, or classification of user groups, that are generally used in the transportation field: spatial equity, modal equity, and equity between income groups. These dimensions can be specified on the basis of cost, benefit, or ability-to-pay. These three dimensions of user classification and three measurements are intertwined, as discussed in the following paragraphs. 


\section{Spatial Equity}

The concept of spatial equity corresponds to Rawls' "principle of liberty," which states that society should guarantee the right of access to jobs, goods, and services from any location (Raux and Souche, 2003). In this research, spatial equity is evaluated by categorizing users based on their location of residence or jobs.

\section{Modal Equity}

The concept corresponds to the "principle of equal opportunity," and involves the equality of treatment of different users and, in particular, the user-pays principle (Raux and Souche, 2003). It assumes that policies must not favor particular groups of people over others and thus implies that users should be charged the costs incurred to the system by their usage, i.e., "get what you pay for and pay for what you get" (VTPI, 2005a). Thus, by setting up a pricing scheme that charges users for the exact cost they impose, modal equity can be better achieved. Modal equity, however, can be compromised if a policy intends specific cross-subsidies between user groups, as exemplified in Section 5.2.2.

\section{Equity between Different Income Groups}

The concept corresponds to the "principle of difference," which explicitly considers social inequalities and their consequences with regard to transportation (Raux and Souche, 2003). This concept deals with redistribution of the outcome between groups with different needs and abilities (VTPI, 2005a). Also, it entails an ideological and philosophical question as to what extent society should support those who are economically, socially, or physically disadvantaged. Often quoted definitions as guidelines for this question are progressivity and regressivity, which measure the extent a policy favors or disfavors economically and socially disadvantaged members of a society. Given that, equity between income groups is more complex to evaluate than modal equity since it requires knowing one more factor, the target level of progressivity/regressivity. In other words, we can conclude if a policy is desirably progressive only when the desirable level of progressivity is well defined in a measurable manner.

Many transportation pricing policies are considered regressive since the pricing scheme usually charges the same amount regardless of the income level of the user. Given a toll rate or 
fuel tax, a proportional burden to income is inherently higher for lower-income users than higher income users. However, the regressivity of pricing also depends on available travel options and revenue dedication policies (Wachs, 2003). For example, if toll revenues collected from relatively higher-income users are used in financing a public transit system for those who are less able to afford paying the tolls, it can be neutral or progressive with respect to income.

\section{Three Measurements of Equity}

Intertwined with these three dimensions (spatial, modal, and between income groups) are three different measurements of equity: cost, benefit, and ability-to-pay (Adams et el., 2001). First, it is often argued that the system costs should be fairly distributed among users based on the amount of usage. Usage, in turn, is considered as a gauge of the damage or degradation brought to the system by its use. This concept is well represented in the Highway Cost Allocation Study in Section 3.4.3, which is an example of cost-basis modal equity evaluation. Another perspective of the equity issue is to pursue pricing schemes that charge users on the basis of the benefits they accrue from the system. The third approach is to duly consider users' ability-to-pay by designing a progressive taxation and pricing policy so that lower-income users pay proportionately lower prices compared to other users.

The quantitative analysis (Section 5.2.2) accomplished in the present study restricts its scope to spatial and modal equity on the basis of user costs measurement. It is because there is greater difficulty and less precision in measuring user benefits compared to costs. Also, determining the level of regressiveness/progressiveness of a taxation mechanism is not only a technical problem but also a political issue that requires legal support and public consensus. However, the impacts of alternative financing schemes on equity between different income groups are also discussed in Section 5.2.3.

\subsubsection{Self-Financing Concept and Equity Measurement}

In this study, the equity problem is viewed as the "breaking-down" of the efficiency problem, which means that the formulation described in the efficiency context in Section 3.3.3 can be applied. In the equity problem however, it is sought to maximize social surplus, albeit not for the entire population but for each segregated group. The efficiency level achieved in each group can 
be determined and the relative equity between groups can be computed. Equity will be measured or evaluated for each alternative on the basis of the system cost incurred by each user group. For quantitative evaluation (results presented in Section 5.2.2), the self-financing ratio concept is introduced. There are three dimensions under consideration:

\section{Spatial Equity}

A transportation policy may, by design or by default, discriminate among users according to the geographic locations of their residences and/or jobs. It is not rare for higher level governments (federal or state) to subsidize highway construction in areas that have small populations that may be "unprofitable" considering the population size or for other reasons. Equity is sought, thus in this research, between regional subgroups by population levels (rural and urban).

\section{Modal Equity}

Equity between modes secured by a particular pricing scheme can be appraised and compared by breaking down the entire system into modal subgroups to have separate welfare functions. Two different classifications of vehicle types are used in Section 4.3.2.

\section{Jurisdictional and Functional Independence}

A state's highway system is administered and maintained by different levels of government, but not every governmental unit is self-financed. Usually, lower level governments are subsidized by those at a higher level based on the amount of current assets they need for operation and preservation. A discussion of governmental units securing financial independence to sustain their own transportation systems is beyond the scope of this study. However, given the concept of direct user charging, it is still meaningful to establish user fee rates for each jurisdictional or functional highway class to cover the expense so that the revenue generated can be dedicated to its own source. Again, this coincides with the user-pay principle.

\subsubsection{Highway Cost Allocation Study}

Highway cost allocation studies (HCAS) provide a framework that quantifies highway-related costs attributable to and user fee revenues contributed by each user group. The most recent major 
study was conducted at the federal level in 1997 and it was updated and extended in 2000 (FHWA, 1997; FHWA, 2000c). As a part of the study, a spreadsheet-based tool was developed for state-level analyses. This tool, with updated Indiana-specific input values, was used to provide referable calculation of a future VMT fee structure (Section 4.3.2). A cost allocation study was also conducted for the State of Indiana in 1984 (Sinha et al., 1984), and was updated in 1989 (Sinha et al., 1989).

As results of the federal level HCAS, equity ratios, which measure the ratio of the revenue collected through fees and taxes to the costs imposed on the system for each vehicle class, were calculated (Table 3.7). The methodology used in highway allocation study, described in Appendix B, has limitations such that highway agency costs are used instead of economic costs; and that the costs used do not reflect what transportation agencies should spend, but what are actually being spent (FHWA, 1997). Yet, the values obtained here can give an idea of the equity status between vehicle classes.

Table 3.7 Equity Ratios Obtained from FHWA Highway Cost Allocation Study in 1997 and 2000

\begin{tabular}{|l|l|l|}
\hline \multicolumn{2}{|l|}{ Vehicle Class/ Registered Weight } & 1997 \\
\hline Passenger Vehicles & 1.0 & 1.0 \\
\hline Autos & 1.4 & 1.5 \\
\hline Pickups/Vans & 0.1 & 0.2 \\
\hline Buses & 1.1 & 1.1 \\
\hline All Passenger Vehicles & \multicolumn{2}{l|}{} \\
\hline Single Unit Trucks & 1.5 & 1.5 \\
\hline$\leq 25,000$ pounds & 0.7 & 0.7 \\
\hline 25,001 - 50,000 pounds & 0.5 & 0.4 \\
\hline$>50,000$ pounds & 0.9 & 0.9 \\
\hline All Single Unit Trucks & 1.6 & 1.4 \\
\hline Combination Trucks & 1.1 & 1.0 \\
\hline$\leq 50,000$ pounds & 1.0 & 0.9 \\
\hline $50,001-70,000$ pounds & 0.9 & 0.8 \\
\hline $70,001-75,000$ pounds & 0.6 & 0.5 \\
\hline $75,001-80,000$ pounds & 0.5 & 0.4 \\
\hline $80,001-100,000$ pounds & 0.9 & 0.8 \\
\hline$>100,001$ pounds & & \\
\hline All Combination Trucks & & \\
\hline Source: FHWA & & \\
\hline
\end{tabular}

Source: FHWA (2000a) 
Table 3.7 shows the estimated federal equity ratios of the 2000 HCAS under the current highway user charge structure, compared to the values estimated in 1997. It is noted that automobiles pay about the same share of federal highway user fees as their share of highway costs, while pickups and vans pay substantially more than their cost responsibility. This difference is primarily attributable to automobile's better fuel economy, which means lower fuel tax payment. Equity for single unit and combination trucks is highly dependent on the weight of the vehicles. As a class, single units pay about $90 \%$ of their federal highway cost responsibility. Equity ratios for combination trucks as a group dropped from $90 \%$ to $80 \%$ of their cost responsibility from 1997 to 2000 . This reduction mainly arises because combination trucks pay a smaller share of federal user fees under the TEA-21 program structure.

Table 3.8 summarizes the results of Indiana's highway cost allocation studies. The results indicate that passenger vehicles and single unit trucks pay more than their cost responsibility, while combination trucks pay considerably less than their cost shares.

Table 3.8 Equity Ratios Obtained from Indiana Highway Cost Allocation Studies

\begin{tabular}{|c|c|c|}
\hline Vehicle Class/ Registered Weight & $1985 / 86$ & 1988 \\
\hline \multicolumn{3}{|l|}{ Passenger Car } \\
\hline Small passenger cars & 0.764 & 1.071 \\
\hline Standard/compact passenger cars, pickup & 1.382 & \multirow{3}{*}{1.385} \\
\hline Cars with 1-axle trailer & 1.075 & \\
\hline Cars with 2-axle trailer & 0.878 & \\
\hline All Passenger Vehicles & 1.249 & 1.289 \\
\hline Buses & 0.977 & 0.909 \\
\hline \multicolumn{3}{|l|}{ Single Unit Trucks } \\
\hline 2-axle trucks & 1.446 & 1.222 \\
\hline 3-axle single unit trucks & 0.820 & 1.044 \\
\hline 4-axle single unit trucks & 1.029 & 0.910 \\
\hline All Single Unit Trucks & 1.241 & 1.050 \\
\hline \multicolumn{3}{|l|}{ Combination Trucks } \\
\hline 2S1 tractor-trailer & 0.522 & \multirow{3}{*}{0.695} \\
\hline 3S1 tractor-trailer & 0.667 & \\
\hline 2S2 tractor-trailer & 0.475 & \\
\hline 3S2 tractor-trailer & 0.513 & 0.643 \\
\hline Other 5-axle & 1.196 & 0.871 \\
\hline 6 or more axle & \multirow{2}{*}{0.550} & 0.652 \\
\hline 7 or more axle & & 0.625 \\
\hline All Combination Trucks & 0.536 & 0.655 \\
\hline
\end{tabular}

Source: Sinha et al. $(1984,1989)$ 


\subsection{Implementation Costs}

\subsubsection{Cost Structure of Pricing Schemes}

\section{Physical Costs of System}

The physical costs of a system are borne by several items, including the initial installation, equipment deployment, and operation.

- Installation costs occur at the initial construction stage.

- Deployment costs occur when there is a need to distribute equipment to individual vehicles. As demonstrated in Oregon's VMT fees system, the users may need to be given on-board units at low or no cost in the initial stage before all vehicle manufacturers are obliged to install one for each vehicle.

- Operation and maintenance costs are required on a regular basis.

\section{Cost of Administration}

- Bureaucratic costs occur when a new system is introduced.

- Enforcement costs can vary depending upon system configuration. Usually, the greater the accuracy in detecting violations the authority pursues, the larger are the enforcement costs required.

\section{User Inconvenience}

User inconvenience arises when it is necessary to stop at toll booths to pay tolls, to purchase and install equipment on their vehicles, or to pay additional bills.

Various technological options entail different levels of implementation costs and difficulties as discussed in Section 2.5.2. For each alternative, implementation costs are estimated referring to the information available from several comparable implementations. 


\subsection{Public Acceptability}

\subsubsection{Factors that Affect Public Acceptability}

Important factors that have influence on public acceptability of road pricing policies are defined by Schade and Schlag (2003) as the following:

Problem perception: For a road pricing scheme to be successfully implemented, there should be high level of problem awareness that would eventually lead to willingness for the public to accept solutions suggested by public agencies.

Knowledge about options: At often times, it is the lack of knowledge/information that causes opposition to a road pricing policy. It is argued that public outreach and education is critical in obtaining acceptability.

Perceived effectiveness of the proposed measures: Especially when the community has not been exposed to any similar pricing and taxation measures before, thus when they do not believe that those measures could solve transportation-related problems, it becomes more possible for a pricing policy to face low public acceptability. This phenomenon is called the "strategic response" hypothesis when respondents try to justify their rejection of a policy by claiming that they perceive it as ineffective (Rienstra et al., 1999).

Socio-economic factors: Factors such as income, education, gender, age, and political affiliation are known to have influence on acceptability. Hamideh et al., (2006) found that population groups who present high acceptability towards local option transportation sales tax are characterized as those with higher levels of education, Democratic Party affiliations, and relatively lower household incomes.

For a successful implementation of a pricing scheme, public acceptability first should be understood; any hindrances or obstacles should be sorted out; and appropriate remedies should be taken place. The following section discusses tools to communicate public opinion. Implementation plans to tackle low acceptability situation are further discussed in Chapter 6 . 


\subsubsection{Public Opinion Survey}

Public opinion surveys can be a good tool to understand the perception and attitude of users. However, unless caution is paid to the following issues, results from survey may lead to wrong observations and conclusions. First, a sample should be selected carefully so it can well represent the entire population. The sampling needs to be designed to have enough observations for each subgroup of the population; for example, with respect to geographic regions, and demographic and socio-economic characteristics.

Also, given that surveys often inquire about a respondent's attitude toward options that have not yet been implemented, the features and possible problems of the stated preference data should be noted. Unlike revealed preferences, actual observations on choices can occur, and answers to hypothetical questions can be biased for several reasons including: (a) a respondent may not have enough information/knowledge that he/she would have needed if it were an actual situation; (b) one may conjecture the intentions of a survey and manipulate his/her answers assuming that they can influence the outcome decision; and (c) one may exaggerate the importance of specific attributes of hypothetical options when they are emphasized in the survey questionnaire. For example, if a survey asking the pros and cons of a toll road were held in a region where toll roads have never been implemented, large difference could be observed between answers to the survey questions and actual responses to the toll road when it is implemented.

Being aware of these problems, focus groups for a smaller number of respondents have been tried in several cases as supplements or substitutes for questionnaire-based surveys of a large number sample. This approach enables a decision-maker to uncover detailed information on respondents' experiences and perceptions and their interaction, in advance in order to conclude a strategy that can win public acceptability. 


\subsection{Policy Alignment}

\subsubsection{National Perspectives}

It has been suggested that federal level strategies for transportation funding should eventually phase out the federal motor fuel tax and replace it with a federal VMT tax (NCF, 2005; TRB 2005; NCHRP 2006). Strategies in the short-, medium-, and long-term are summarized below:

\section{Short-Term Strategies}

Indexing federal motor fuel taxes would have the most immediate impact. The motor fuel tax is the only major existing tax that is not indexed to inflation. Other strategies include:

- Closing exemptions to the Highway Trust Fund (HTF) so that revenues dedicated to transportation are spent on transportation.

- Recrediting interest to the HTF so that the HTF can reap the full benefit of the revenue paid into the fund by users.

- Dedicating $10 \%$ of U.S. Customs import revenues to transportation to account for transportation's contribution to the facilitation of international commerce.

- Giving state and local governments more revenue and investment options by authorizing the expanded use of tolling and by encouraging states to index their motor fuel taxes to account for inflation.

- Stimulating greater use of innovative finance tools so that states can make transformative investments in their transportation infrastructure. These tools include federal loan guarantees, private activity bonds, tax-credit bond financing, and investment tax credits.

\section{Medium-Term Strategies}

A new approach to transportation user fees should help meet the nation's transportation needs from 2010 to 2015. These strategies include:

- Broadening the base of user payments to the HTF by collecting a vehicle fee to capture fair payments from hybrid and other alternative fuel vehicles. 
- Ensuring that any subsidies for the purchase of hybrid and nonpetroleum-powered vehicles come from the general fund, as was done for ethanol fuel subsidies, rather than the HTF.

- Recommending that the recently authorized National Surface Transportation Infrastructure Financing Commission oversee a new cost allocation study, setting principles and guidelines for the efficient and equitable allocation of HTF fees.

\section{Long-Term Strategies}

The federal government should provide leadership for state and local governments to implement new systems of financing transportation funding that reduce reliance on the motor fuel tax. These strategies include:

- Implementing a mileage-based transportation revenue system to help address long-term revenue shortfalls.

- Adopting two vehicle miles of travel (VMT) fees: a state VMT fee as well as a localoption VMT fee to help ease metropolitan congestion.

- Indexing VMT fees to inflation to help close the annual gap between transportation needs and revenues.

- Consider varying the VMT by vehicle weight, fuel type and consumption, environmental impact, road system, and/or geography to account for different levels of use and impact and to ensure that all users of the system pay their fair share of infrastructure costs.

\subsubsection{Compatibility with Federal Strategy}

Under the current structure of highway finance, where a large portion of state expenditures is provided by federal funding, the effectiveness and efficiency of a state's policy is essentially affected by federal programs. Therefore, policies of a state government will perform most effectively and will return the best outcome when they coincide well with federal policies, especially regarding a long-term strategy. A proper alignment of the overall direction of a state program can thus be critical for success. 
However, on the other hand, the coming decade will observe constraints in the federal budget, which has been amplified recently, as well as increasing demands of the states for autonomy. These conditions will presumably lead to the leveling or a decline of federal funding and introduction of new charging schemes. TRB has provided a reassessment of federal responsibilities and concluded that federal funding should be based on user fees (TRB, 2005):

- Providing aid to ensure that the states do not underinvest in routes of major national significance for commerce, travel, and public safety and security. For example, a state may be unwilling to invest in such a route if sufficient user fee revenue cannot be collected from out-of-state vehicle operators to pay for the cost of serving them because travelers buy fuel outside the state.

- Standards setting, in cooperation with states and local governments, to gain efficiencies in construction and operation and to ensure uniformity of highway features needed to allow efficient nationwide passenger and freight traffic (for example, compatibility of road design with vehicle).

- Research and development, since all highway agencies share an interest in innovation, especially in the development of improved forms of charging.

In other words, a major alteration is foreseen in the relationship between federal, state, and local governments. When the federal long-run blueprint of nationwide usage-based charging, described in the previous section, is realized, state and local governments would have higher discretionary power to control revenue and pricing. Within the context of this new relationship, the federal government might be required to take a new role, oversight of possible abuse of monopoly power by governments.

Restating the above, compatibility with federal policy should be assessed based on two criteria. First, we need to know whether execution of an alternative aligns well with federal level strategy. And second, it needs to be appraised if an alternative is eligible to meet the listed federal goals, including adequate investment in significant routes and rebuff of misusing monopolistic power. Section 5.5 scrutinizes short-term and long-term strategies proposed at the federal level and assesses the compatibility of each alternative. 


\section{CHAPTER 4. DEVELOPING ALTERNATIVES}

This chapter characterizes each of the alternatives proposed in Chapter 2 in terms of its adequacy as a revenue source, the impact on system efficiency, start-up/operation/administration cost, the impact on system equity, and public/political acceptability. The first alternative is to make relevant adjustments in the existing highway taxation system, such as motor fuel taxes, vehicle registration and licensing fees, local option sales tax, and other general taxes. The second alternative does not include any changes in the current taxation system; rather it tries to match the deficit with revenues from new financing tools. The last alternative is to completely replace the current fuel taxes with an innovative pricing method, usage-based charging. The basic structure of this innovative approach, as well as possible variations that aim to provide more comprehensive highway pricing, is argued.

For numerical analysis, highway system information for the State of Indiana, including the current budget balance, assets, demand, and future needs of highway financing was reviewed. Table 4.1 summarizes highway expenditure information for the most recent three years and their averages, which were obtained from the highway statistics. Also, the Highway Performance Monitoring System (HPMS) database was utilized to obtain the highway asset information clustered by road function class and by pavement type, as summarized in Table 4.2. In order to obtain the demand data by vehicle type and road functional class in Table 4.3, Indiana Statewide Travel Demand Model (ISTDM) was used. 
Table 4.1 Disbursements for the Indiana State-Administered Highways by Road Functional Class (thousand dollars)

\begin{tabular}{|c|c|c|c|c|c|c|c|c|c|}
\hline \multirow[t]{2}{*}{ Location } & \multirow[t]{2}{*}{ Functional Class } & \multicolumn{4}{|c|}{$\begin{array}{l}\text { Disbursements for State-Administered } \\
\text { Highways (including Federal-Aid) }\end{array}$} & \multicolumn{4}{|c|}{$\begin{array}{c}\text { Estimated Disbursements for State- } \\
\text { Administered Highways Supported by State } \\
\text { Generated Funds Only }\end{array}$} \\
\hline & & 2004 & 2003 & 2002 & Average & 2004 & 2003 & 2002 & Average \\
\hline \multirow[t]{5}{*}{ Rural } & Interstate & 164,861 & 145,527 & 165,139 & 158,509 & 109,860 & 35,545 & 73,196 & 72,867 \\
\hline & Other Principal Arterial & 279,368 & 202,461 & 165,315 & 215,715 & 186,912 & 157,946 & 101,234 & 148,697 \\
\hline & Major Arterial & 238,753 & 142,377 & 148,057 & 176,396 & 183,020 & 109,649 & 96,840 & 129,836 \\
\hline & Major Collector & 289,947 & 589,948 & 260,622 & 380,172 & 262,384 & 568,276 & 245,394 & 358,685 \\
\hline & Rural Subtotal & 972,929 & $1,080,313$ & 739,133 & 930,792 & 742,177 & 871,415 & 516,664 & 710,085 \\
\hline \multirow[t]{5}{*}{ Urban } & Interstate & 280,424 & 267,396 & 218,646 & 255,489 & 152,064 & 144,119 & 68,688 & 121,624 \\
\hline & Other Freeway/Expressway & 12,419 & 11,484 & 15,465 & 13,123 & 4,468 & 3,533 & 4,216 & 4,072 \\
\hline & Other Principal Arterial & 239,930 & 121,401 & 184,506 & 181,946 & 158,353 & 66,225 & 92,224 & 105,601 \\
\hline & Major Arterial & 32,797 & 14,692 & 10,578 & 19,355 & 28,004 & 11,361 & 8,933 & 16,099 \\
\hline & Urban Subtotal & 565,571 & 414,973 & 429,195 & 469,913 & 350,889 & 217,238 & 174,061 & 247,396 \\
\hline \multicolumn{2}{|l|}{ Total } & $1,538,500$ & $1,495,286$ & $1,168,328$ & $1,400,705$ & $1,093,066$ & $1,088,653$ & 690,725 & 957,481 \\
\hline
\end{tabular}

Source: Highway Statistics 2002, 2003, 2004

Table 4.2 State Highway Asset Information by Road Functional Class and Pavement Type

\begin{tabular}{|c|c|c|c|c|c|c|c|c|c|}
\hline \multirow{2}{*}{ Location } & \multirow{2}{*}{ Functional Class } & \multicolumn{4}{|c|}{ Number of Miles by Pavement Type } & \multicolumn{4}{|c|}{ Lane-Miles by Pavement Type } \\
\hline & & Flexible & Composite & Rigid & Total & Flexible & Composite & Rigid & Total \\
\hline \multirow[t]{5}{*}{ Rural } & Interstate & 179 & 91 & 499 & 770 & 358 & 183 & 1,019 & 1,560 \\
\hline & Other Principal Arterial & 450 & 102 & 1,001 & 1,553 & 900 & 203 & 2,002 & 3,106 \\
\hline & Major Arterial & 1,257 & 35 & 892 & 2,185 & 2,515 & 71 & 1,784 & 4,370 \\
\hline & Major Collector & 3,999 & 19 & 657 & 4,675 & 7,999 & 37 & 1,314 & 9,350 \\
\hline & Rural Subtotal & 5,918 & 247 & 3,050 & 9,215 & 11,836 & 494 & 6,120 & 18,385 \\
\hline \multirow[t]{5}{*}{ Urban } & Interstate & 110 & 75 & 214 & 399 & 292 & 205 & 491 & 988 \\
\hline & Other Freeway/Expressway & 12 & 24 & 69 & 105 & 25 & 46 & 143 & 213 \\
\hline & Other Principal Arterial & 173 & 66 & 874 & 1,112 & 258 & 133 & 1,351 & 1,741 \\
\hline & Major Arterial & 36 & 4 & 141 & 181 & 38 & 7 & 162 & 207 \\
\hline & Urban Subtotal & 336 & 169 & 1,301 & 1,806 & 617 & 390 & 2,151 & 3,154 \\
\hline \multicolumn{2}{|l|}{ Total } & 6,254 & 416 & 4,351 & 11,021 & 12,454 & 885 & 8,270 & 21,539 \\
\hline
\end{tabular}

Source: Highway Performance Monitoring System 
Table 4.3 Annual Vehicle-Miles-Traveled on State Highway System

\begin{tabular}{|c|c|c|c|c|c|c|c|c|c|}
\hline \multirow{2}{*}{ Location } & \multirow{2}{*}{ Functional Class } & \multicolumn{4}{|c|}{ Total VMT in million } & \multicolumn{4}{|c|}{ Automobile VMT in million } \\
\hline & & Flexible & Composite & Rigid & Total & Flexible & Composite & Rigid & Total \\
\hline \multirow[t]{6}{*}{ Rural } & Interstate & $2,020.3$ & $1,058.1$ & $6,165.4$ & $9,243.8$ & $1,455.0$ & 717.1 & $4,620.3$ & $6,792.4$ \\
\hline & Other Principal Arterial & $1,094.6$ & 428.0 & $4,280.5$ & $5,803.1$ & 932.6 & 370.0 & $3,618.2$ & $4,920.9$ \\
\hline & Major Arterial & $1,777.3$ & 75.2 & $2,711.2$ & $4,563.7$ & $1,576.7$ & 67.0 & $2,396.4$ & $4,040.1$ \\
\hline & Major Collector & $5,361.0$ & 66.2 & $2,820.6$ & $8,247.8$ & $4,842.1$ & 59.7 & $2,531.3$ & $7,433.2$ \\
\hline & Minor Collector & 210.5 & 0.0 & 56.5 & 267.0 & 186.8 & 0.0 & 48.9 & 235.8 \\
\hline & Rural Subtotal & $10,463.7$ & $1,627.5$ & $16,034.2$ & $28,125.4$ & $8,993.3$ & $1,213.9$ & $13,215.1$ & $23,422.3$ \\
\hline \multirow[t]{6}{*}{ Urban } & Interstate & $2,243.3$ & $1,684.4$ & $3,301.2$ & $7,228.9$ & $1,876.9$ & $1,438.9$ & $2,688.6$ & $6,004.4$ \\
\hline & Other Freeway/Expressway & 95.8 & 238.2 & 680.5 & $1,014.6$ & 85.8 & 201.8 & 586.9 & 874.5 \\
\hline & Other Principal Arterial & $1,098.1$ & 822.1 & $6,813.0$ & $8,733.1$ & $1,020.7$ & 794.0 & $6,327.8$ & $8,142.5$ \\
\hline & Minor Arterial & 390.5 & 125.4 & $2,982.8$ & $3,498.6$ & 373.8 & 120.6 & $2,833.2$ & $3,327.6$ \\
\hline & Collectors & 35.4 & 0.0 & 347.6 & 383.0 & 33.4 & 0.0 & 325.9 & 359.4 \\
\hline & Urban Subtotal & $3,863.1$ & $2,870.1$ & $14,125.1$ & $20,858.3$ & $3,390.7$ & $2,555.2$ & $12,762.4$ & $18,708.4$ \\
\hline \multicolumn{2}{|l|}{ Total } & $14,326.8$ & $4,497.6$ & $30,159.2$ & $48,983.6$ & $12,384.0$ & $3,769.2$ & $25,977.5$ & $42,130.7$ \\
\hline \multirow{2}{*}{ Location } & \multirow{2}{*}{ Functional Class } & \multicolumn{4}{|c|}{ Single Unit Truck VMT in million } & \multicolumn{4}{|c|}{ Combination Truck VMT in million } \\
\hline & & Flexible & Composite & Rigid & Total & Flexible & Composite & Rigid & Total \\
\hline \multirow[t]{6}{*}{ Rural } & Interstate & 123.8 & 167.8 & 645.0 & 936.7 & 429.1 & 164.5 & 921.2 & $1,514.8$ \\
\hline & Other Principal Arterial & 108.2 & 38.9 & 437.7 & 584.8 & 53.8 & 19.2 & 224.4 & 297.4 \\
\hline & Major Arterial & 146.0 & 7.1 & 236.9 & 389.9 & 54.3 & 1.1 & 78.3 & 133.6 \\
\hline & Major Collector & 438.4 & 6.0 & 260.1 & 704.5 & 79.0 & 0.5 & 30.6 & 110.0 \\
\hline & Minor Collector & 21.1 & 0.0 & 7.9 & 29.0 & 2.3 & 0.0 & 0.0 & 2.3 \\
\hline & Rural Subtotal & 837.6 & 219.9 & $1,587.5$ & $2,644.9$ & 618.4 & 185.3 & $1,254.5$ & $2,058.1$ \\
\hline \multirow[t]{6}{*}{ Urban } & Interstate & 193.3 & 147.0 & 283.6 & 623.9 & 174.3 & 101.8 & 324.6 & 600.7 \\
\hline & Other Freeway/Expressway & 8.7 & 29.4 & 70.2 & 108.3 & 1.8 & 6.7 & 23.3 & 31.8 \\
\hline & Other Principal Arterial & 66.1 & 27.8 & 406.2 & 500.1 & 11.1 & 5.1 & 74.3 & 90.5 \\
\hline & Minor Arterial & 15.3 & 4.5 & 139.5 & 159.2 & 1.7 & 0.6 & 9.5 & 11.8 \\
\hline & Collectors & 1.7 & 0.0 & 20.7 & 22.4 & 0.2 & 0.0 & 1.1 & 1.2 \\
\hline & Urban Subtotal & 285.0 & 208.7 & 920.2 & $1,413.9$ & 189.1 & 114.1 & 432.8 & 736.1 \\
\hline \multicolumn{2}{|l|}{ Total } & $1,122.6$ & 428.5 & $2,507.7$ & $4,058.8$ & 807.5 & 299.4 & $1,687.3$ & $2,794.2$ \\
\hline
\end{tabular}

Results obtained by running Indiana Statewide Travel Demand Model (ISTDM) base scenario 
The present study mainly focuses on evaluation of revenue generating options that can sustain the current expenditure level with the given current highway demand. In addition, future highway needs are also considered to provide financing strategies that can not only maintain and preserve the current state highway system but also expand and improve it.

As mentioned in Chapter 1, previous need studies provided a range of future highway needs varied by approaches and assumed scenarios. The most recent business plan for INDOT estimated that the annual funding gap would be gradually increasing each year to reach $\$ 167$ million in 2010 and \$405 million in 2015 (INDOT, 2005). The analysis was conducted for a future scenario which assumed completion of projects that are planned not only to preserve the existing facilities but also to improve mobility and accessibility. A separate highway needs study conducted by JTRP (Sinha et al., 2005) provided another set of future financial needs. Considering all projects in the INDOT long range plan and those generated by HERS modeling system, the JTRP study estimated that the annual funding gap could range between $\$ 860$ and $\$ 1,120$ billion. The present study primarily refers to the results from the INDOT's business plan.

The quantitative analyses carried out in this chapter are based on the following four major data sets: expenditures, assets, demand, and future needs. 


\subsection{Alternative 1 - Adjusting Current Tax System}

In Indiana, the revenues from several state and local taxes are used for highway-related purposes. Some taxes, including fuel taxes and vehicle registration fees, are earmarked for transportation funding. The first alternative will consider how to target the transportation budget needed by adjusting the rates or charging mechanisms for these existing revenue sources.

\subsubsection{Increase in Fuel Tax Rates}

Discussion in this section regarding a fuel tax amendment as an alternative to fuel tax may seem contradictory. The following analysis is, however, still meaningful in that it provides a basis for the analysis of other alternatives and comparison between them.

The fuel tax increase that would be required to meet the assessed needs can be estimated based on revenue projections. First, in terms of the state gasoline tax, considering the 3.1 billion gallons of gasoline consumed in fiscal year 2003 and an annual revenue gap that ranges from $\$ 167$ to $\$ 405$ million during the period of 2010 through 2015, simple calculation (\$167-405 million $\div 3.1$ billion gallons) returns 5.4 to 13.1 cents per gallon of increment. In Indiana, the gasoline tax rate, which remained at 15 cents per gallon between 1988 and 2002, was raised to 18 cents/gallon in January 2003. Reflecting the inflation impact by using the CPI (Consumer Price Index), however, the rate of 15 cents in 1988 can be converted into 26 cents in 2006 , which is 8 cents higher than the current level. Although this simple reasoning shows that the motor fuel tax rate is below the buying power it used to have, an increase in the tax rate up to 13.1 cents per gallon would be drastic, considering the strong emotional reluctance to fuel tax increases.

The second option considers adjustment of the state diesel tax rate. Currently, diesel fuel users pay two separate user fees: 1) 16 cents per gallon motor carrier fuel use tax; and 2) 11 cents per gallon motor carrier surtax. The combined 27 cents per gallon total user fee on diesel fuel based on 830 millions gallons of annual average consumption (in 2003) yields \$224 million per year. For reference, 27 cents in 1988 could be converted to about 47 cents in 2006 . In order to 
cover the entire annual deficit ( $\$ 167-405$ million) only from diesel users, it would be necessary to increase the fees on diesel fuel by a range of 20.1 to 48.8 cents per gallon, which would be about at least $80 \%$ of the current rate.

Third approach consists of raising both the gasoline and diesel fuel taxes, keeping the current ratio of 18 cents to 27 cents unchanged. Under this condition, it is calculated that we need 3.8 to 9.2 cents per gallon of increase in the gasoline tax and 5.7 to 13.8 cents per gallon of increase in diesel fuel tax. The calculations are shown in Table 4.4. The result is modest compared to the previous two examples.

Table 4.4 Fuel Tax Increases Needed to Bridge Funding Gap

\begin{tabular}{|l|c|c|}
\hline & Gasoline & Diesel \\
\hline Annual consumption (base 2003) & 3.1 billion gallons & 0.86 billion gallons \\
\hline Current tax ratio & 18 cents/gallon & 27 cents/gallon \\
\hline Rate increase & $\alpha$ & $1.5 \alpha$ \\
\hline Revenue generated with raised rates & $(3.1)(\alpha)$ & $(0.86)(1.5 \alpha)=(1.29)(\alpha)$ \\
\hline Increase in per gallon rate & $3.8 \sim 9.2$ cents & $5.7 \sim 13.8$ cents \\
\hline
\end{tabular}

It is noteworthy that the figures above only provide reference values if we consider modification of the current fuel tax rates. For actual implementation, a rate plan will have to be established deliberately, taking into account the trends and the predictions of fuel consumption by fuel type, the ratio between different types of motor fuels, and the new rates for alternative fuels. The general features of this alternative are summarized below:

Revenue Generation: This alternative inherits advantages and disadvantages of the current fuel tax as a revenue source. As is well known, fuel taxes as a dedicated source for transportation needs can be evaluated to be accountable and, assuming continuous adjustment with inflation, can be relatively stable. Sufficiency will depend on how much these rates can be increased.

System Efficiency: Since a fuel tax is closer to being a perfect direct use charging method than other existing funding sources, such as vehicle registration fees and appropriations from general taxes, this alternative will secure more system efficiency. However, there still remains a problem of unfairness between vehicles with different fuel efficiency and vehicles with traditional and alternative fuels. 
Equity: The fuel tax system essentially follows the user-pay-principle, and in that regard, it is more equitable than other general taxes. Yet, it is still possible to improve the equity between users with different geographical locations, vehicle classes, costs imposed on the system, etc.

Start-up/Operation/Administration Cost: Minimal operation and administration costs will be added to the existing tax collection system. However, there will be some costs incurred to promote and make the change.

Public/Political Acceptability: As perceived, an increase in fuel taxes is difficult to implement due to political reasons. In order to execute this alternative, much effort will be needed to persuade the public to accept its necessity and to promote the efficiency brought to the system.

\subsubsection{Increase in Other Taxes}

As another option under this category, more general forms of taxes are subject to analysis, namely, vehicle registration and licensing fees, and for local agencies, local option sales taxes and property taxes. Assessment of these alternatives will follow the same framework as the fuel tax increase.

\section{Vehicle Registration and Licensing Fees}

Currently, revenues from vehicle registration and licensing taxes contribute to $25 \%$ of Indiana's state highway budget, being the second largest source following fuel taxes. Being earmarked for transportation-related purposes, the revenues from these sources are distributed to the Motor Vehicle Highway Account, Motorcycle Operators Safety Education Fund, State Highway Fund, and Local Road and Street Fund. There are also contributions from service charges, title fees, transfer fees, etc. (Sinha et al., 2005).

Revenue Generation: Mathematically, it is possible to adjust the current rates of these fees to meet the financial needs assessed, assuming no public opposition to a tax increase. Looking at the actual numbers, given that the current revenue from registration and licensing is around \$300 million and assessed annual deficit reaches \$405 million dollars in 2015 (INDOT, 2005), a $135 \%$ increase in these fees will be required to bridge the financial gap. In this regard, it seems neither possible nor wise to pursue the financial effectiveness by charging users four times more in licensing and registration fees. However, it is technically feasible to secure additional 
revenues by raising the current rates, and moreover, these are quite accountable sources that are earmarked for transportation purposes. On the other hand, since these are one-time fees, it is acceptable to assume that there will be little or no impact on the demand per vehicle, which is interpreted as the distance-traveled of each registered vehicle. It could be the case, however, that the number of registrations will decrease due to increased fees, and thus the total number of vehicle-miles traveled will decrease. Assuming that the elasticity of vehicle ownership with respect to vehicle registration fees is very small, the revenues from these fees can be considered stable.

System Efficiency: Charging users regardless of their usage of facilities does not necessarily encourage users to use system resources efficiently.

Equity: This measure has nothing to do with equity between users based on either benefits gained or costs they impose on the system. Assuming that higher income taxpayers have more expensive vehicles (i.e., they will pay more of such fees), this scheme can be seen as a relatively progressive taxation mechanism.

Start-up/Operation/Administration Cost: There will be no start-up costs and little additional operation costs. This alternative will add only a small amount of administration cost since the only effort needed will be adjusting the fee rates accordingly. However, it may entail costs for public outreach.

Public/Political Acceptability: When an increase is modest enough, it is expected to face little or no resistance/argument from the public since they are already paying such fees and expect occasional increases. But when drastic change is being considered, sufficient efforts will be needed to explain the rationale of fee increases.

\section{Options for Local Agencies}

Given that considerable portion of state highway revenues is distributed to local governments to sustain local highway systems, measures that can increase local highway revenues are estimated. First, Local Option Transportation Sales Taxes temporarily increase the sales tax rate to dedicate the additional revenue exclusively to transportation purposes and are authorized in 33 states of the U.S. In many states, sales tax is one of the most politically feasible financing tools for transportation investments among existing ones. It was observed in counties in California that taxpayers are more willing to approve sales taxes options than any other source (Goldman et al., 2001). As observed from other states, enacting a local option sales tax for transportation purposes 
requires political steps such as appropriate legislation by the state government, placement of referenda on the election ballot by county governments, and approval by voters (that requires one-half or two-third approval). Many measures were found to propose a half-percent or quarterpercent increase in sales taxes, in most cases with "sunset dates," which means they are in effect only during a specified period of time (Adams et al., 2001).

Sales taxes are advantageous in that the government can promote relatively small rate adjustments in order to target the same amount of tax revenue increase because sales taxes are applied to a variety of items; thus, its increment appears to be less than the others. For example, if the government charges $0.5 \%$ more sales tax and uses the revenues for transportation purposes, then an average household that spends $\$ 2,000$ monthly on sales-tax-applied products (BTS, 2005a), will contribute $\$ 10$ more per month to the transportation budget through this local option. On the other hand, assuming that the expenditures on motor fuels of that household are $\$ 100$ per month (BTS, 2005a), which is approximately equivalent to 50 gallons, the fuel tax would need to be raised by 20 cents/gallon to achieve that same $\$ 10$ of tax revenue. Generally, when people face two different types of tax increase measures, one of which is a sales tax increase of $0.5 \%$ point and the other a fuel tax increase of 20 cents/gallon (111\% raise), they will likely perceive the former to be a lesser burden.

In Indiana, the total revenue from sales tax is approximately $\$ 5$ billion, of which $0.76 \%$ is distributed to the Public Mass Transportation Fund, 0.04\% to the Industrial Rail Service Fund, and $0.17 \%$ to the Commuter Rail Service Fund (ILSA \& OFMA, 2005). The recent five-year trend is summarized in Table 4.5. Supposing $0.5 \%$ point of increase in sales tax as a local option, \$25 million could be collected annually through this account.

Table 4.5 Revenue and Distribution of Sales Tax, Indiana (thousand dollars, \%)

\begin{tabular}{|c|c|c|c|c|c|c|}
\hline Fiscal Year & GF & PTRF & PMTF & IRSF & CRSF & TOTAL \\
\hline 2001 (000's) & $2,187,582$ & $1,499,201$ & 28,485 & 1,499 & 6,372 & $3,723,139$ \\
\hline 2003 (000's) & $2,270,542$ & $1,902,007$ & 29,589 & 1,549 & 6,576 & $4,210,262$ \\
\hline 2005 (000's) & $2,443,612$ & $2,516,766$ & 31,963 & 1,661 & 7,047 & $5,001,049$ \\
\hline Avg. (01 05) & $2,290,041$ & $1,970,337$ & 29,897 & 1,563 & 6,639 & $4,298,477$ \\
\hline Ratio \% (2005) & 53.28 & 45.84 & 0.70 & 0.04 & 0.15 & 100.00 \\
\hline Ratio \% (avg.) & 48.86 & 50.32 & 0.64 & 0.03 & 0.14 & 100.00 \\
\hline
\end{tabular}

Source: ILSA \& OFMA (2005)

GF (General Fund); PTRF (Property Tax Replacement Fund); PMTF (Public Mass Transportation Fund); IRSF (Industrial Rail Service Fund); CRSF (Commuter Rail Service Fund) 
Currently, only a part of the 92 counties in Indiana have enacted local option wheel taxes for transportation. Revenue collected from this source is not significant.

The features of this alternative are summarized below:

Revenue Generation: As roughly calculated above, the local option sales tax can provide a certain amount of funding deficit ( $\$ 25$ million per year through a $0.5 \%$ point of an option). However, it is generally noticed that the revenue from sales tax might not be as stable as desired since retail sales are sensitive to economic conditions. Also, as mentioned above, since it is usually endorsed with an expiration date that comes in 5 10 years, another referendum would be needed to extend the effective period. In terms of accountability, unlike a simple subsidy from sales tax revenue to the transportation budget, the local option sales tax has the advantage that the revenue dedication is specified from the initiation.

System Efficiency: The amount of an individual's payment of sales taxes is rarely connected with transportation system use. Thus, charging sales taxes cannot act as a direct incentive to efficient use of the transportation system. In that regard, the local option sales taxes cannot secure system efficiency.

Equity: We can hardly say that funding the transportation system with sales tax revenues satisfies the user-pay principle. It is rather a subsidy from the buying public to transportation system users. Although those two groups could be identical as a whole, individually it is not a system where people pay for what they use.

Start-up/Operation/Administration Cost: This alternative requires minimal operation and administration costs since sales taxes for other purposes are being collected already. Some initial costs will be needed in promotion and public outreach before going through the voting process.

Public/Political Acceptability: Knowing that people are generally more comfortable with existing taxes than something unfamiliar, this alternative is expected to face less reluctance from the public, but it may require substantial efforts to explain the necessity of such financial tools and the expected benefits to the public.

For local agencies, use of property tax revenue can also be considered. The rationale to subsidize the local transportation system with revenue from their local property taxes is that, without access by local roads, individual properties would be less valuable. The access is not only for property owners to enter and egress from their properties, but also to provide access to public services that maintain and enhance amenity, safety, and security of the property (e.g., garbage 
collection, postal delivery, public transit, and police and fire services) (Adams et al., 2001). In this respect, property tax can be considered a user fee for local streets and roads.

The characteristics of this alternative are as follows:

Revenue Generation: The major problem with using property tax is that there is great pressure to dedicate this revenue for non-transportation intentions, such as libraries, parks, schools, and low-income housing (Adams et al., 2001). Given that, its sufficiency, accountability, or stability as a revenue stream cannot be ascertained.

System Efficiency: As discussed above, property tax can be considered as one type of user charging. However, the charging mechanism is not as obviously connected with the exact usage of the system as other taxes, such as gas taxes or vehicle registration fees. Therefore, its role as a market price that can result in efficient resource allocation is not accomplished.

Equity: Since the amount of property tax an individual pays does not necessarily reflect the amount used or the benefit gained from the transportation system, it could be less equitable than more direct user fees. On the other hand, being aware that more property tax is collected from the wealthier, we can say that this is a more progressive way to fund the transportation system.

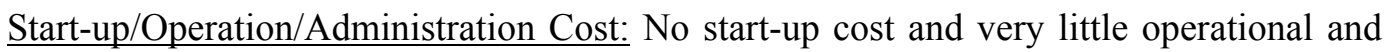
administration costs are involved.

Public/Political Acceptability: Distributing tax revenue after collection is not publicly seen, and there is thus less chance to face strong resistance from the public. However, it is still important to establish a clear principle that advocates appropriation of property tax revenue to local transportation projects.

\subsubsection{Overall Assessment of Alternative 1: Base Case}

\section{Adequacy as Revenue Sources}

It is numerically probable to generate enough revenue that eliminates the needs gap through any of the four types of incumbent taxes discussed in this section. As witnessed in the approximate calculations above, however, a financing strategy depending upon the existing source results in radical changes in tax rates. In order to remedy this problem, any combinations of those taxes can 
be chosen to capture the same revenue with less severe increases in their rates. For example, Indiana could establish a ballot measure for $1.0 \%$ increase in the local option sales tax that would fund local roads and public transit, which would gain approval from a majority of the public. Securing $\$ 50$ million annually with the local option tax, the state could also raise the vehicle registration and licensing fees by $10 \%$ to add $\$ 30$ million, while adjusting the fuel taxes to 35 cents for gasoline and 50 cents for diesel per gallon. However, before determining the amounts of tax increases, the impacts should be carefully studied. Different mixtures of tax treatments can cause different impacts on the revenue stream from the perspectives of stability and accountability.

\section{Cost of Implementation}

Since the current collection system will be expanded or adjusted, these alternatives will have little significant costs for initiation, operation, or administration. There could be some cases where public outreach may require not only money, but also considerable investment of time and effort.

\section{System Efficiency and Equity}

Since taxes other than motor fuel taxes do not directly measure and charge for transportation system usage, it is not evident that adjustment of those taxes will help the system achieve more efficiency. Thus, the impact on transportation system efficiency will be affected by a selected mixture of tax treatments. Moreover, all of the taxation tools have different impacts on each user group, bringing about different equity impacts. For example, a combination treatment that depends more on a fuel tax increase and less on a sale tax increase reflects better the cost each user imposes on the system and avoids cross-subsidy from non-users to users. On the other hand, a mixture consisting of more subsidies from property tax is a more progressive alternative that funds more from the wealthier group of people. 


\subsection{Alternative 2 - Current Tax System Supplemented by Other User Fees}

Instead of making changes in the current tax system, including fuel taxes, other types of user fees can be considered as supplements to it. As explored in Chapter 2, road tolls and distance-based fees are two of the most promising types of user fees. Road tolls also can be implemented either by the public sector or through road section privatization. This category includes three options, all of which maintain the current fuel tax system and pursue additional revenue: first would be establishing tolls on some roads; secondly, by the long-term leasing of road sections to private consortium; and, finally, adding a distance-based charging in addition to fuel taxes.

\subsubsection{Fuel Tax Supplemented by Toll Pricing}

Examples from many states in the U.S. and other countries implementing road tolls were reported in Chapter 2. As discussed, caution is required in determining toll levels, which are subject to the objectives of tolling. For example, if the purpose of tolling is to reduce road congestion, the marginal cost a user imposes on the system needs to be referred to as the basis of pricing. On the contrary, if tolls aim to recover the costs of construction and operation, the rates need to be determined in order to yield equilibrium of the balance sheet. These two objectives often conflict with each other, and thus, the objectives of a tolling scheme should be specified before planning the toll structure.

It has been generally learned that there exists an interrelationship between the objective of tolling, the types of facilities that are tolled and public acceptability on the implementation. The concept of cost compensation seems to make more sense to the public when tolls are established on newly-built highways or bridges. Since congestion has not been realized yet on the new roads in this case, a marginal cost pricing scheme is not really relevant. Regarding this type of projects, there are some issues that require discussion. First, the period for charging tolls to pay back the construction costs should be determined. Second, the impact on users' travel choices needs to be examined in greater detail to predict toll revenue because demand forecasts for new 
construction projects usually entail higher risk (i.e., uncertainty) than those for existing facilities. On the other hand, converting currently free highways into tolled facilities does not seem to be easily supported by the users unless they are congested enough (definition of "enough" congestion can be different in each case). Users generally believe that the roads they are using are already paid for. Rephrasing this phenomenon, introducing tolls on existing highways requires some rationale other than revenue seeking. Most commonly that reason is: it will lower congestion by controlling demand.

Following is a discussion on the general features of this alternative:

Revenue Generation: Toll roads in the U.S. generally do not run in debt, which means that the revenues usually cover at least their initial setup and operation costs. It is often doubted, however, whether revenues from toll roads can significantly contribute to the transportation budget. In Indiana, 157 miles of Indiana Toll Road earns \$36 million per year after paying off its operation and maintenance costs, which is as much as $3.7 \%$ of the total state needed highway revenue. Assuming first that there is an additional annual need ranged from $\$ 167$ to $\$ 405$ million during 2010-2015 period and secondly that road tolls are the only revenue source, road miles that need to be tolled can be approximated. Using the net cash value per mile of the Indiana Toll Road, we need approximately 750 to 1816 more miles of toll road assuming a similar net profit rate (\$167 405 million $\div$ \$35 million $=4.77 \sim 11.57$; 4.77 11.57 times of 157 mile toll road $=$ $749 \sim 1816$ miles). It means that about $7 \%$ to $17 \%$ of the entire state highway system would have to be tolled with similar toll rates as in the Indiana Toll Road.

On the other hand, since toll revenues can be earmarked for transportation purposes, this alternative is advantageous in terms of its accountability. To assure the stability of the revenue stream, a demand study should be performed in great detail so that user responses to toll pricing, such as modal shift, route change, and departure time adjustment, can be precisely captured. Especially in the case of constructing new toll facilities, it is difficult to predict demand, and conservative forecasts therefore may be required.

As an illustration purpose, the present study conducted macroscopic transportation simulation for scenarios that impose tolls on a typical interstate corridor of Indiana. Typical interstate corridor is defined by the following characteristics:

- Two-way four- or six-lane interstate highway system;

- Urban section length ratio is about $20 \%$ of the entire corridor;

- $\quad$ AADT ranges between 20,000 and 100,000, averaged around 40,000; 
- Approximate composition of AADT is $75 \%$ of automobiles, $10 \sim 15 \%$ SUT, and 10 15\% CT

Detailed description of the analysis procedure is given in Appendix A. Based on two assumptions on monetary value of travel time, $\$ 16.44$ and $\$ 23.03$ per hour, ranges of demand elasticity with respect to toll rates by vehicle type were obtained as presented in Table 4.6. It is observed that, the higher the travel time value, the less elastic the demand becomes. It is also noted that single unit truck (SUT) is the user group with the least elastic demand, while combination trucks (CT) present very elastic demand especially when travel time value is low. Demand elasticity values obtained in the present study is comparable with those reviewed in Section 3.2.3.

Table 4.6 Demand Elasticity of Indiana's Interstate Users with Respect to Toll Rate

\begin{tabular}{|c|c|c|c|c|}
\hline \multirow{2}{*}{ Vehicle Type } & \multicolumn{2}{|c|}{ Travel Time Value $=\$ 16.44 / \mathrm{hr}$} & \multicolumn{2}{c|}{ Travel Time Value $=\$ 23.03 / \mathrm{hr}$} \\
\cline { 2 - 5 } & Minimum & Maximum & Minimum & Maximum \\
\hline Automobile & -0.245 & -0.487 & -0.166 & -0.314 \\
Single Unit Trucks & -0.100 & -0.206 & -0.061 & -0.150 \\
Combination Trucks & -0.306 & -1.219 & -0.142 & -0.264 \\
Average & -0.250 & -0.665 & -0.149 & -0.284 \\
\hline
\end{tabular}

On the basis of the elasticity values, annual toll revenues were calculated for various toll schedules. The minimum and maximum of the revenue for each scenario are summarized in Table 4.7. For example, if toll rates are set up 3, 8, and 16 cents per mile for automobiles, single unit trucks, and combination trucks, respectively, the annual revenue would range either between $\$ 55$ and $\$ 71$ million or between $\$ 66$ and $\$ 77$ million depending on the assumed travel time values. 
Table 4.7 Forecast of Toll Revenues from a Typical Indiana Interstate (in thousand dollars)

\begin{tabular}{|c|c|c|c|c|c|}
\hline \multirow{2}{*}{\multicolumn{2}{|c|}{ Toll Schedule Scenarios }} & \multicolumn{2}{|c|}{ Travel Time Value $=\$ 16.44 / \mathrm{hr}$} & \multicolumn{2}{|c|}{ Travel Time Value $=\$ 23.03 / \mathrm{hr}$} \\
\hline & & Min Revenue & Max Revenue & Min Revenue & Max Revenue \\
\hline \multirow{4}{*}{1} & Auto: $2 \varnothing / \mathrm{mile}$ & 26,916 & 26,916 & 26,916 & 26,916 \\
\hline & SUT: $7 \varnothing /$ mile & 12,946 & 15,588 & 13,718 & 16,094 \\
\hline & CT: $14 \notin /$ mile & 3,653 & 15,548 & 11,232 & 19,327 \\
\hline & Total & 43,515 & 58,053 & 51,866 & 62,337 \\
\hline \multirow{4}{*}{2} & Auto: $3 \varnothing / \mathrm{mile}$ & 36,424 & 36,424 & 36,424 & 36,424 \\
\hline & SUT: $8 \notin /$ mile & 15,827 & 17,621 & 16,367 & 18,272 \\
\hline & CT: $16 \notin /$ mile & 2,406 & 17,352 & 13,055 & 21,855 \\
\hline & Total & 54,657 & 71,397 & 65,846 & 76,550 \\
\hline \multirow{4}{*}{3} & Auto: $3.5 \phi / \mathrm{mile}$ & 39,424 & 40,921 & 40,489 & 41,421 \\
\hline & SUT: $9 \phi /$ mile & 17,405 & 19,643 & 18,144 & 20,443 \\
\hline & CT: $18 \notin /$ mile & 2,068 & 25,881 & 14,413 & 27,331 \\
\hline & Total & 58,897 & 86,445 & 73,046 & 89,194 \\
\hline \multirow{4}{*}{4} & Auto: $4 \varnothing /$ mile & 43,390 & 43,390 & 43,390 & 43,390 \\
\hline & SUT: $10 \notin /$ mile & 18,960 & 20,894 & 19,685 & 21,621 \\
\hline & CT: $20 £ /$ mile & 2,804 & 23,388 & 14,989 & 25,001 \\
\hline & Total & 65,155 & 87,673 & 78,064 & 90,013 \\
\hline
\end{tabular}

* The length of the corridor was set as about 160 miles.

System Efficiency: Ideally, if we can charge the exact marginal cost of highway use in a perfectly demand-responsive manner, then the system will experience maximum efficiency. System efficiency can be improved considerably by having a well-designed toll plan regardless. Narrowing down the scope of analysis to only the tolled facilities, ignoring the equity problem against other toll-free facilities, tolls are an excellent form of direct usage-based charging. If facilities and regions to be tolled are reasonably selected, then the tolls will be good user fees in the system as a whole.

Equity: It is often argued that most tolls are very regressive pricing mechanisms in the sense that users are identically charged regardless of their ability to pay. By collecting the same amount of money from everyone, users with a higher monetary value of their travel time, who generally belong to a higher income group, will get more benefit than others. As seen in many congestion toll examples, however, by having the toll revenue contribute to driving alternatives, such as public transportation, toll pricing can benefit lower income groups to become less regressive. 
Start-up/Operation/Administration Cost: Any necessary roadside equipment should be installed for an electronic toll collection system. Also, a communication counterpart on each vehicle should be deployed. Costs vary according to the technology suite selected. Generally, DSRC (Dedicated Short Range Communication) with road gantry facilities, equipped with a smart-card-type on-board unit, is associated with higher costs for roadside infrastructure and lower cost for vehicle equipment. On the other hand, technology based on GPS communication is characterized by less expensive roadside facilities and more expensive devices on each vehicle.

Public/Political Acceptability: Many public opinion surveys on toll pricing projects have found that users are more willing to accept tolls if they have already experienced congestion reduction after toll implementation. However, if the tolls do not have a significant impact on demand management, intending to raise revenue rather than to reduce congestion, then people will generally perceive tolls as another type of taxes added to fuel taxes. 


\subsubsection{Fuel Tax Supplemented by Privatization of Road Segments}

Constructing a highway system and operating it has long been considered as a governmental authority as well as responsibility. Getting the private sector involved in highway provision, especially in the form of long-term lease, however, is receiving much attention. As mentioned and illustrated in Chapter 2, it is generally believed by proponents that privatization offers an opportunity to leverage governmental funding by collecting lump sum revenue at the point of leasing. However, there is strong objection to road privatization and some of the criticisms include the following: First, its segments having different ownership and/or operationship, integration and cohesion of the highway system is not likely to be achieved. Second, being aware that public sector is more eligible for low-interest or interest-free loans than its private counterpart, it could be cheaper to publicly finance highway projects. Third, non-compete clauses, as often included in concession agreements, legal approval for monopolistic business, which is not promising for the efficiency of market economy. Fourth, by accepting unsolicited proposals, state governments are opening profitable road segments to private consortia only to take the responsibility for the rest of the system (Samuel, 2005).

Most of the criticisms of this option are rooted in the fact that the private sector aims to maximize its profit, not to benefit society. The difference in objectives causes differences in decision-making, and in turn, different outcomes. For example, when the use of toll profit is completely at the discretion of a private consortium, it would not contribute to, say, improve the National Highway System or to enhance the mobility of low-income or elderly citizens, which could have been an objective through a state government. In addition, supposing a 30-year contact between a state government and a private consortium that involves lump sum payments, a state government would not have any funding source after spending that money. Also, the public and private sectors have different incentives for toll discount and/or exemption, which are incompatible with each other: social welfare and market drive. The public sector would implement a discount/exemption for particular users with intention to subsidize the low-income population or public transportation. On the other hand, unless it is enforced, the only inducement for a private consortium to discount or exempt user tolls would be market forces, e.g., 
competition. Finally, considering from the users' perspectives, it is expected that toll increases will be generally higher when a toll road is privatized.

In spite of those concerns, there are several incentives for the public sector to bring in private interests. First of all, motivated by profit seeking, the private sector can access and invest much larger amounts of money secured from bank loans and equity capital than can the public sector (Samuel, 2005). Also, by having a private consortium finance, construct, and operate highways, it can become more possible to introduce innovative and efficient delivery of projects. Carefully structured concession agreements may enable governments to prevent many of the aforementioned problems as well as to fully enjoy advantages of public-private partnership (Samuel, 2005). The government can effectively control toll level, for example, by having a clause that caps the toll increase at a rate less than or equal to the inflation rate captured by the consumer price index (CPI). Also, to prevent the private sector from leasing out the most profitable routes and avoid lower demand routes, the government can contract out a bundle of roads. When demands on the roads are interdependent between one another, integrated operation can better secure user benefits.

Considering privatization as a revenue source, supplementing the current fuel tax-based public finance system, the features of this alternative are as follows:

Revenue Generation: This alternative may have a revenue leverage effect, but it is often doubted whether long-term leasing to the private sector can fundamentally solve the resource problem, i.e., that privatization may facilitate the use of innovative procurement, management and finance techniques but they are not revenue sources per se (NCHRP, 2006). As observed in the recent examples of a long-term lease (Chicago Skyway and Indiana Toll Road), such an arrangement is in fact a short-term cash infusion at the cost of long-term toll revenue, and its role as a revenue source is secured only when it can be associated with new projects.

System Efficiency and Equity: When the authority to determine toll schedules belongs solely to the private concessionaire, the efficiency and equity of the entire highway system will likely not be pursued. It can help more efficient use of resources, however, by fostering innovative and cost-saving project delivery methods.

Start-up/Operation/Administration Cost: Governments should bear some costs, but they are generally insignificant and include the costs incurred during the course of bidding, negotiating to reach a concession agreement, and auditing and investigation over the contract period. 
Public/Political Acceptability: This alternative is relatively new and generally not a preferred option to the public. Acceptability on this issue is known to be related to how a project is advertised and where and how to spend the cash influx.

\subsubsection{Fuel Tax Supplemented by Usage-Based Fees}

This option considers imposing usage-based fees in addition to the current fuel tax, in the form of distance-based or weight-distance-based charging in a statewide manner. Additional fee rates that are required to satisfy the financing needs can be calculated by studying demand and funding gap after the fuel tax, similarly as outlined and applied in Section 4.3.

However, compared to the rather simpler option of increasing fuel tax, or to a completely new approach, which is discussed in the next section, the significance of this alternative can be blurred for several reasons. First, although institution and implementation of additional fees will be costly and very research-intensive, the outcome strategy will not be able to solve all the drawbacks of the current fuel tax system, i.e., the problems of the fuel tax structure remain with previous options as well, but they do not require as massive and demanding studies as needed in this state-wide application. Secondly, it is more likely for users to perceive this pricing structure as "double taxation" despite the fact that they are paying the same amount in total. Therefore, it will be harder to win public acceptability. Thirdly, the cost of operating and maintaining two systems, e.g., fuel taxes and weight-distance fees, will be generally higher than for a single and integrated system. The overall features of this alternative are summarized below:

Revenue Generation: Fee rates can be adjusted to generate targeted revenue, can be considered a revenue deficit after the revenues received from fuel taxes. Since it would be earmarked for transportation purposes, the accountability of this combined funding source would be secure. With an expected decrease in revenue per vehicle-miles of fuel taxes, the rates of additional VMT fees would need to be adjusted accordingly.

System Efficiency: Being a user fee system, this combined alternative would better address the efficiency issue. Usage charging and system efficiency is discussed in more detail in the next alternative. 
Equity: User charging and price discrimination between user groups are discussed in the following sections.

Start-up/Operation/Administration Cost: Generally, there will be a considerable amount of system deployment and installment costs, although costs vary according to the technology configuration options. There are not enough actual data thus far for predicting the cost of implementation. However, the cost comparisons of each technological option in the pilot study of the State of Oregon (Kim et al., 2002) are a good reference. Table 4.8 summarizes the comparison of total cost for four different scenarios: center collection with GPS base; center collection with odometer; gas pump collection with GPS; and gas pump collection with odometer.

Table 4.8 Estimated Cost of Implementation for Technology Options

\begin{tabular}{|l|l|l|l|l|}
\hline Cost elements/task & $\begin{array}{l}\text { On-vehicle } \\
\text { equipment }\end{array}$ & $\begin{array}{l}\text { Getting Data Off } \\
\text { Vehicle }\end{array}$ & Computing Tax & Collecting Tax \\
\hline Center + GPS based & High & High & Medium & Medium \\
\hline Center + odometer & High & Very high & Low & Low \\
\hline Gas pump + GPS & Medium & High & Medium & Medium \\
\hline Gas pump + odometer & Medium & Very high & Low & Low \\
\hline
\end{tabular}

Source: Kim et al. (2002)

A GPS-based system was determined to have more initial hardware costs than an odometer-based system. When the option is chosen to have a center collect the data, the initial cost of data collection decreased, but center establishment costs are required. On the other hand, the method to collect at gas pumps, which is based on a Point-of-Sale system, was characterized as having large setup costs for data collection and a relatively easier tax computing and collecting process facilitated by software that would be run by oil companies.

Public/Political Acceptability: It is highly probable that users would have the impression that their highway usage is double-taxed both by fuel taxes and additional VMT fees. To acquire public acceptance, substantial efforts need to be made in public outreach and communications so the logical grounds and user benefits of this pricing scheme can be fully understood. 


\subsubsection{Overall Assessment of Alternative 2}

\section{Adequacy as Revenue Sources}

Planning a pricing scheme, which includes selection of which services to charge (e.g., a specific road section to be tolled or a particular area to be access-charged) and selection of charging rates, is one of the most important tasks. What makes the problem more complicated is that the two objectives of the pricing scheme, revenue generation and system efficiency, can sometimes conflict with each other, resulting in different levels of charging rates.

\section{Cost of Implementation}

Such new systems usually incur high start-up costs associated with new infrastructure and invehicle devices. As observed from other markets of cutting-edge technologies, the prices of devices will gradually decrease as the market matures. In most cases, implementation of new systems entails a considerable amount of cost and effort in demonstrations and results analysis. Having a transitory period of adaptation is preferred to making a sudden change to a new system. The costs therefore should be analyzed, not only for the design of the final and stabilized stage of the system but also for the intermediate steps of implementation. Establishment of a transition strategy and estimation of costs are shown in Section 4.3 and further discussed in Chapter 6.

\section{System Efficiency and Equity}

User fees are generally superior to non-user taxes in achieving system efficiency. However, since this alternative is combined with current fuel taxes, there will be a relative loss in terms of efficiency compared to the next alternative, which replaces the existing system with a completely new scheme. The equity impact varies depending on the fee structure, revenue dedication, and any additional policy to discount or exempt fees for some groups of users. 


\subsection{Alternative 3 - Replacing Fuel Taxes with New Pricing Schemes}

The last alternative is the most innovative and the least dependent upon traditional funding mechanisms. It considers abandoning the current fuel tax system completely and introducing a usage-based charging scheme and possible adaptation of this basic philosophy, in advance, to a more comprehensive pricing strategy.

\subsubsection{VMT Fees}

To follow up the self-financing theorem discussion in Chapter 3, the following paragraphs summarize the numerical analysis results that can be referenced in designing the VMT fee rates as a replacement for the current fuel tax structure. Due to insufficient data, the following analysis was done only for the state highway system. Local analysis should be accomplished as data are prepared.

The data was collected from the FHWA reports on highway statistics, a highway financing needs study (Sinha et al., 2005), and Indiana Statewide Travel Demand Model (ISTDM) results (INDOT 2004, 2005). Recent records of Indiana's expenditures for state highway system, including reimbursement from the federal government, were obtained from the highway statistics. Regarding historical information for the state's revenue account, its forecast, and future gaps in funding, the results of the highway financing needs study were consulted. A four-step transportation planning model was completed in ISTDM to calculate the vehicle miles traveled by road functional classes.

Incorporating all information available, the average unit rates (in dollars per mile) for the suggested distance-based charging schemes were calculated using several different scenarios. The basic unit rate calculation is described in the following equation:

$$
\text { Charge per Usage }=\frac{\text { Cost Associated with Usage }}{\text { Total Amount of Usage }}
$$


The appropriate unit rates (in cents/mile) for the distance-based charging scheme were calculated for each of three scenarios:

- Scenario 1: The proposed scheme covers the current state highway expenditure, on the assumption that the VMT fee would replace fuel tax, vehicle registration, and all other revenue sources.

- Scenario 2: The proposed scheme covers the current state highway while maintaining revenue from vehicle registration.

- Scenario 3: The proposed scheme covers not only the current state highway expenditure but also addresses the future funding gap as identified by Indiana's highway needs study (2) to attain desired level of system performance.

Each scenario involves two sub-scenarios: (i) the proposed financing system covers all expenses that are currently incurred through federal-aid apportioned to the state as well as stategenerated funds, (ii) federal aid is maintained at current level, and thus the proposed financing system is needed to replace only those expenditures that are supported by state-generated funds. It can be stated that the former refers to a VMT fee that replaces both the federal and state fuel taxes, while the latter to a VMT fee that substitutes the state fuel tax only. Tables 4.9 through 4.11 summarize the results for each scenario.

\section{Scenario 1: Distance-Based Fees to Cover the Current Expenditure}

Under this scenario, users pay a price that corresponds to the level of highway usage. As aforementioned, a unit rate can be established for two cases: to establish "state plus federal" VMT fee; or to establish state VMT fee only. In the former case, it is determined that users will need to pay 2.9 cents/mile of VMT fee instead of combined 36.4 cents/gallon of federal and state gasoline $\operatorname{tax}(51.4$ cents/gallon for diesel). On the other hand, when this new pricing method replaces the state fuel tax system, users need to pay 2.0 cents/mile of VMT fee as well as the federal fuel tax, which is currently 18.4 cents per gallon for gasoline and 24.4 cents for diesel. If the suggested pricing strategy aims to discriminate price between different services, then each road functional class should have different rates as shown in Table 4.9. 
Table 4.9 VMT Values and VMT Fee Rates to Cover State Highway Disbursements

\begin{tabular}{|l|l|r|c|c|}
\hline Location & Functional Class & VMT per year & $\begin{array}{c}\text { Unit Rate }(\varnothing / \text { VMT) } \\
\text { (State + Federal VMT fee) }\end{array}$ & $\begin{array}{c}\text { Unit Rate }(\phi / V M T) \\
\text { (State VMT fee) }\end{array}$ \\
\hline \multirow{3}{*}{ Rural } & Interstate & $9,243,841,445$ & 1.7 & 0.8 \\
& Other Principal Arterial & $5,803,052,510$ & 3.7 & 2.6 \\
& Minor Arterial & $4,563,686,615$ & 3.9 & 2.8 \\
& Major Collector & $8,514,769,640$ & 4.5 & 4.2 \\
\cline { 2 - 5 } & Rural Subtotal (Average) & $28,125,350,210$ & $\mathbf{3 . 3}$ & $\mathbf{2 . 5}$ \\
\hline \multirow{5}{*}{ Urban } & Interstate & $7,228,927,565$ & 3.5 & 0.4 \\
& Other Freeway/Expressway & $1,014,585,025$ & 1.3 & 1.2 \\
& Other Principal Arterial & $8,733,145,490$ & 2.1 & 0.5 \\
& Minor Arterial & $3,498,646,180$ & 0.6 & $\mathbf{1 . 2}$ \\
\cline { 2 - 5 } & Urban Subtotal (Average) & $20,475,304,260$ & $\mathbf{2 . 3}$ & $\mathbf{2 . 0}$ \\
\hline
\end{tabular}

\section{Scenario 2: Distance-Based Fees While Maintaining Vehicle Registration Revenue}

The same logic is applied as in the previous case, except that revenue from vehicle registrations is kept at its current level (which averaged \$339 million per annum over the past three years and formed approximately $25 \%$ of total State highway receipt). As such, only a part of the overall highway expenditure is expected to be covered by the proposed VMT fee scheme. As seen in Table 4.10, average unit rates for the VMT fee are lower than those for Scenario 1: 2.2 cents/mile to replace both the state and federal fuel taxes and 1.3 cents/mile to replace state fuel tax.

Table 4.10 Mileage Fee Rate to Cover Highway Expenditure, Maintaining Vehicle Registration Fee (thousand dollars, cents per mile)

\begin{tabular}{|c|c|c|c|c|c|}
\hline Location & Functional Class & $\begin{array}{c}\text { Disbursement } \\
\text { incld. Federal } \\
\text { Aid } \\
\end{array}$ & $\begin{array}{l}\text { Estimated Disbursement } \\
\text { supported by State Fund }\end{array}$ & $\begin{array}{c}\text { Unit Rate ( } £ / \text { VMT) } \\
(\text { State }+ \text { Federal VMT } \\
\text { fee })\end{array}$ & $\begin{array}{c}\text { Unit Rate ( } \varnothing / \text { VMT) } \\
\text { (State VMT Fee) }\end{array}$ \\
\hline \multirow[t]{5}{*}{ Rural } & Interstate & 119,527 & 45,849 & 1.3 & 0.5 \\
\hline & OPA & 163,738 & 96,304 & 2.8 & 1.7 \\
\hline & Minor Arterial & 133,657 & 83,571 & 2.9 & 1.8 \\
\hline & Major Collector & 289,154 & 232,755 & 3.4 & 2.7 \\
\hline & Rural Subtotal & 706,076 & 458,479 & 2.5 & 1.6 \\
\hline \multirow[t]{5}{*}{ Urban } & Interstate & 193,519 & 79,546 & 2.7 & 1.1 \\
\hline & OFE & 9,863 & 2,538 & 1.0 & 0.3 \\
\hline & OPA & 137,285 & 67,208 & 1.6 & 0.8 \\
\hline & Minor Arterial & 14,768 & 10,517 & 0.4 & 0.3 \\
\hline & Urban Subtotal & 355,435 & 159,808 & 1.7 & 0.8 \\
\hline \multicolumn{2}{|c|}{ Total (Average Rate) } & $1,061,511$ & 618,287 & 2.2 & 1.3 \\
\hline
\end{tabular}


Scenario 3: Distance-Based Fees to Cover the Current Expenditure and Future Needs

INDOT's business report (INDOT, 2005) concluded that Indiana's highway system will require \$25 billion over the 2006-2020 analysis period to maintain the system at desired performance level. For illustration purposes, annual funding needs by highway class in year 2010 are presented in Table 4.11. Applying VMT fee rates calculated in Table 4.10 to predicted amount of travel, projected revenues from the VMT fee scheme are determined. Then, the VMT fee rates needed to supplement the revenues from vehicle registration and related fees are determined $\left(6^{\text {th }}\right.$ column in Table 4.11). Finally, it is concluded that additional VMT fee of 0.3 cents/mile will have to be collected to meet the future needs. This gives 2.5 cents/mile to replace both the state and federal fuel taxes; and 1.6 cents/mile to replace the current state fuel tax.

Table 4.11 Mileage Fee Rate to Meet Future Needs in Year 2010 (thousand dollars, vehicles, cents per mile)

\begin{tabular}{|c|c|c|c|c|c|c|c|c|}
\hline \multirow[b]{2}{*}{ Location } & \multirow{2}{*}{$\begin{array}{l}\text { Functional } \\
\text { Class }\end{array}$} & \multirow{2}{*}{$\begin{array}{l}\text { Funding } \\
\text { Needs }\end{array}$} & \multirow{2}{*}{$\begin{array}{l}\text { VMT per year } \\
\text { (in million) }\end{array}$} & \multirow{2}{*}{$\begin{array}{c}\text { Projected Rev. } \\
\text { (rates in Table 4.10) }\end{array}$} & \multirow{2}{*}{$\begin{array}{l}\text { Funding } \\
\text { Gap }\end{array}$} & \multicolumn{3}{|c|}{ VMT Fee Rates ( $\not / V M T)$} \\
\hline & & & & & & \begin{tabular}{|c|}
$\begin{array}{c}\text { Additional } \\
\text { Rate }\end{array}$ \\
\end{tabular} & $\begin{array}{l}\text { State }+ \\
\text { Federal }\end{array}$ & State only \\
\hline \multirow[t]{5}{*}{ Rural } & Interstate & 166,792 & 11,385 & 147,215 & 19,577 & 0.2 & 1.5 & 0.7 \\
\hline & OPA & 226,987 & 7,147 & 201,667 & 25,320 & 0.4 & 3.2 & 2.0 \\
\hline & MA & 185,613 & 5,621 & 164,619 & 20,995 & 0.4 & 3.3 & 2.2 \\
\hline & $\mathrm{MC}$ & 400,039 & 10,487 & 356,136 & 43,903 & 0.4 & 3.8 & 3.2 \\
\hline & Subtotal & 979,431 & 34,641 & 869,637 & 109,795 & 0.3 & 2.8 & 1.9 \\
\hline \multirow[t]{5}{*}{ Urban } & Interstate & 268,840 & 8,903 & 238,347 & 30,492 & 0.3 & 3.0 & 1.4 \\
\hline & OFE & 13,809 & 1,250 & 12,148 & 1,661 & 0.1 & 1.1 & 0.4 \\
\hline & OPA & 191,454 & 10,756 & 169,087 & 22,367 & 0.2 & 1.8 & 1.0 \\
\hline & MA & 20,367 & 4,309 & 18,189 & 2,178 & 0.1 & 0.5 & 0.4 \\
\hline & Subtotal & 494,469 & 25,218 & 437,771 & 56,698 & 0.2 & 2.0 & 1.0 \\
\hline \multicolumn{2}{|c|}{ Total (Average Rate) } & $1,473,900$ & 59,859 & $1,307,407$ & 166,493 & 0.3 & 2.5 & 1.6 \\
\hline
\end{tabular}

Recently, Indiana DOT has collected a great amount of upfront revenue from the longterm lease of the Indiana Toll Road to a private concessionaire (issues and execution described in Section 2.4.2). Being solely dedicated for investment in highway system according to a new highway preservation and construction program, the "Major Moves," the upfront revenue (\$3.8 billion) is expected to partially resolve the funding gap problem. In October of 2007 and October of 2006, \$75 million each year was distributed to local governments according to the MVH 
distribution formula. The rest (\$3.65 billion) was to be used in reducing funding gap for the state highway system. For purpose of numerical analysis, it was assumed that the revenue is evenly distributed over the coming 10-year period, and among highway functional classes proportionately to the current funding gaps. Consequently, the required VMT fee rates can be adjusted as presented in Table 4.12. It was calculated that the additional revenue from the Major Moves can lower the required fee rates by 0.6 cents per mile on average. It is noteworthy, however, that the amount of fee adjustment would vary depending on the detailed expenditure plan.

Table 4.12 Mileage Fee Rate to Meet Future Needs, Maintaining Vehicle Registration Fee (thousand dollars, vehicles, cents per mile) (Year 2010)

\begin{tabular}{|l|l|r|c|c|c|c|}
\hline \multirow{2}{*}{ Location } & Functional Class & \multirow{2}{*}{$\begin{array}{c}\text { Funding } \\
\text { Gap }\end{array}$} & \multirow{2}{*}{$\begin{array}{c}\text { Annual revenue from } \\
\text { the Major Move }\end{array}$} & \multicolumn{3}{|c|}{ VMT Fee Rates ( $\phi /$ VMT) } \\
\cline { 5 - 7 } & & $\begin{array}{c}\text { Reduction due to } \\
\text { additional revenu }\end{array}$ & $\begin{array}{c}\text { Rate } \\
\text { (State + Federal) }\end{array}$ & $\begin{array}{c}\text { Rate } \\
\text { (State only) }\end{array}$ \\
\hline Rural & Interstate & 19,577 & 42,919 & 0.4 & 1.1 & 0.3 \\
& OPA & 25,320 & 55,508 & 0.8 & 2.4 & 1.2 \\
& Minor Arterial & 20,995 & 46,027 & 0.8 & 2.5 & 1.4 \\
& Major Collector & 43,903 & 96,248 & 0.9 & 2.9 & 2.2 \\
& Rural Subtotal & 109,795 & 240,702 & $\mathbf{0 . 7}$ & $\mathbf{2 . 1}$ & $\mathbf{1 . 3}$ \\
\hline \multirow{3}{*}{ Urban } & Interstate & 30,492 & 66,848 & 0.8 & 2.3 & 0.7 \\
& OFE & 1,661 & 3,641 & 0.3 & 0.8 & 0.1 \\
& OPA & 22,367 & 49,035 & 0.5 & 1.3 & 0.5 \\
& Minor Arterial & 2,178 & 4,774 & 0.1 & 0.4 & 0.2 \\
\cline { 5 - 7 } & Urban Subtotal & 56,698 & 124,298 & $\mathbf{0 . 5}$ & $\mathbf{1 . 5}$ & $\mathbf{0 . 5}$ \\
\hline
\end{tabular}

\section{Technological Prototype}

Recent technological improvements in GPS and communication are expected to enable a more flexible and dynamic pricing scheme with lower administration costs. The suggested pricing scheme can be realized using the system described below, but is not necessarily restricted to this particular one.

Each vehicle, equipped with an onboard computer, will receive GPS information at points where the rate changes. The vehicle odometer will measure the traveled distance between each pair of rate change points to calculate the fees for using that particular road section. The onboard 
computer will then calculate the fee based on pre-entered unit rates and accumulate the total amount owned. A traveler will prepay, receive a bill, or pay at gas stations for the total amount traveled, utilizing communication technology based on wireless connection or a smart card. For privacy protection purposes, all the raw data can be discarded from the system completely after calculating and billing the fees. According to the system status and pricing strategic goals, the rates can be adjusted, technically very easily, but only when it is legitimately approved. Other possible technological alternatives and system components are discussed in detail in Chapter 6, which provides a demonstration plan and transitory strategy.

The characteristics of this alternative are summarized in Section 4.3.3.

\subsubsection{Future Adaptation of VMT Fees - Comprehensive Pricing}

A nationwide road use metering system has been suggested as a part of long-term road financing strategy. Under this federal level strategy, each state or sub-state jurisdiction can determine independently its own rate structure (TRB, 2005). The present study proposes a usage-based

pricing scheme for the State of Indiana, tentatively called as Indiana's Statewide Comprehensive Usage-based Road Pricing (ISCURP). The rationale of ISCURP is as the following:

First, ISCURP will be designed as a statewide pricing for the entire roadway system of Indiana. Although tolls on individual facilities may solve site-specific congestion problems or improve revenue stream, it is important to understand their impact on other parts of the network. In this regard, tolling on particular road sections has to be planned and implemented in the context of the entire network. The intent is to have a pricing plan embracing all components in the statewide network considering interactions among them.

Second, it is a usage-based pricing method. ISCURP will directly charge users based on their usage, according to the monetary cost they impose on the road system.

Third, it is characterized by its comprehensiveness. ISCURP will identify every single vehicle-mile driven within the boundary of the state in terms of its location, jurisdiction, functional class, vehicle class, and weight. The expected congestion level, emission, and any other externalities can also be included. A given set of identifiers will be mapped to a particular rate a specific usage. The following formula represents a fee to be paid by an individual user: 


$$
F e e=\sum_{i} \sum_{L O S} \text { Mileage }(i, L O S) \times \text { Rate }(i, C, L O S)
$$

where, $i$ is road section identification, $L O S$ is level of service or equivalent congestion index of a road section during a specific time period of a day, and $c$ is vehicle class identification. Road section $i$ 's are identified by location (urban/rural) and functional class. In defining vehicle classes, axle weight information will also be included, so that further price variations can be introduced based on distance-weight combinations, if needed.

Having different costs of supply, it is more efficient to price various service levels differently rather than to charge every usage the same. The reasoning for price variation is discussed below:

Location and Functional Class: Rural Interstates generally accommodate more freight travel than urban systems and thus experience further road wear, while urban roads suffer more from congestion and higher peak hour concentrations of trips than the rural system. Also, each functional class of roadway system has different characteristics and requirements in their design and performance standards. In this regard, ISCURP can be designed to have expenditures required for the provision of service on a particular roadway system fully covered by revenues collected from relevant usage within that location and functional class.

Vehicle Configuration: Vehicle classes and weight categories are the most apparent and popular basis of price variation. It is generally accepted that road wear costs need to be shared on the basis of equivalent single axle load (ESAL) weighted VMT, while VMT or passenger car equivalents (PCE) weighted VMT is recommended to be used in distribution of non-load-related costs. Categorization of highway costs and their allocation rules are discussed in detail in the following sections.

Congestion Level: Externalities imposed on other users of the system are also important cost components of highway usage, congestion being one of the most prominent examples. In ISCURP, additional rates that reflect congestion level will be applied on the top of the basic fee rate structure.

Recognizing all levels of price variation, ISCURP can be specified by a prototype rate plan illustrated in Table 4.13 . 
Table 4.13 Prototype of ISCURP Rate Schedule

\begin{tabular}{|c|c|c|c|c|c|c|c|c|c|c|}
\hline \multirow{2}{*}{$\begin{array}{l}\text { Population } \\
\text { Level }\end{array}$} & \multirow[t]{2}{*}{ Functional Classes } & \multirow{2}{*}{$\begin{array}{l}\text { Level of } \\
\text { Service }\end{array}$} & \multicolumn{8}{|c|}{ Vehicle Classes } \\
\hline & & & Auto & $\begin{array}{l}\text { Pickups/ } \\
\text { Vans }\end{array}$ & Buses & $\begin{array}{c}\text { SUT } \\
(\leq 25 \mathrm{~K} \mathrm{lbs})\end{array}$ & $\cdots$ & $\begin{array}{c}\text { CT } \\
(\leq 50 \mathrm{~K})\end{array}$ & $\cdots$ & Avg. \\
\hline \multirow{6}{*}{$\begin{array}{l}\text { Rural } \\
\text { Area }\end{array}$} & Interstates & $\mathrm{A} \sim \mathrm{C}$ & $\begin{array}{c}\# \\
\phi / \text { mile }\end{array}$ & $\ldots$ & & & & & & \\
\hline & & $\begin{array}{l}\mathrm{D} \sim \mathrm{E} \\
\mathrm{F}\end{array}$ & $\ldots$ & & & & & & & \\
\hline & $\begin{array}{l}\text { Other Principal } \\
\text { Arterials }\end{array}$ & $\begin{array}{l}\mathrm{A} \sim \mathrm{C} \\
\mathrm{D} \sim \mathrm{E} \\
\mathrm{F}\end{array}$ & & & & & & & & \\
\hline & Major Arterials & $\begin{array}{l}\mathrm{A} \sim \mathrm{C} \\
\mathrm{D} \sim \mathrm{E} \\
\mathrm{F}\end{array}$ & & & & & & & & \\
\hline & Minor Arterials & $\begin{array}{l}\mathrm{A} \sim \mathrm{C} \\
\mathrm{D} \sim \mathrm{E} \\
\mathrm{F}\end{array}$ & & & & & & & & \\
\hline & Average & $\begin{array}{l}\mathrm{A} \sim \mathrm{C} \\
\mathrm{D} \sim \mathrm{E} \\
\mathrm{F}\end{array}$ & & & & & & & & \\
\hline \multicolumn{11}{|c|}{ Rural Average } \\
\hline \multirow[t]{5}{*}{$\begin{array}{l}\text { Urban } \\
\text { Area }\end{array}$} & Interstates & $\begin{array}{l}\mathrm{A} \sim \mathrm{C} \\
\mathrm{D} \sim \mathrm{E} \\
\mathrm{F}\end{array}$ & & & & & & & & \\
\hline & $\begin{array}{l}\text { Other Freeways/ } \\
\text { Expressways }\end{array}$ & $\begin{array}{l}\mathrm{A} \sim \mathrm{C} \\
\mathrm{D} \sim \mathrm{E} \\
\mathrm{F}\end{array}$ & & & & & & & & \\
\hline & $\begin{array}{l}\text { Other Principal } \\
\text { Arterials }\end{array}$ & $\begin{array}{l}\mathrm{A} \sim \mathrm{C} \\
\mathrm{D} \sim \mathrm{E} \\
\mathrm{F}\end{array}$ & & & & & & & & \\
\hline & Minor Arterials & $\begin{array}{l}\mathrm{A} \sim \mathrm{C} \\
\mathrm{D} \sim \mathrm{E} \\
\mathrm{F}\end{array}$ & & & & & & & & \\
\hline & Average & $\begin{array}{l}\mathrm{A} \sim \mathrm{C} \\
\mathrm{D} \sim \mathrm{E} \\
\mathrm{F}\end{array}$ & & & & & & & & \\
\hline \multicolumn{11}{|c|}{ Urban Average } \\
\hline Average & & & & & & & & & & \\
\hline
\end{tabular}

In order to provide reference values for possible unit rates, this research conducted a cost allocation analysis using the HCAS based on Indiana's expenditure and demand data. The results can be interpreted as the initial structure for the ISCURP fee rates by location, road function class, and vehicle type. Two different vehicle type classifications are suggested in Table 4.14. The assumptions and procedure for the cost allocation analysis is described in Appendix B. 
Table 4.14 Initial Reference Values of ISCURP Fee Rates (cents per mile)

\begin{tabular}{|c|c|c|c|c|c|c|c|c|c|c|c|c|c|}
\hline & \multicolumn{6}{|c|}{ Rural } & \multicolumn{6}{|c|}{ Urban } & \multirow{2}{*}{ Average } \\
\hline & Int & OPA & MA & $\mathrm{MaC}$ & $\mathrm{MnC}$ & Average & Int & OFE & OPA & MA & Collector & Average & \\
\hline \multicolumn{14}{|c|}{ 3-Vehicle Type Classification } \\
\hline SUT & 1.91 & 7.95 & 12.31 & 19.65 & 32.12 & 9.72 & 7.65 & 7.29 & 9.91 & 5.58 & 20.91 & 8.26 & 9.18 \\
\hline $\mathrm{CT}$ & 6.38 & 30.27 & 53.18 & 109.90 & 135.69 & 18.79 & 33.29 & 37.09 & 62.12 & 27.64 & 71.86 & 37.02 & 23.54 \\
\hline Auto & 0.63 & 1.07 & 1.59 & 2.04 & 4.93 & 1.40 & 0.86 & 0.75 & 0.66 & 0.23 & 0.74 & 0.67 & 1.07 \\
\hline LT4 & 0.71 & 1.47 & 2.25 & 2.85 & 5.28 & 1.86 & 1.51 & 1.18 & 1.15 & 0.44 & 1.07 & 1.16 & 1.51 \\
\hline SU2 & 1.73 & 6.60 & 10.57 & 16.15 & 25.01 & 8.04 & 6.78 & 6.72 & 9.12 & 4.04 & 16.00 & 7.61 & 7.86 \\
\hline SU3 & 2.27 & 9.26 & 14.90 & 26.82 & 41.06 & 12.52 & 9.08 & 10.08 & 14.38 & 6.45 & 24.21 & 9.50 & 11.61 \\
\hline CS5 & 5.44 & 25.36 & 42.64 & 80.48 & 112.54 & 15.06 & 28.21 & 32.88 & 48.53 & 23.63 & 84.56 & 30.86 & 18.98 \\
\hline CS6 & 6.38 & 31.01 & 50.80 & 110.56 & 151.12 & 26.21 & 32.77 & 41.64 & 61.29 & 31.33 & 108.12 & 38.31 & 29.55 \\
\hline CS7+ & 8.36 & 42.04 & 69.55 & 156.17 & 205.31 & 35.51 & 45.15 & 58.16 & 84.00 & 44.67 & 156.97 & 52.85 & 40.32 \\
\hline CT4- & 2.66 & 11.17 & 18.04 & 31.67 & 48.34 & 12.58 & 11.50 & 12.66 & 18.12 & 8.27 & 31.86 & 12.61 & 12.49 \\
\hline CT5 & 6.98 & 35.24 & 58.36 & 113.82 & 152.17 & 21.22 & 40.17 & 45.49 & 66.12 & 33.14 & 128.72 & 42.84 & 27.27 \\
\hline CT6+ & 3.81 & 16.65 & 27.21 & 55.81 & 78.89 & 9.87 & 16.63 & 20.99 & 31.27 & 15.12 & 52.54 & 16.78 & 11.49 \\
\hline DS5 & 5.77 & 28.42 & 47.82 & 93.89 & 105.18 & 14.23 & 32.98 & 39.45 & 58.05 & 32.98 & 100.95 & 35.30 & 20.57 \\
\hline DS6 & 5.98 & 30.30 & 50.67 & 118.74 & 109.50 & 14.69 & 34.20 & 45.39 & 67.51 & 44.12 & 105.08 & 36.81 & 20.30 \\
\hline DS7 & 9.29 & 49.29 & 81.34 & 209.42 & 219.20 & 27.50 & 53.65 & 75.07 & 108.62 & 69.78 & 178.84 & 62.43 & 35.84 \\
\hline
\end{tabular}

OPA: other principal arterial; MA: minor arterial; MaC: major collector; MnC: minor collector; OFE: other freeway and expressway

Auto: automobiles and motorcycles; SUT: Single Unit Truck; CT: Combination Truck; LT4: pickups, vans and other light 2-axle, four tire vehicles; SU2, SU3, SU4+: 2-, 3-, and 4- or more axle single unit trucks; CS3, CS4, 3S2, CS5, CS6, CS7+: 3-, 4-, 5-, 6-, and 7- or more axle tractor-semi-trailer trucks with two categories of 5-axle vehicles, one with standard tandem axles and one with split tandem axles; CT4-, CT5, CT6+: 3-, 4-, 5-, and 6- or more axle trucktrailer combinations; DS5, DS6, DS7, DS8+: 5-, 6-, 7-, and 8- or more axle twin trailer/semi-trailer combinations TS: Triple trailer combinations; and Bus: buses 


\subsubsection{Overall Assessment of Alternative 3}

The pricing schemes introduced in Sections 4.3.1 and 4.3.2 are not necessarily two different approaches. Rather, both are based on the same perspective, and the latter one can be considered an elaborated version of the former one. Thus, this part of the report summarizes the features of this innovative pricing scheme as one framework.

\section{Adequacy as Revenue Sources}

As seen from the analysis results described above, the agency can come up with an adequate fee rate plan that yields sufficient revenue by researching the needs and demands. Supported by proper authority, the suggested fee system can be earmarked for transportation purposes to insure its accountability. The plan's stability also depends on the fee rates, especially in the long-term and future demand.

\section{Cost of Implementation}

As seen in the previous section, the technology setup selected will determine the cost of implementation. The total costs of implementation consists of the capital cost for infrastructure and devices; operation costs for labor, any necessary upgrade, and maintenance; and administration costs for the initial setup of the bureaucracy, user enforcement, and more intangibly, inconveniences experienced by users while getting used to the new system. In terms of capital costs, usually more recently invented technologies (i.e., GPS and cellular communication) entail higher costs, but at the same time are more suitable to region-wide application and more flexible for future alterations. Therefore, selecting a system configuration should consider not only the out-of-pocket cost for the initial start-up, but also the potential costs for future adaptations.

\section{System Efficiency and Equity}

Since the rate plan intends to charge users directly based on their usage of the highway system, it could act as a proxy of market price. As mentioned in Section 4.3.2, assuming a perfect usagereflecting pricing scheme that takes into account all the costs imposed on the system by a 
particular usage, the system will realize maximum efficiency. Provided that the system is designed to be capable of keeping track of the revenue generated by each road segment and each road user, then we can also apply abundant knowledge of the revenue distribution to make decisions on capacity expansion (Adams et al., 2001).

\section{Public/Political Acceptability}

Since this alternative is a completely new system that transforms the current paradigm of highway pricing, a study on users' responses should be carried out to predict acceptability. A survey can be performed to reveal factors that hinder implementation of new pricing schemes and to understand public preferences between several different financing options. 


\section{CHAPTER 5. COMPARISON OF THE ALTERNATIVES}

According to the evaluation criteria established in Section 3.1 (Table 3.1), this chapter compares suggested alternatives. Criteria under which comparisons are made include the plan's adequacy as a revenue source (sufficiency, stability, and accountability), its impact on system efficiency and equity, the costs of implementation, public acceptability, and policy alignment. After the comparisons are presented, a conclusion is drawn on which alternative would be the most suitable for the current situation and future trends.

\subsection{Adequacy as a Funding Mechanism}

\subsubsection{Sufficiency and Stability}

The sufficiency of the revenues generated by each alternative funding scheme varies according to its detailed implementation plan. For example, the revenue sufficiency of the option to increase the current fuel taxes is a function of the amount of tax increase, which will be decided by policymakers. Therefore, the sufficiency of the revenue is not a dependent variable that can be measured or forecasted, rather it is an objective function that can be targeted and controlled by policy initiation and implementation. This section, instead of providing a direct comparison of the revenue sufficiency of each alternative, therefore will factor out the exogenous forces that may affect each alternative's sufficiency and stability and impact of each will be discussed. 


\section{Alternative 1 - Adjusting Current Tax System}

In order to consider an adjustment of the current funding strategy to a level that will generate sufficient revenue, a fuel tax increase, inflation-indexing of the fuel tax, and an increase in vehicle registration fees, as well as increase or introduction of other taxes, will be considered.

First of all, one of the most influential factors that affect the sufficiency and stability of the fuel tax revenue stream is improvement in fuel efficiency. The "Annual Energy Outlook" (EIA, 2007) provides projections of fuel efficiency by vehicle types for a reference case and for high and low energy price cases, which are presented in Table 5.1. Based on the reference case, the prediction is that fuel efficiency will increase at average annual compound rate of $0.4 \% \sim 0.8 \%$. By calculating the annual compound rate of the reciprocals of these values, it is translated into a $0.4 \% \sim 0.7 \%$ annual decreases in per vehicle-mile revenues of fuel taxes. This trend is magnified if higher energy prices are expected, whereby fuel efficiencies are predicted to increase, with an annual rate of $0.5 \% \sim 0.9 \%$. In this case, revenue per vehicle-mile will decrease $0.5 \% \sim 1.0 \%$ annually with fixed rates of fuel taxes. We call this problem degeneration of per vehicle-mile revenue. Since the current fuel taxes are maintained as a major funding source, all the options in this tax adjustment category inherently share this revenue degeneration problem.

Table 5.1 Fuel Efficiency Forecasts by Energy Price Scenario

\begin{tabular}{|l|l|cccccccc|}
\hline Vehicle Types / Energy & Price Scenarios & 2005 & 2006 & 2010 & 2015 & 2020 & 2025 & 2030 & $\begin{array}{c}\text { Annual } \\
\text { rate (\%) }\end{array}$ \\
\hline \multirow{2}{*}{ Light-Duty Vehicle } & Reference case & 25.2 & 25.7 & 27.3 & 27.9 & 28.2 & 28.9 & 29.2 & $0.6 \%$ \\
(New) & High price & 25.2 & 25.7 & 27.8 & 29.3 & 30.5 & 31.4 & 31.9 & $0.9 \%$ \\
& Low price & 25.2 & 25.7 & 27.1 & 27.5 & 27.6 & 28.1 & 28.3 & $0.5 \%$ \\
\hline \multirow{3}{*}{ Light-Duty Vehicle } & Reference case & 19.6 & 19.7 & 19.8 & 20.6 & 21.2 & 21.8 & 22.2 & $0.5 \%$ \\
(Stock) & High price & 19.6 & 19.7 & 19.8 & 20.9 & 22.0 & 23.1 & 23.9 & $0.8 \%$ \\
& Low price & 19.6 & 19.7 & 19.8 & 20.6 & 21.1 & 21.5 & 21.8 & $0.4 \%$ \\
\hline \multirow{3}{*}{ Trucks 8500-10000 } & Reference case & 14.6 & 14.8 & 15.8 & 16.4 & 16.7 & 17.2 & 17.4 & $0.7 \%$ \\
& High price & 14.6 & 14.8 & 15.9 & 16.8 & 17.5 & 18.1 & 18.4 & $0.9 \%$ \\
& Low price & 14.6 & 14.8 & 15.8 & 16.3 & 16.5 & 16.8 & 17.0 & $0.6 \%$ \\
\hline \multirow{3}{*}{ Trucks 8500-10000 (Stock) } & Reference case & 14.1 & 14.2 & 14.7 & 15.5 & 16.2 & 16.7 & 17.0 & $0.8 \%$ \\
& High price & 14.1 & 14.2 & 14.7 & 15.7 & 16.5 & 17.3 & 17.9 & $0.9 \%$ \\
\hline \multirow{2}{*}{ Trucks over 10000lbs } & Low price & 14.1 & 14.2 & 14.7 & 15.5 & 16.1 & 16.4 & 16.7 & $0.7 \%$ \\
(Overall) & Reference case & 6.0 & 6.0 & 6.0 & 6.2 & 6.4 & 6.6 & 6.7 & $0.4 \%$ \\
& High price & 6.0 & 6.0 & 6.0 & 6.2 & 6.6 & 6.8 & 6.9 & $0.5 \%$ \\
& Low price & 6.0 & 6.0 & 6.0 & 6.2 & 6.4 & 6.5 & 6.6 & $0.4 \%$ \\
\hline
\end{tabular}

Source: EIA (2007) 
Degeneration of revenue will become more severe if the fuel tax rate remains as nonindexed to the inflation rates. As pointed out in Section 4.1.1, in order to uphold the buying power of the gasoline fuel tax, which was 15 cents per gallon in 1988, the current (2006) rate should be adjusted to 26 cents per gallon, which is a $44 \%$ increase. Assuming a $2.98 \%$ annual increase in the CPI (which is the average increase rate for the past two decades), the noninflation-indexed fuel tax rates of 2006 will generate $89 \%$ of per gallon revenue in $2010,66 \%$ in 2020 , and only $49 \%$ in 2030.

When vehicle registration fee increases are considered, we should take into account the possibility of avoidance of in-state registration due to higher registration fees compared to the adjacent states. Pratt and Hoffer (1985) analyzed the responsiveness of heavy vehicle registrations to tax differences to conclude that there are no evident interstate variations in registration fees and vehicle taxes. The study found that the state registration fees and taxes accrue only $2 \%$ of the total annual operating costs of trucking companies, and that the primary decision factor for location of vehicle registration was the state's demand for transport services. Therefore, when it is modest, an increase in vehicle registration fees will not necessarily result in repulsion of registration frequency at the interstate level.

Appropriations from general accounts, such as sales tax, income tax, and property tax, entail less stability of the revenue stream than earmarked sources. First, strenuous competition between governmental expenses exists, including education, medical care, environmental controls, etc. Also, the taxed activities of general accounts are usually poorer indications of highway financing needs than highway related activities. For instance, it could be the case that, in a particular year, revenue from sales tax is fairly low due to an economic recession, but the highway financial needs could exceed the average trend due to newly launched rehabilitation projects. Local option taxes, which are usually established with fixed sunset dates, are inherently disadvantageous in terms of stability because approval from voters is required after its expiration. In addition, it should be noted that appropriations from general sources are not significant portions of the total highway budget.

In conclusion, the factors that adversely affect the sufficiency and stability under future revenues of options in the first category include improvement of fuel efficiency, inflation, and competition between governmental expenses. If the fuel tax based financing is to be continued, it would be desirable to have the tax rates inflation-indexed and to consider an increase in vehicle 
registration fees. In addition, long term local option taxes for local governments should be considered, 20 years for example, as used in some other states (NCHRP, 2006).

\section{Alternative 2 - Current Fuel Tax Supplemented by Other User Fees}

As the current fuel tax based system is maintained, problems with fuel taxes-degeneration of per mile and per gallon revenue - linger in this alternative as well. By introducing other user fees to supplement fuel taxes, however, the sufficiency and stability of the revenue stream can be enhanced.

As a first option, legislation can be established to allow tolling of newly constructed highways and bridges for the financing of their construction and maintenance. If tolls are well designed to earn enough to cover the costs associated, the revenues from other sources only need to support the maintenance and operation of the rest of the system. In this case, demand on tolled roads is a key variable that determines the sufficiency and stability of the revenues. If realized demand is less than expected or fluctuates more than assumed, then this additional funding source will not be able to significantly enhance the sufficiency and stability of the revenue stream. In planning toll roads, therefore, issues such as competing or complementing relationships between the toll roads and adjacent non-tolled routes, the demand elasticity to the toll level, the forecast for future demand, and the period the tolls are in effect, need to be addressed.

Uncertainty of travel demand can be an even larger issue that impairs adequacy if a toll road is privatized. To share possible risks, leasing contracts are occasionally observed to include a revenue preservation clause, under which the public agency should guarantee the minimum level of revenue to a private concessionaire, while excessive revenue beyond a certain level would be contributed to a governmental budget. If the actual demand is too low to yield the agreed minimum revenue, then the public agency will suffer the burden of paying the private consortium the revenue shortfall.

With the third option, a fuel tax supplemented by VMT fees, the fee rates can be determined at any level that is analyzed to generate target revenue. When supported by sufficient resources to research adequate fee rates, there will not be any significant factors that can undermine sufficiency and stability of the revenue stream. It should be noted that processes such as data collection and analyses on cost/demand and the choice of a VMT fee rate, may necessitate dynamic and recursive features, as discussed in Chapter 6. 


\section{Alternative 3 - Replacing Fuel Taxes with New Pricing Schemes}

By replacing the current fuel tax-based revenue structure, this alternative actually eliminates the disadvantages of the current system. As discussed and analyzed in Chapter 4, revenue sufficiency and stability can be preserved by selecting relevant VMT fee rates.

\subsubsection{Accountability}

Accountability is a legal and institutional matter, unlike the sufficiency and stability problems, which are generally approached by analytical methods. Also, it is a problem not only of revenue generation, but also of revenue dedication (expenditure) strategy.

Rephrasing the definition of accountability given in Section 3.2.2, a financing mechanism is perfectly accountable if its payers are identical to its recipients. Evaluation of the accountability of the alternatives thus varies, depending on the level of payers/recipients aggregation. Viewing highway users as one homogenous group, the issue is to assess whether a particular financing tool receives revenue only from highway users and pays only for the highway system. In this regard, many of the current funding mechanisms, including motor fuel taxes, vehicle registration fees, and tolls, are transportation-dedicated, so therefore are accountable revenue sources. Also, proposed direct user charging schemes, including VMT fees, which can be expected to be earmarked as replacements of fuel taxes, are also accountable. Other highway related general taxes may not be accountable since their payers are not always highway users. Whether and how much of a portion of general taxes should be spent on the highway system is a complex problem, which often requires subjective assessments.

We can elaborate further on accountability by disaggregating payers/recipients into subgroups, such as rural/urban residents, highway/transit users, tolled/non-tolled roads users, etc. With this setup, an ideal accountability is to spend the revenue from a subgroup only in benefiting that specific subgroup. For an extreme example, we can imagine a budgeting system that consists of a number of exclusive accounts belonging to each subgroup of users, e.g., rural interstates truckers fund, county motorcycle user account, etc. The financial efficacy and efficiency of a budgeting system that is exclusively separated in too much detail is questionable. Therefore, the 
level of accountability should be targeted to achieve the best financial efficiency and can only be attained when coupled with a relevant expenditure plan.

Overall, from the perspective of the present study, better accountability is attributed to earmarking the generated revenue for transportation (or highway) purposes. In other words, an alternative that includes earmarked revenue sources is better in terms of accountability than those which depend on general (non-earmarked) sources. Local option taxes, in this regard, could be options to enhance accountability of appropriation from general accounts. 


\subsection{System Efficiency and Equity}

\subsubsection{System Efficiency}

The impact on system efficiency of each alternative can be compared from two perspectives. First, as mathematically demonstrated in Section 3.3.3, a financing structure that self-finances the system is one that maximizes the total social welfare (i.e., the system efficiency). From this viewpoint, system efficiency is closely related to revenue sufficiency at an aggregate level. Given that the assessed need is optimal, if a suggested financing method procures adequate revenue to meet the need, then it can be said to be efficient. As acknowledged, each alternative can be designed (by selecting relevant tax increases, toll rates, or per mile rates) to secure target revenue if the only aim is revenue sufficiency. Therefore, we are not directly comparing in this study whether or not each alternative is self-financing.

Second, a suggested pricing scheme should function as a price signal to users. In other words, a specific fee/tax rate plan should be structured to encourage socially beneficial activities and to restrain the opposite. As an illustration, a trip by a heavier vehicle that causes increased road wear or a trip on a congested road should be charged a higher price, for it incurs higher costs to the system. Although theoretically, a market mechanism works best when the marginal cost is

priced, it is not quite feasible or practical to measure and apply the exact marginal cost for each highway usage. Chapter 6 discusses the difficulty of calculating and implementing marginal-costbased pricing, the drawbacks of a fully responsive pricing structure, and a compromise solution. The following paragraphs discuss and compare competence as a market force of each alternative.

\section{Alternative 1 - Adjusting Current Tax System}

The current fuel tax based system generally works as a proxy of highway usage, although it is distorted in a sense in that vehicles with higher fuel efficiency pay less than what they actually used and those with lower efficiency pay more. Thus, this first alternative, which maintains fuel taxes as the major revenue source, can modestly fulfill system efficiency. However, since other taxes that are subject to adjustment within this category do not directly reflect the amount of use, 
the role as a price signal to users could be compromised. As pointed out in Section 4.1.3, the impacts on system efficiency can differ conditionally depending on the mixture of tax treatments.

\section{Alternative 2 - Current Fuel Tax Supplemented by Other User Fees}

Being supplemented by other revenue sources such as usage-based fees, this alternative will generally better function as a market force than the first alternative. Nevertheless, caution is needed since poorly designed fee structures can misrepresent the market mechanism and may not necessarily promote efficient utilization of the system. For example, in the toll road option, road sections to be tolled and the rates to be charged should be carefully determined based on the demand level and in a way that approximates the marginal cost.

\section{Alternative 3 - Replacing Fuel Taxes with New Pricing Schemes}

Based on the above, ISCURP could be the best in attaining system efficiency, but the fee structure must be well designed. A detailed implementation scheme and research agenda are addressed in Chapter 6.

\subsubsection{Modal Equity}

Equity between modes under the current highway funding strategy is best represented by equity ratios calculated by a Highway Cost Allocation Study, the national level reference values for which are summarized in Table 3.7. It has been found that the fuel tax-based current system is not equitably distributing the cost between mode users, and in fact, passenger vehicles in general and lighter trucks are subsidizing heavier trucks.

Similarly, the present study evaluates equity between road functional classes by applying the concept of the self-financing ratio as discussed in Section 3.4.2 (Oh et al., 2007). The results presented in Table 5.2 are based on state expenditure and revenue data for Indiana. These values indicate how much each road functional class is paying compared to the revenue received from. For instance, comparing the rural average (1.06) and the urban average (0.92), we can conclude that under the current state fuel tax system, the rural highway system is subsidizing urban 
highways. Also within the rural highway system, the rural interstate system is the major subsidizer, while other functional classes are paying less than the expenditures they incur.

Table 5.2 Self-Financing Ratio under Current Fuel Tax System by Road Function Class

\begin{tabular}{|l|l|c|c|}
\hline Location & Functional Class & $\begin{array}{c}\text { With respect to } \\
\text { the whole system }\end{array}$ & $\begin{array}{c}\text { Within subsystem } \\
\text { (rural/urban) }\end{array}$ \\
\hline Rural & Interstate & 2.19 & 2.07 \\
& OPA & 0.86 & 0.82 \\
& Major Arterial & 0.99 & 0.93 \\
& Major Collector & 0.52 & 0.49 \\
\cline { 2 - 4 } & Rural Average & $\mathbf{1 . 0 6}$ & $\mathbf{1 . 0 0}$ \\
\hline \multirow{5}{*}{ Urban } & Interstate & 1.00 & 1.08 \\
& OFE & 1.70 & 1.84 \\
& OPA & 0.90 & 0.98 \\
& Major Arterial & 0.32 & 0.34 \\
& Urban Average & $\mathbf{0 . 9 2}$ & $\mathbf{1 . 0 0}$ \\
\hline \multicolumn{2}{|l}{ Average Rate } & $\mathbf{1 . 0 0}$ & - \\
\hline
\end{tabular}

Based on the above, it can be concluded that both the first and second alternatives, which retain the current fuel tax system, entail a certain level of inequity between different classes of users. Highway systems using these alternative funding schemes are tolerating cross-subsidy between different classes of users.

If a pricing structure makes every value of equity ratios and self-financing ratios identical to one, then it can be said to realize perfect modal equity. Consequently, equity between vehicle classes and road function classes will be best achieved with the suggested comprehensive VMT fee structure shown in Tables 4.14 (a) and (b).

\subsubsection{Equity between Income Groups}

As discussed in Section 3.4.1, equity between income groups is a challenging criterion to evaluate since it requires an answer to an ideological or political question: to what extent should a 
particular income group support or be supported by others? In other words, how regressive/progressive should a highway fiscal policy be? The question becomes more complex considering that equity is also greatly influenced by revenue allocation policy. Hence, quantitative evaluation and comparison of equity requires more rigorous and extensive study, which is beyond the scope of this research. In the following paragraphs, however, commonly accepted wisdom on each alternative is summarized.

Fuel taxes are generally considered to be regressive when measured by a common indicator, the fraction of income taken by the fuel tax. However, it is often pointed out that the regressive nature of fuel tax is exaggerated (Wachs, 2003). As a matter of fact, people in higher income groups usually drive more and therefore pay more fuel taxes. By allocating fuel tax revenue in such a way to support public transit systems, which are generally used more by lower income groups, fuel taxes can benefit them as well.

Using the same indicator, sales taxes have been evaluated to be generally as regressive as fuel taxes (Wachs, 2003). However, dedicating revenue from sales taxes to highway purposes is often said to be regressive, considering that highway users, who more often than not own their vehicles, are generally wealthier than non-users. In other words, that part of the sales tax revenue that would have been spent on other purposes, including medical support, education, etc., is spent on highways to support the relatively higher income segment of the population.

Although tolls are often considered a regressive tax, user fees can be designed to convey a certain level of progressivity by introducing fee discounts/exemptions for specific income groups. Also, a system under which different services are priced differently will provide more travel choices to the users and will eventually make the wealthier, which usually have a higher willingness-to-pay, pay more. Again, more in-depth analysis on equity between income groups becomes possible only when equipped with an expenditure plan, and in turn, the flows of tax burden, revenue generation, public expense, and benefit of each income group then can be tracked. 


\subsection{Cost of Implementation}

As specified in Section 3.3.2, two components of implementation costs to be compared between alternatives are physical cost and administration cost. The former includes the cost to install, deploy, operate, and maintain a system and its components, while bureaucratic and enforcement costs are categorized as administration cost.

\subsubsection{Physical Cost}

The feasibility and implementation costs of technological options receive a great deal of attention as important decision-making factors. Remarkable advances in the areas of information and communication technology in the past decades, however, have taught us that costs of technology should not be considered as restricting constraints. This is especially true regarding a long-term strategy that will be implemented over the course of at least 20 years of a highway financing policy. History tells us that, for many types of technology, the cost of production and deployment drops drastically as the market matures. Echoing this sentiment, a financially infeasible option from a present day perspective may become reasonably available in the future.

Currently, regarding pricing options for state-wide level applications, only a handful of

pilot studies have been conducted as illustrated in Section 2.3. Due to the lack of information on implemental experiences, the discussion in this section does not go much beyond reviewing the cost analysis results available to date, foreseeing future potential, and discussing associated problems.

\section{Alternative 1 - Adjusting Current Tax System}

Implementation of the options under this category does not necessarily involve significant changes in a system or adoption of new technologies. Therefore, a public agency's out-of-pocket cost for the physical structure of this system is negligible. 


\section{Alternative 2 - Current Fuel Tax Supplemented by Other User Fees}

With this approach, the cost depends on the type and scope of the supplementing user fees. When toll roads are considered, the cost of toll collection is known to range from about $10 \%$ of the toll revenue when electronically collected and up to $40 \%$ with traditional tollbooths (VTPI, 2005c).

For options under this category, either implementing a toll or privatizing road segments, system integration is an important factor for consideration. A consistent and interoperable configuration for each tolled segment facilitates lower costs for initial installation, operation, and maintenance, as well as the cost borne by users for the purchase of vehicle equipment. Issues related to system consistency and future adaptation is discussed in the following paragraphs regarding new pricing schemes.

\section{Alternative 3 - Replacing Fuel Taxes with New Pricing Schemes}

In order to illustrate the cost of a state-wide usage-based charging scheme, this study has largely referred to one notable project which currently is under demonstration in Oregon (Kim et al., 2002). Three scenarios were examined in detail in the Oregon study: 1) collecting VMT data using GPS and radio frequency automatic vehicle identification (RF-AVI) tags and to have a fee collection center (FCCTR) for information synthesis and billing; 2) utilizing vehicle odometer and RF-AVI to gather VMT data and to have FCCTR; and 3), utilizing vehicle odometer and RFAVI for VMT data collection and to calculate and charge fees at gas station (without a fee collection center).

For each scenario, the cost, system durability, reliability/accuracy, and possibility of future expansion were analyzed, and the important findings are summarized as follows:

- A GPS configuration entails much higher on-vehicle equipment costs than an odometerbased configuration.

- It is much cheaper to collect, calculate, and collect VMT tax at a gas pump than to have a fee collection center.

- The tested on-vehicle units (GPS-based device, readers and antennae in a RF-based AVI system) are all very durable.

- The GPS system had problems with signal loss and increased signal acquisition time in the presence of obstacles such as tall buildings, trees, and mountainous surroundings. Accuracy can be improved by using sophisticated a GPS system, which is expensive 
however. On the other hand, the odometer and RF-AVI suite were tested and were shown to be $99.9 \%$ accurate, which is quite acceptable for implementation.

- In terms of future expansion, a GPS-based system has more potential than an odometerbased system. For example, a comprehensive pricing scheme that discriminates VMT tax rates according to geographical regions can be more easily implemented with a GPSbased system than with an odometer system.

More recent research results have recommended having GPS-based data collection supplemented by a redundant vehicle odometer to adjust possible GPS system errors and to communicate and charge at fuel pumping stations (Whitty et al., 2006). With the suggested technological configuration, the capital cost was estimated as shown in Table 5.3, assuming 1,800 fueling stations statewide. The most expensive tasks are installation of data transferring equipment at each fuel pump and improvement of the point-of-sale system. Although it is not based on actual data, the state system capital cost is not significant at approximately \$32 million for 1,800 fueling stations.

Table 5.3 VMT Fee Capital Costs Estimates

\begin{tabular}{|lr|}
\hline Cost Items & \multicolumn{1}{c|}{ Estimates } \\
\hline Data Transfer: & \\
\hline Equipment & $\$ 3,874,000$ \\
Software & $\$ 2,250,000$ \\
Installation & $\$ 10,800,000$ \\
\hline Other Fueling Station Infrastructure: & \\
\hline Point-of-Sale System Improvements & $\$ 9,171,000$ \\
Dedicated Telephone Lines & $\$ 236,000$ \\
\hline Contingencies & $\$ 5,270,000$ \\
\hline Total Fueling station Capital Costs & $\$ \mathbf{3 1 , 6 0 1 , 0 0 0}$ \\
\hline State System Capital Costs, Including Contingencies & $\$ 1,200,000$ \\
\hline Total Capital Costs & $\mathbf{\$ 3 2 , 8 0 1 , 0 0 0}$ \\
\hline
\end{tabular}

Source: Whitty et al. (2006) 


\subsubsection{Administration Cost}

As outlined in Section 3.5.1, administration costs consist of the bureaucratic cost and the enforcement cost. Generally, introducing a new system incurs higher costs to the agency for legislation, a change and update of routines, and employee education.

As for enforcement cost, the more complicated a pricing scheme is constructed; the more expensive it will be to enforce. For example, the simplest fee structure that charges every user in the system the same amount, the enforcement task will consist of only monitoring whether or not a user paid. On the other hand, more complicated pricing schedules, such as HOT lanes, will require an enforcement system consisting of several tasks, e.g., vehicle identification, vehicle occupancy observation, and deferred fee calculation. The cost of enforcement will generally rise as the pricing structure becomes more complicated. As discussed in Section 2.5.2, however, the cost of enforcement varies also according to the target accuracy of violation detection. Usually, the given status of technological feasibility, the marginal cost of accuracy enhancement tends to increase as the accuracy level rises. In other words, pursuing a 100\% trustworthy detection system may be neither financially viable nor efficient. The effectiveness of enforcement, which can be represented as the voluntary compliance rate of users, depends on a combination of detection accuracy and fines for violation. Thus, the level of detection accuracy can be compromised if accompanied by a penalty that is high enough to urge users to comply with the rule.

\section{Alternative 1 - Adjusting Current Tax System}

This alternative does not add any new pricing mechanism to the current tax system so the costs of administration will be negligible. As mentioned in Section 4.1, some of these options may include costs for legislation, public outreach, and ballot measures.

Alternative 2 - Current Fuel Tax Supplemented by Other User Fees

In many toll road implementation cases (Section 2.2.2), it was found that administration and enforcement cost is not significant compared to the toll revenue received. In addition, as 
discussed above, enforcement costs can be lowered if the system configuration is designed with relatively low detection accuracy and a high violation fine.

\section{Alternative 3 - Replacing Fuel Taxes with New Pricing Schemes}

According to Whitty et al. (2006), the administration cost of a mileage-based pricing scheme varies depending upon the scenario. Whitty showed that the two fee collection methods compared in Sections 4.2.3 and 5.3.1 presented significant difference in their administration costs. First, it was found that the centralized data and fee collection (i.e., a system with FCCTR) may be costprohibitive. Alternatively, fee collection at fueling stations was analyzed to be much more efficient and cost-effective in that it has very low enforcement costs and low evasion by users. Currently, the Road User Fee Task Force (RUFTF) of Oregon is searching for a better

enforcement program for the FCCTR configuration through assessment of traffic fines and access to a private debt collection system (Whitty et al., 2006).

In conclusion, if well designed, the administration costs for the VMT fee system can be decreased sufficiently to secure financial effectiveness of the pricing scheme. 


\subsection{Public Acceptability}

Several recent surveys carried out in different parts of the U.S. were reviewed to gain insight to the level of public support for various forms of transportation funding sources, including taxes, fees, and tolls. The respondents' experience and knowledge certainly influence their attitudes and perceptions so survey results may vary by regions and socio-economic characteristics. The conclusions and findings of each public opinion study therefore will be discussed in consideration of the background of the surveys and the socio-demographic and transportation-related characteristics of the respondents. The information will then be synthesized to a structured comparison between the suggested alternatives in terms of their prospects for public acceptability.

In most cases, the studies utilizing a survey consisted of two parts of experiments: a quantitative survey and a qualitative focus group. The former is characterized by a questionnairebased survey on a sample population that is used as a basis to project opinions of the whole population. The latter was conducted with a small group of interviewees, who were selected carefully to represent a sampling of the whole population. The goal in this second approach was to reveal how people think, facilitated by providing detailed information and interactive communication (Lawrence, 2006).

\section{Texas}

Kockelman et al. (2006) conducted a survey in Texas in 2005, where 2,111 residents across the state were asked their preferences between several transportation funding options, of which 324 completed the questionnaire. As a complement to this survey, focus groups were conducted to more deeply communicate with the users and to learn important factors that determine a user's attitude toward pricing policies. Following is a summary of the major findings:

- The main proponents for new transportation pricing policies are those who are more exposed to toll experience and congestion problem, i.e., regular toll road users and more frequent peak-hour drivers.

- Tolls are preferred to gas taxes; the improvement of existing roads before building new ones is also supported. 
- Education matters; disseminating more accurate and detailed information on transportation funding helped increase public awareness of the necessity/legitimacy/ benefits of tolling. General opposition was observed to the idea of converting currently free roads into toll roads.

- Well-planned revenue dedication is one of the key factors that can help the agency win public acceptance.

- Plausible reasons to defend conversion of existing roads into toll roads are congestion reduction and road improvements.

- Likely proponents of road pricing are those who are older, more educated, or employed part-time, or who commute long-distances.

- Distrust of government officials was clearly observed.

- Order of preference among options: (1) sales tax, (2) emission fee, (3) taxes on automobile parts, (4) taxes on heavy vehicles, (5) congestion pricing, (6) toll revenues, (7) property taxes, (8) state income taxes.

\section{Washington}

Both the telephone survey of 1,118 residents and the six focus group activities, each of which had six to eleven participants, were held in Washington State (Lawrence, 2006). Questions in the telephone survey and issues in the focus group discussions were designed to understand the prevailing attitudes toward transportation issues. Important lessons obtained are as follows:

- It is generally perceived that additional funds to supplement the current fuel taxes are needed for upkeep of the highway system, but would not be needed if government would spend the revenue more efficiently.

- Conditional acceptance of tolling was observed. Tolls are acceptable when applied on a project-by-project basis, when revenue is spent on the tolled facility, and when there are alternative free routes.

- Strong opposition against imposing tolls on existing roads was observed.

- Cynicism about government spending is one of the main obstacles of novel options.

- Cordon tolling and an annual mileage fee are considered unacceptable and unfair.

- A statewide tolling system generates apprehension because of its complexity and fears of abuse, fraud, and writing a blank check. 
- For participants of focus groups, support for toll roads substantially improved, as they were more informed during the focus group activities about the problems and options.

- The order of preference among the options: (1) tolls on new roads/bridges; (2) lanespecific or optional tolls, such as HOT lanes, that allow options to users; (3) tolls on existing roads/ bridges; (4) increases in the gasoline tax; (5) cordon tolling; (6) replacing the gasoline tax with an annual mileage fee; and (7) replacing the gasoline tax with system-wide tolls.

\section{Minnesota}

A general market survey and a stated-preference survey among residents of the Twin Cities area were carried out by Minnesota Department of Transportation (2006) as a component of a larger project to test the feasibility of mileage-based charges. Four hundred randomly-selected residents received a telephone call for the general market survey, where they were asked about their socioeconomic characteristics, trip attributes, attitudes, and knowledge, and their interest in a mileagebased program. A subset of the participants supplied inputs to the stated-preference survey. It was found in this study that, generally, there was not great interest in mileage-based program in the Twin City metro area. However, one particular population group that appeared to be interested was those who plan to lease, rather than purchase, their next vehicle.

\section{California}

Dill and Weinstein (2007) conducted a public opinion survey in California in 2006. Residents received telephone calls asking their opinions on a range of revenue options to fund transportation, including taxes and fees, bonds, and tolling. It was revealed that there was fairly strong public support for some tolling options.

- The most popular option was to increase the vehicle registration fee in a way to reflect the vehicle's air pollutant emissions and gas mileage.

- Options to increase the current fuel taxes, sales taxes, or vehicle license fees, enjoyed a similar level of support, about $40 \%$.

- Residents of regions with toll roads and HOT lanes tended to support these concepts more.

- The income level did not have a significant influence on the level of support.

- Younger adults showed more support on innovative funding tools. 
Synthesizing the lessons learned from recent surveys, the alternatives of the present study were evaluated, as discussed below.

\section{Alternative 1 - Adjusting Current Tax System}

A fuel tax increase may not be the least popular policy, although it will generally face opposition from the public. Tax increases or new forms of taxes/fees, including vehicle registration fees, sales tax, and emission tax, may not be abhorrent approaches either.

\section{Alternative 2 - Current Fuel Tax Supplemented by Other User Fees}

The acceptance of toll roads is strongly conditional. Having a newly built toll road is not a bad idea, while converting currently free roads into toll roads may not be well received. Tolls are acceptable when users have another option that is free and when congestion is reduced effectively.

\section{Alternative 3 - Replacing Fuel Taxes with New Pricing Schemes}

Apparently, the public shows the least inclination to this new scheme; namely, potential problems such as double taxation, fraud, system malfunction, etc. However, the main cause of disfavor can be a lack in information and experience with this new policy. Also, focus groups results from other states tell us that education and outreach can improve acceptability considerably, especially when accurate and detailed information is communicated.

The most important lesson here is that public acceptability is something that can be changed over time, as users' experience accumulates and as substantial public outreach effort continues. As seen in most of the surveys, if a particular policy is well-designed to benefit the system and its users, then awareness usually entails support for it. In conclusion, we are not searching for an option that is the easiest in attaining public acceptability within the current level of market maturity and the general perception. Rather, an effort should be made for a selected strategy, which should be of course the best to meet the other criteria (system efficiency, financial viability, and equity between users), to intensively communicate with the public about the rationale and legitimacy of it. In other words, public acceptance should not be a crucial criterion that can eliminate an alternative that would have been preferred otherwise. Instead, it should be considered a state variable that guides the direction of public outreach. 


\subsection{Policy Alignment}

\section{Compatibility with Federal Policy}

As discussed in Section 3.7.1, the long-term goal envisioned by a TRB study (NCHRP, 2006) is to replace the current federal fuel tax system with a distance-based pricing scheme. The stepwise process proposed for federal strategy is shown in Figure 5.1. The proposal calls for the implementation of short-term funding mechanisms until 2015: indexing federal fuel tax, implementing motor fuel sales taxes at the federal level, indexing the heavy vehicle use tax, eliminating exemptions to the Highway Trust Fund (HTF), and recapturing the interest of HTF balances.

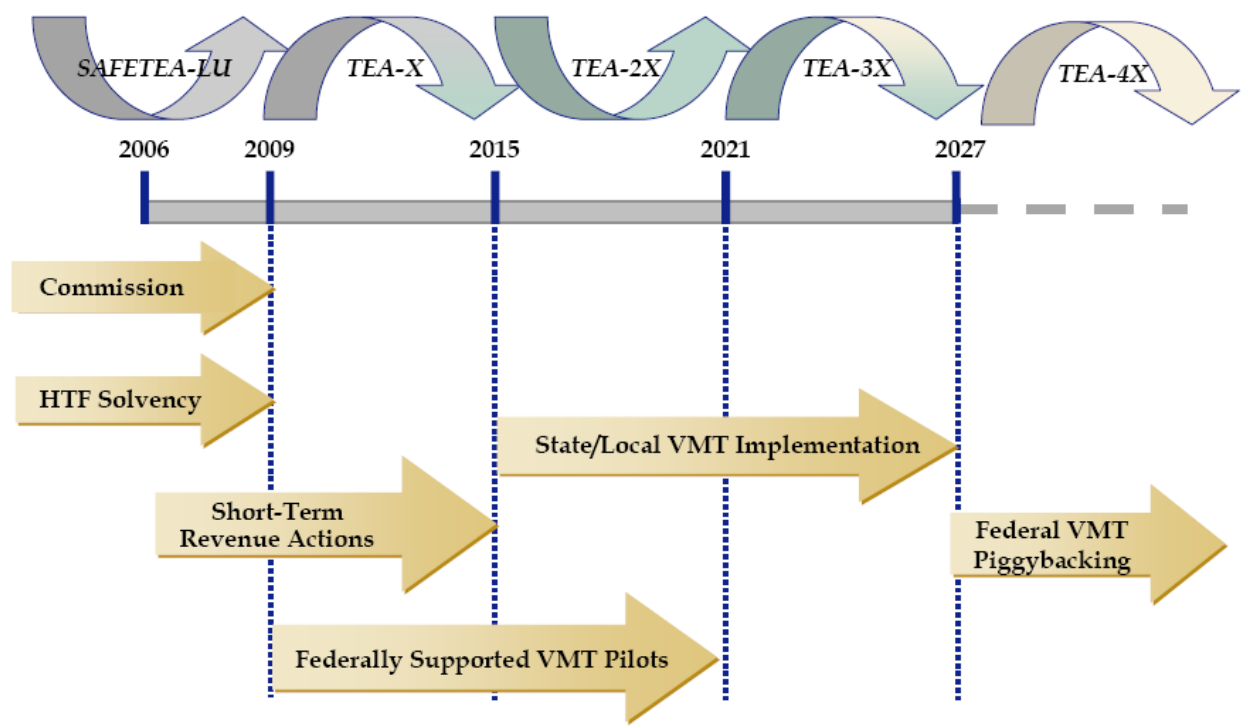

Figure 5.1 Timeframe for Revenue Transition (NCHRP, 2006)

Meanwhile, the timeframe indicates that federally supported research and demonstration of new pricing systems, including VMT fees, should be carried out. State and local governments will be able to implement VMT fees as experience and resources are accumulated through pilot 
studies. When the state/local level VMT fee system is mature enough, the federal government can piggyback on state VMT fees.

\section{Alternative 1 - Adjusting Current Tax System}

Based on the suggested federal strategy and timeframe, the options under this first category suit the federal level short-term actions.

\section{Alternative 2 - Current Fuel Tax Supplemented by Other User Fees}

This approach can be applied during the course of experimentation with tolling and VMT-based charging, and before fuel taxes are completely succeeded by new pricing schemes. Partially studied and evaluated options can take roles as supplemental revenue sources to the fuel taxes.

\section{Alternative 3 - Replacing Fuel Taxes with New Pricing Schemes}

VMT fees or the ISCURP structure suggested in Section 4.3 are compatible with the long-term federal strategy. The numerical analyses summarized in Section 4.3.1 (Tables 4.10, 4.11, and 4.12) present two different VMT fee rates: one state VMT fee schedule; and the other piggybacking future federal VMT fees.

\subsection{Summary}

In this chapter, the alternatives developed in Chapter 4 were evaluated according to the evaluation criteria suggested in Chapter 3. Table 5.4 summarizes the evaluation results to provide a concise comparison between alternatives, and the features of each alternative were shown as they pertain to each corresponding evaluation criterion. Also, with respect to each criterion, the best specification of each alternative is given when available.

In conclusion, in terms of long-term revenue adequacy, system efficiency, and modal equity, complete replacement of the current fuel tax system with a new usage-based charging scheme is recommended. This new scheme will require considerable input for its implementation, such as knowing the physical and administrative costs for startup and maintenance, accumulating a considerable body of knowledge through research and experimentation, and continuous public outreach and education program. 
Table 5.4 Comparison of Alternatives

\begin{tabular}{|c|c|c|c|}
\hline \multirow[b]{2}{*}{ Criteria } & \multicolumn{3}{|c|}{ Alternatives } \\
\hline & $\begin{array}{l}\text { Tax adjustments: fuel taxes, vehicle } \\
\text { registration fees, sale tax, property tax }\end{array}$ & $\begin{array}{l}\text { Fuel tax supplemented by } \\
\text { usage-based fees: tolls, VMT fees }\end{array}$ & $\begin{array}{l}\text { Complete replacement of current } \\
\text { system: VMT fees, ISCURP }\end{array}$ \\
\hline $\begin{array}{l}\text { Revenue Adequacy } \\
\text { (sufficiency/stability/ } \\
\text { accountability) }\end{array}$ & $\begin{array}{l}\text { - Adequacy may not be achieved, } \\
\text { especially in the long-term, due to } \\
\text { several factors: enhancement in fuel } \\
\text { economy; inflation (when not } \\
\text { indexed); competition between other } \\
\text { governmental expenses; and weaker } \\
\text { indication of highway financing } \\
\text { needs of general taxes } \\
\text { The best implementation: Indexing } \\
\text { fuel tax and vehicle registration fee }\end{array}$ & $\begin{array}{l}\text { - Adequacy may not be achieved due } \\
\text { to enhancement of fuel economy; } \\
\text { inflation (when not indexed); and } \\
\text { demand elasticity with respect to } \\
\text { tolls (uncertainty of demand) } \\
\text { - When supplemented by VMT fees, } \\
\text { the rate can be calculated to meet the } \\
\text { funding needs } \\
\text { - The best implementation: Indexing } \\
\text { fuel tax and establishing VMT fees } \\
\text { on top of the fuel tax with adequate } \\
\text { fee rates that can meet the funding } \\
\text { needs }\end{array}$ & $\begin{array}{l}\text { - By selecting adequate VMT fee } \\
\text { rates, sufficiency can be secured. } \\
\text { - If continuous update of fee rate is } \\
\text { allowed, stability is also attained. } \\
\text { - The best implementation: The most } \\
\text { adequate VMT fee rates considering } \\
\text { recent expenditure are calculated by } \\
\text { road function class and vehicle type } \\
\rightarrow \text { (with no other source) } 3.1 \notin / \mathrm{mi} \text {; } \\
\text { (with vehicle registration fee) } \\
2.2 \notin / \text { mi in average }\end{array}$ \\
\hline $\begin{array}{l}\text { Efficiency } \\
\text { (self-financing/ } \\
\text { price signal) }\end{array}$ & $\begin{array}{l}\text { - Does not give perfect price signal to } \\
\text { users; taxes other than fuel taxes not } \\
\text { being direct usage charge } \\
\text { - Level of efficiency Depends on the } \\
\text { mixture of tax treatment } \\
\text { - The best implementation: Indexing } \\
\text { and increasing fuel tax, i.e. less } \\
\text { depending upon other taxes, which } \\
\text { are not usage-based }\end{array}$ & $\begin{array}{l}\text { With well designed toll/VMT fees, } \\
\text { can give proper price signal users } \\
\text { - Level of efficiency depends on the } \\
\text { toll/fee levels } \\
\text { - The best implementation: Indexing } \\
\text { fuel tax and adding efficient toll } \\
\text { pricing/VMT fees based on the } \\
\text { marginal costs, which counts } \\
\text { impacts of externalities (e.g. } \\
\text { congestion, emission) }\end{array}$ & $\begin{array}{l}\text { - Has the highest potential to achieve } \\
\text { system efficiency } \\
\text { - Level of efficiency depends on the } \\
\text { fee rate plan } \\
\text { - The best implementation: The } \\
\text { ISCURP fee schedule, of which } \\
\text { revenue covers the total expenditure, } \\
\text { and which reflects marginal costs } \\
\text { that counts impacts of externalities } \\
\text { (e.g. congestion, emission) }\end{array}$ \\
\hline
\end{tabular}


Table 5.4 Comparison of Alternatives (Continued)

\begin{tabular}{|c|c|c|c|}
\hline \multirow[b]{2}{*}{ Criteria } & \multicolumn{3}{|c|}{ Alternatives } \\
\hline & $\begin{array}{l}\text { Tax adjustments: fuel taxes, vehicle } \\
\text { registration fees, sale tax, property tax }\end{array}$ & $\begin{array}{l}\text { Fuel tax supplemented by } \\
\text { usage-based fees: tolls, VMT fees }\end{array}$ & $\begin{array}{l}\text { Complete replacement of current } \\
\text { system: VMT fees, ISCURP }\end{array}$ \\
\hline $\begin{array}{l}\text { Equity } \\
\text { (between modes, road } \\
\text { functional classes, and } \\
\text { income groups) }\end{array}$ & $\begin{array}{l}\text { - Does not guarantee perfect fairness } \\
\text { between users } \rightarrow \text { evidenced by } \\
\text { equity ratio (by vehicle classes) and } \\
\text { self-financing ratio (by road function } \\
\text { class) of current fuel tax, both of } \\
\text { which should have had value of one } \\
\text { (1) otherwise } \\
\text { - Level of equity depends on the } \\
\text { mixture of tax treatment } \\
\text { - The best implementation: Indexing } \\
\text { and increase fuel tax }\end{array}$ & $\begin{array}{l}\text { - Does not guarantee perfect fairness } \\
\text { between users since it maintains fuel } \\
\text { tax, with which equity ratio and self- } \\
\text { financing ratio are not all identical } \\
\text { - Level of equity depends on the } \\
\text { toll/fee levels } \\
\text { - The best implementation: Indexing } \\
\text { fuel tax and setting up toll/fee } \\
\text { schedule that charges each user } \\
\text { group for the cost it incurs to the } \\
\text { system }\end{array}$ & $\begin{array}{l}\text { - Better spatial/modal equity between } \\
\text { user groups can be achieved by fee } \\
\text { schedule reflecting different costs } \\
\text { imposed by each group } \\
\text { - Depends on the fee rate plan } \\
\text { - The best implementation: A pricing } \\
\text { scheme where a price for unit } \\
\text { demand is identified according to its } \\
\text { characteristics (i.e. vehicle type, } \\
\text { road function class, location, } \\
\text { jurisdiction, congestion level, etc.) }\end{array}$ \\
\hline $\begin{array}{l}\text { System Cost } \\
\text { (physical/administration) }\end{array}$ & $\begin{array}{l}\text { - No physical cost; negligible } \\
\text { administration cost }\end{array}$ & $\begin{array}{l}\text { - Physical cost depends on system } \\
\text { configuration and technology type } \\
\text { - Administration cost depends on } \\
\text { system configuration but may not be } \\
\text { significant }\end{array}$ & $\begin{array}{l}\text { - Initial capital cost for statewide } \\
\text { VMT fee was estimated to be } \$ 33 \mathrm{M} \\
\text { for } 1800 \text { gas stations } \rightarrow 2.5 \% \text { of } \\
\text { annual highway revenue ( } \$ 1.3 \mathrm{~B}) \\
\text { - Admin cost depends on system } \\
\text { configuration; may not be significant }\end{array}$ \\
\hline Public acceptability & $\begin{array}{l}\text { - Relatively less reluctance and } \\
\text { disapproval than VMT fees } \\
\text { - More support when the use of } \\
\text { revenue is up-front to the public }\end{array}$ & $\begin{array}{l}\text { - Converting existing non-tolled roads } \\
\text { into toll roads are distasted } \\
\text { - Tolls are supported when it is to } \\
\text { support building new roads; when } \\
\text { there is alternative toll-free options } \\
\text { of travel and congestion is reduced }\end{array}$ & $\begin{array}{l}\text { - The public is not generally inclined } \\
\text { to this unfamiliar policy } \\
\text { - Education and communication can } \\
\text { make difference }\end{array}$ \\
\hline Policy Alignment & $\begin{array}{l}\text { - Compatible with proposed short-term } \\
\text { federal strategy }\end{array}$ & $\begin{array}{l}\text { - Compatible with proposed medium- } \\
\text { term federal strategy }\end{array}$ & $\begin{array}{l}\text { - Compatible with proposed long-term } \\
\text { federal strategy }\end{array}$ \\
\hline
\end{tabular}




\section{CHAPTER 6. IMPLEMENTATION RECOMMENDATIONS}

As discussed and compared in Chapters 4 and 5, some of the alternatives are more viable for immediate implementation due to their relatively low initial investment and negligible startup barriers. On the other hand, while a completely new system could fundamentally solve long-term highway financing problems, it has the drawback of needing a substantial period of time for incubating, researching, and accumulating experience with such a system.

Considering the complicated nature of the problem, no one particular action can be selected as an alternative to the current system. Instead, building a strategic plan is recommended, which would deal with the problem in a stepwise manner and eventually could realize the policy goals with maximum efficiency and effectiveness.

There are three strategic approaches with attendant timelines and they overlap with one another. In the following paragraphs these approaches are presented.

\subsection{Short-Term Strategy $(2007 \sim 2015)$}

Goal

To resolve the current revenue shortfall relying on the present framework of highway funding

The near-term strategy for Indiana can be to implement a combination of options under the first alternative category. Effort should be made to improve the current system, with the objectives of revenue adequacy and system efficiency.

Possible Actions

Increase in Fuel Tax to Account for Inflation Losses 
The gasoline tax in Indiana was 15 cents per gallon from 1988 to 2002 when it was increased to the current level of 18 cents. Since 1988, diesel tax and motor carrier surtax (MCST) have remained 16 and 11 cents per gallon, respectively. Any increase in fuel taxes would attempt to catch up to inflation loses from 1988 to a particular selected year. Table 6.1 compares, on the basis of the Consumer Price Index (CPI), the fuel tax revenue predictions for three scenarios: accounting inflation losses from 1988 to (a) 2000; (b) 2005; and (c) 2007. For example, if tax rates are adjusted to account for the inflation impact since 1988 to 2000, then the gasoline tax rate would be $19.8 \notin /$ gallon, diesel tax rate $21.1 \notin /$ gallon, and the MSCT rate $14.5 \phi / g a l l o n$, with an increase in total fuel tax revenue of $19.0 \%$ in each year over the base case.

Table 6.1 Forecast of Annual Revenue for Fuel Tax Increase Cases (CPI-Based)

\begin{tabular}{|l|c|r|r|r|r|c|}
\hline \multirow{2}{*}{ Type } & \multirow{2}{*}{ Rate ( $\phi$ /gallon) } & \multicolumn{2}{|c|}{ Revenues in 2005 constant dollar (thousand) } & \multirow{2}{*}{$\begin{array}{c}\text { increase } \\
\text { w.r.t base } \\
\text { case }\end{array}$} \\
\cline { 3 - 6 } & & 2008 & 2010 & 2015 & 2020 & \\
\hline Gasoline & 18 (base) & 538,889 & 538,694 & 546,368 & 573,892 & \\
& 19.8 (catch-up to 2000) & 592,831 & 592,617 & 601,059 & 631,338 & $10.0 \%$ \\
& 25.1 (catch-up to 2005) & 750,988 & 750,717 & 761,412 & 799,768 & $39.4 \%$ \\
& 26.6 (catch-up to 2007) & 796,366 & 796,078 & 807,419 & 848,093 & $47.8 \%$ \\
\hline Special Fuel & 16 (base) & 171,569 & 162,081 & 196,204 & 194,450 & \\
(Diesel) & 21.1 (catch-up to 2000) & 226,491 & 213,965 & 259,012 & 256,697 & $32.0 \%$ \\
& 26.8 (catch-up to 2005) & 286,915 & 271,048 & 328,112 & 325,179 & $67.2 \%$ \\
& 28.4 (catch-up to 2007) & 304,251 & 287,426 & 347,938 & 344,828 & $77.3 \%$ \\
\hline MCST & 11 (base) & 120,477 & 131,401 & 163,246 & 202,807 & \\
& 14.5 (catch-up to 2000) & 159,044 & 173,465 & 215,504 & 267,730 & $32.0 \%$ \\
& 18.4 (catch-up to 2005) & 201,474 & 219,743 & 272,997 & 339,156 & $67.2 \%$ \\
& 19.5 (catch-up to 2007) & 213,648 & 233,021 & 289,492 & 359,649 & $77.3 \%$ \\
\hline Sum & Base case & 830,934 & 832,176 & 905,818 & 971,149 & \\
& Catch-up to 2000 & 978,365 & 980,048 & $1,075,575$ & $1,155,764$ & $19.0 \%$ \\
& Catch-up to 2005 & $1,239,376$ & $1,241,508$ & $1,362,520$ & $1,464,103$ & $50.8 \%$ \\
& Catch-up to 2007 & $1,314,264$ & $1,316,525$ & $1,444,849$ & $1,552,570$ & $59.9 \%$ \\
\hline
\end{tabular}

Base case prediction source: Sinha et al. (2005)

- Inflation impact since 1988 to a selected year is incorporated based on CPI (Consumer Price Index).

- CPI beyond 2005 was assumed to increase 3\% annually.

While CPI is commonly used from highway users' perspectives as it indexes prices of retail goods, the agency's cost to provide and sustain state highway system may be more closely related to Producer Price Index (PPI). In this regard, fuel tax revenue was predicted applying the same procedure but on the basis of PPI as presented in Table 6.2. Overall, predicted revenues are lower than ones based on CPI due to a slower increase rate of PPI. For instance, when tax rates 
are adjusted to reflect inflation impact from 1988 to 2000, the gasoline tax rate would increase to $18.6 \phi /$ gallon, diesel tax rate $19.9 \phi /$ gallon, and the MSCT rate $13.7 \phi / g a l l o n$, thereby the total annual revenue would increase by $11.9 \%$ over the base case revenue.

Table 6.2 Forecast of Annual Revenue for Fuel Tax Increase Cases (PPI-Based)

\begin{tabular}{|l|c|c|r|r|r|r|}
\hline \multirow{2}{*}{ Type } & \multirow{2}{*}{ Rate (ф/gallon) } & \multicolumn{2}{|c|}{ Revenues in 2005 constant dollar (thousand) } & \multirow{2}{*}{$\begin{array}{c}\text { increase } \\
\text { w.r.t base } \\
\text { case }\end{array}$} \\
\cline { 3 - 6 } Gasoline & 18 (base) & 2008 & 2010 & 2015 & 2020 & \\
& 18.6 (catch-up to 2000) & 558,889 & 538,694 & 546,368 & 573,892 & \\
& 21.6 (catch-up to 2005) & 646,935 & 557,256 & 565,194 & 593,666 & $3.4 \%$ \\
& 22.9 (catch-up to 2007) & 686,334 & 686,702 & 655,915 & 688,957 & $20.0 \%$ \\
\hline Special Fuel & 16 (base) & 171,569 & 162,081 & 695,860 & 730,914 & $27.4 \%$ \\
(Diesel) & 19.9 (catch-up to 2000) & 212,976 & 201,198 & 243,557 & 194,450 & \\
& 23.0 (catch-up to 2005) & 247,161 & 233,493 & 282,651 & 280,124 & $24.1 \%$ \\
& 24.5 (catch-up to 2007) & 262,213 & 247,713 & 299,864 & 297,184 & $52.8 \%$ \\
\hline MCST & 11 (base) & 120,477 & 131,401 & 163,246 & 202,807 & \\
& 13.7 (catch-up to 2000) & 149,554 & 163,115 & 202,645 & 251,754 & $24.1 \%$ \\
& 15.8 (catch-up to 2005) & 173,559 & 189,297 & 235,172 & 292,164 & $44.1 \%$ \\
& 16.8 (catch-up to 2007) & 184,128 & 200,825 & 249,494 & 309,957 & $52.8 \%$ \\
\hline Sum & Base case & 830,934 & 832,176 & 905,818 & 971,149 & \\
& Catch-up to 2000 & 919,986 & 921,569 & $1,011,396$ & $1,086,800$ & $11.9 \%$ \\
& Catch-up to 2005 & $1,067,655$ & $1,069,492$ & $1,173,737$ & $1,261,245$ & $29.9 \%$ \\
& Catch-up to 2007 & $1,132,676$ & $1,134,624$ & $1,245,218$ & $1,338,055$ & $37.8 \%$ \\
\hline
\end{tabular}

Base case prediction source: Sinha et al. (2005)

- Inflation impact since 1988 to a selected year is incorporated based on PPI (Producer Price Index).

- PPI beyond 2005 was assumed to increase 3\% annually.

\section{$\underline{\text { Inflation-Indexing of Fuel Tax }}$}

In addition to the changes discussed above, inflation-indexing of fuel taxes can be considered. In the revenue prediction results presented in Tables 6.3 and 6.4, the 2006 rates are adjusted upward to keep up with an inflation rate of $3 \%$ per year, starting from the modified rates presented in Tables 6.1 and 6.2, respectively. An inflation rate of 3\% is relatively conservative as the most recent trend reveals a rate increase of $6 \sim 7 \%$. Table 6.3 shows that, by adjusting for inflation, the revenue from fuel tax in 2015 could increase by $22.3 \%$ to $64.3 \%$, depending upon the year used to adjust initially the existing rates. When based on PPI, the range of revenue increase would be lower than what was estimated using CPI; it will be between $15.0 \%$ and $41.6 \%$, as noted in Table 6.4 . 
Table 6.3 Revenue Forecast for Fuel Tax Indexing Cases (CPI-Based)

\begin{tabular}{|c|c|c|c|c|c|c|}
\hline \multirow{2}{*}{ Type } & \multirow{2}{*}{ Rate ( $\phi /$ gallon) in 2006} & \multicolumn{4}{|c|}{ Revenues in 2005 constant dollar (thousand) } & \multirow{2}{*}{$\begin{array}{c}\% \text { increase in } 2015 \\
\text { w.r.t base case }\end{array}$} \\
\hline & & 2008 & 2010 & 2015 & 2020 & \\
\hline \multirow{4}{*}{ Gasoline } & 18 (base) & 538,889 & 538,694 & 546,368 & 573,892 & \\
\hline & 19.8 and index afterward & 610,615 & 610,395 & 619,091 & 650,278 & $13.3 \%$ \\
\hline & 25.1 and index afterward & 773,518 & 773,239 & 784,254 & 823,761 & $43.5 \%$ \\
\hline & 26.6 and index afterward & 820,256 & 819,961 & 831,642 & 873,536 & $52.2 \%$ \\
\hline \multirow{4}{*}{$\begin{array}{l}\text { Special Fuel } \\
\text { (Diesel) }\end{array}$} & 16 (base) & 171,569 & 162,081 & 196,204 & 194,450 & \\
\hline & 21.1 and index afterward & 233,285 & 220,384 & 266,782 & 264,398 & $36.0 \%$ \\
\hline & 26.8 and index afterward & 295,522 & 279,179 & 337,955 & 334,935 & $72.2 \%$ \\
\hline & 28.4 and index afterward & 313,379 & 296,048 & 358,376 & 355,173 & $82.7 \%$ \\
\hline \multirow[t]{4}{*}{ MCST } & 11 (base) & 120,477 & 131,401 & 163,246 & 202,807 & \\
\hline & 14.5 and index afterward & 163,815 & 178,669 & 221,969 & 275,762 & $36.0 \%$ \\
\hline & 18.4 and index afterward & 207,518 & 226,335 & 281,186 & 349,330 & $72.2 \%$ \\
\hline & 19.5 and index afterward & 220,057 & 240,011 & 298,177 & 370,438 & $82.7 \%$ \\
\hline \multirow[t]{4}{*}{ Sum } & Base case & 830,934 & 832,176 & 905,818 & 971,149 & \\
\hline & Catch-up to 2000 and index & $1,007,716$ & $1,009,449$ & $1,107,842$ & $1,190,437$ & $22.3 \%$ \\
\hline & Catch-up to 2005 and index & $1,276,558$ & $1,278,754$ & $1,403,396$ & $1,508,026$ & $54.9 \%$ \\
\hline & Catch-up to 2007 and index & $1,353,692$ & $1,356,021$ & $1,488,194$ & $1,599,147$ & $64.3 \%$ \\
\hline
\end{tabular}

Base case prediction source: Sinha et al. (2005)

- Inflation impact since 1988 to a selected year is incorporated based on CPI (Consumer Price Index).

- CPI beyond 2005 was assumed to increase $3 \%$ annually.

Table 6.4 Revenue Forecast for Fuel Tax Indexing Cases (PPI-Based)

\begin{tabular}{|c|c|c|c|c|c|c|}
\hline \multirow{2}{*}{ Type } & \multirow{2}{*}{ Rate ( $\varnothing /$ gallon) in 2006} & \multicolumn{4}{|c|}{ Revenues in 2005 constant dollar (thousand) } & \multirow{2}{*}{$\begin{array}{c}\% \text { increase in } 2015 \\
\text { w.r.t base case }\end{array}$} \\
\hline & & 2008 & 2010 & 2015 & 2020 & \\
\hline \multirow[t]{4}{*}{ Gasoline } & 18 (base) & 538,889 & 538,694 & 546,368 & 573,892 & \\
\hline & 18.6 and index afterward & 574,180 & 573,973 & 582,150 & 611,476 & $6.5 \%$ \\
\hline & 21.6 and index afterward & 666,343 & 666,103 & 675,592 & 709,625 & $23.7 \%$ \\
\hline & 22.9 and index afterward & 706,924 & 706,669 & 716,736 & 752,842 & $31.2 \%$ \\
\hline \multirow{4}{*}{$\begin{array}{l}\text { Special Fuel } \\
\text { (Diesel) }\end{array}$} & $16($ base $)$ & 171,569 & 162,081 & 196,204 & 194,450 & \\
\hline & 19.9 and index afterward & 219,365 & 207,234 & 250,864 & 248,621 & $27.9 \%$ \\
\hline & 23.0 and index afterward & 254,576 & 240,498 & 291,130 & 288,528 & $48.4 \%$ \\
\hline & 24.5 and index afterward & 270,080 & 255,144 & 308,860 & 306,099 & $57.4 \%$ \\
\hline \multirow[t]{4}{*}{ MCST } & 11 (base) & 120,477 & 131,401 & 163,246 & 202,807 & \\
\hline & 13.7 and index afterward & 154,040 & 168,008 & 208,724 & 259,307 & $27.9 \%$ \\
\hline & 15.8 and index afterward & 178,765 & 194,976 & 242,227 & 300,929 & $48.4 \%$ \\
\hline & 16.8 and index afterward & 189,652 & 206,850 & 256,978 & 319,256 & $57.4 \%$ \\
\hline \multirow[t]{4}{*}{ Sum } & Base case & 830,934 & 832,176 & 905,818 & 971,149 & \\
\hline & Catch-up to 2000 and index & 947,586 & 949,216 & $1,041,737$ & $1,119,404$ & $15.0 \%$ \\
\hline & Catch-up to 2005 and index & $1,099,685$ & $1,101,577$ & $1,208,949$ & $1,299,082$ & $33.5 \%$ \\
\hline & Catch-up to 2007 and index & $1,166,656$ & $1,168,663$ & $1,282,574$ & $1,378,197$ & $41.6 \%$ \\
\hline
\end{tabular}

Base case prediction source: Sinha et al. (2005)

- Inflation impact since 1988 to a selected year is incorporated based on PPI (Producer Price Index).

- PPI beyond 2005 was assumed to increase 3\% annually. 


\section{Increase in Vehicle Registration Fees}

Vehicle registration fees, the second largest revenue source for the state highway system, are not indexed for inflation. If vehicle registration fees are indexed to the CPI inflation rate, results would be as presented in Table 6.5. For example, if vehicle registration fees were increased to account for inflation loss since 2000 and the fee rates are then indexed annually for inflation thereafter, then the expected revenue could increase by as much as $69.9 \%$ in 2015 .

Table 6.5 Revenue Forecast for Vehicle Registration Fee

\begin{tabular}{|c|c|c|c|c|c|}
\hline \multirow{2}{*}{ Scenario } & \multicolumn{2}{|c|}{ Revenues in 2005 constant dollar (thousand) } & \% increase in 2015 \\
\cline { 2 - 5 } & 2008 & 2010 & 2015 & 2020 & w.r.t base case \\
\hline Base case & 324,939 & 337,575 & 371,017 & 409,567 & \\
Accounting loss since 2005 \& Indexing & 354,830 & 390,904 & 497,498 & 635,946 & $34.1 \%$ \\
Accounting loss since 2000 \& Indexing & 449,493 & 495,190 & 630,222 & 805,606 & $69.9 \%$ \\
\hline
\end{tabular}

Base case prediction source: Sinha et al. (2005)

- CPI beyond 2005 was assumed to increase 3\% annually.

\section{$\underline{\text { Portion Dedication of General Sales Taxes }}$}

As illustrated in 4.1 .2 , dedication of $0.5 \%$ of the sales tax revenue will generate approximately \$25 million of additional revenue.

\section{Local Government Strategies}

Local option taxes are available in Indiana for transportation purposes. Forty six (46) out of 92 counties have adapted a Local Option Highway User Tax in Indiana. However, the amounts collected are not substantial. Also, other miscellaneous sources can be utilized, such as dedication of a portion of property tax revenues, lottery income, cigarette tax, wheel tax, etc. (NCHRP, 2006).

\section{Charging Alternative-Fuel or New-Technology Vehicles}

Alternative fuel vehicles also cause road wear and should contribute to highway maintenance (TRB, 2005). A legal basis for charging those vehicles can be established and a relevant fee level can be selected. However, the number of such vehicles can be expected not to be significant in near-term. Careful consideration should also be given not to inhibit the introduction of environment-friendly technologies. 


\section{Public Outreach}

As discussed in Section 5.4, public acceptance can be won through continuous efforts of outreach to the public and advertising proposed policies and their benefits. A recent TRB workshop on transportation financing innovations, held in January 2007, observed that one of the most fundamental impediments is the public skepticism toward government spending in general. At this stage, it is absolutely imperative to prepare a long-term procedure to rectify this mindset.

It is suggested that efforts should be taken to build public trust in the state government's capability and integrity in financing state's highway system. A possible forum can be to release a "Transportation Budget Report" to the public on a regular basis, which can be made available in newspapers or on-line. The report can include the following items:

\section{State Highway Program}

- Revenue Information: List highway revenues by source.

- Expenditure Information: List expenditures by program, project, and item.

- Performance Information: Report performance in terms of expenditures and improvements in pavement and bridge conditions, safety, and level of service. (For example, how many dollars of expense in pavement maintenance enhanced pavement quality for how many miles of I-65)

- Financial Balance Information: Provide debt information, if any.

- Disbursement Information: Note the state's disbursement to each locality.

\section{Local Highway Program}

- Revenue Information: List highway revenues at local level by source.

- Expenditure Information: List expenditure of local government by program, project, and item.

- Performance Information: Report aggregated data.

Open and regular communication can only improve public support for a pricing policy, providing assurance that the government is using tax revenues wisely with actual performance information.

Research Needs 
During near-term period, an effort should be made to collect accurate and systematic data as a preparation for future implementation of comprehensive road pricing. Given that the eventual goal is to implement a user-fee-based funding structure, the crucial question is basically "how much to charge each road use?" The numerical analyses presented in Section 4.3 (Table 4.9 through Table 4.11, and Table 4.14) are reference values for the initial implementation only. The numbers should be further elaborated with more accurate and detailed data. In order to find better answers, efforts should be made to know more about the system cost and demand. First of all, a highway cost allocation study needs to be accomplished not only at the state level, but also at the local level. This task is associated with methodical and regular collection and analyses of highway expenditure, revenues, and demand data. As we obtain results from a cost allocation study, we will be equipped with improved knowledge to better determine how much to charge for road usage.

Research seeking the basis for appropriation of revenues from other general taxes is recommended as well. For example, as briefly addressed in Section 4.1.2, the value of a property boosts when it has better transportation access. Such research could provide evidence to support appropriation of a portion of property tax for transportation systems and how much that appropriation should be. Also, since the highway network is one of the major infrastructures that sustain economic growth, a certain portion of the state's income could be attributed to the highway system. Research seeking quantification of the impact on income of a highway or transportation network, could help justify such appropriations from income tax.

\subsection{Medium-Term Strategy $(2010 \sim 2020)$}

\section{Goal}

To prepare and organize for the implementation of Indiana Statewide Comprehensive Usage-based Road Pricing (ISCURP)

As concluded in Chapter 5, the potential benefits of a new pricing scheme as a complete replacement of the current fuel tax system are enormous. Delays in developing these alternative financing tools would be costly (TRB, 2005). The possible benefits can be materialized, however, only when supported by proper preparation, ranging from in-depth research on highway cost, 
funding needs, and demand influence, and public opinion surveys and outreach, to pilot studies and experimentation. Meanwhile, other user fees, such as tolls, could be a supplementary revenue source, as suggested in the second alternative.

\section{Possible Actions}

\section{$\underline{\text { Toll Road Development }}$}

As evaluated, tolls can supplement fuel taxes, which are increased and/or indexed for inflation as the near-term strategy is implemented. It was indicated in Section 4.2.1 that tolls on new highway are better defended in terms of legitimacy and public acceptability than those imposed on existing roads. At the national level, it is desirable for the states to experiment with wide variety of toll development and the SAFETEA-LU gives state governments full discretion to select roads to toll and the rates.

Tolling combined with loan guarantees and bonding is expected to attract additional capital investment from governments as well as the private sector (NCHRP, 2006). One of the advantages is that this combination of financing tools can expedite project delivery. Recalling the calculation in Section 4.2.1, annual earnings of $\$ 35$ million for a 10 mile toll road can be a reference to approximate the funding need from tolling to meet financial adequacy. However, selecting road sections to be tolled and planning a toll schedule require a great deal of study on network impacts and demand responses. Moreover, in the case of leasing a toll road to a private consortium, the concession agreement should be carefully designed in order to protect the benefits of the public while enjoying innovative and efficient procurement and delivery.

\section{Indiana Statewide Comprehensive Usage-based Road Pricing (ISCURP) Pilot Study}

A pilot study to provide the basis for future implementation of ISCURP is needed during this period. Following is a stepwise procedure for this pilot study:

Phase 1: As the first step, the technological standards for ISCURP should be configured along with a timeline for information gathering and a plan for assessment and evaluation. Each potential option will be defined and examined to determine its benefits and costs. The specific criteria will include administrative ease, user convenience, fuel retailers' and distributors' convenience, costs of start-up and operation after the system matures, privacy protection facilitation, and the possibility for ease of future expansion/extension of the system. After 
evaluating options based on these criteria, the best alternative should be selected as a standard technological configuration and the necessary infrastructure should be constructed.

Phase 2: As a next step, system accuracy and reliability should be tested by installing the necessary equipment on probe vehicles. This stage will require hundreds of probe vehicles, which will be mostly government-owned. The accuracy and reliability of the system need to be assessed for criteria that include accuracy of vehicle identification, reliability of vehicle locating ability, accuracy of distance measurement, and reliability of communication capability and capacity (travel and billing information). In case the proposed system cannot achieve a satisfactory level of accuracy and reliability, any possible pitfalls of the system should be investigated and resolved. After confirming that the system yields adequate performance, any required preparation for system-wide implementation can be accomplished.

This phase will require determination of the costs to construct the infrastructure, to deploy in-vehicle devices to probe vehicles, and to install the system at stations, either centralized or scattered, according to the system configured. The selection of a demonstration scope will determine its cost. The spatial scope of the experiment will affect the boundary of highway segments where infrastructure should be built. Also, the number of probe vehicles to be included in the study will determine the cost of in-vehicle unit installation. The trade-off between the cost of demonstration and the quality of the results should be given a great deal of consideration in order to design the most relevant size of experiment.

\section{Public Outreach}

Public opinion surveys on a regular basis can help the implementing agency track changes in the attitude of the public over time. Also focus groups can be utilized to gauge the public attitude toward various financing tools in a more quantitative manner.

Effort should be continuously made to publicize fiscal policy for transportation, probably by releasing Transportation Budget Report suggested earlier. However, other advertising tools (printable media, radio commercials, etc.) can also be utilized to build awareness and trust in government policy.

\section{Information Needs}

To pursue a complete statewide implementation of road pricing, a feedback structure for the pricing scheme is needed. Supported by continuous and intensive data collection structured at the 
initiation, a system needs to be designed to continuously update the cost of the system and the unit rates to be charged.

One possible problem in a pilot study lies in the complication that arises at state borders, given that the systems of adjacent states may be dependent upon technological suites that are not compatible with Indiana's. Efforts should be made at the federal level to select and support technically proven designs for mileage charging (TRB, 2005) so coordination with the federal as well as other state governments can be accomplished.

\subsection{Long-Term Strategy $(2015 \sim)$}

\section{Goal}

\section{To complete ISCURP implementation}

The long-term goal is to fully implement a new pricing scheme in about 20 years from now. The system should be gradually adapted with several implementation steps, including technical trials, pilot experimentation, full-scale but not fully functional, and full-scale as well as fully functional implementation. As the pilot experimentation launched in the first two phases should be returning feedback at this point, the infrastructure of a technically proven system could be expanded statewide, but deployment to users will need a longer time frame for full implementation.

\section{Possible Actions}

\section{$\underline{\text { Statewide Implementation of ISCURP }}$}

The pilot study discussed in Section 6.2 having been completed, the statewide implementation should follow.

Phase 3: In this phase, newly registered vehicles can be mandated or recommended to install equipment with appropriate incentive. For example, financial support can be provided in the purchase of on-board equipment. It should be noted that certain technology options for retrofitting vehicles, such as GPS, are currently expensive (Whitty et al., 2006). Thus, retrofitting vehicles should be carried out over a long time frame.

Phase 4: This phase will require all vehicles in the state to be equipped with relevant onboard units and to pay user fees based on ISCURP, replacing the fuel tax. 


\section{Required Information Base}

After phase 3 is completed, a mid-term evaluation of the ISCURP pilot study should be performed. A change in pricing scheme influences various stakeholders, and thus, dealing with their conflicting interests is the key to success. Therefore, an organized effort should be made to allocate sufficient resources to surveys, data collection, and research in order to observe any problems that may occur with actual implementation. Also, possible conflicts will be identified and resolved through the participation and observation of stakeholder groups, ensuring transparency of the system to the public.

Ironically, a perfectly responsive pricing structure, which dynamically updates unit rates synchronized with the marginal cost, may lose its virtue as a pricing signal. For instance, if the system has only two-fold rates, one for peak hour, the other for non-peak, then the market works very straightforwardly. Those who have lower willingness to pay than the peak price will shift their travel to some other time. Or going a little further, the rate plan can distinguish three time slots: non-peak, peripheral peak, and peak. With this pricing scheme, users' responses to prices will also have three layers: peak to periphery, peak to non-peak, and periphery to non-peak. In an extreme case where the price fluctuates, (e.g., every five minutes) however, users would hardly be able to decide when to travel. Consequently, instead of reasonably adapting their choice of travel to the prices, the users will be confused. Therefore, a fully dynamic and responsive pricing system may not serve the purpose and therefore should be modified in the actual implementation. A study of the users' responsiveness to pricing signals and design of a pricing structure addressing this should be undertaken.

The final outcome of a new pricing scheme can be one that allows each jurisdiction to set up its own fee rate plan and to fund its highway system solely with the fee revenue. At that stage, the state government might want to control the highway policies of local governments, not in a direct way, but rather by guiding long-term statewide goals. This situation resembles the discussion on the relationship between the federal and state governments in Section 3.7. As the federal government reassigns its responsibilities for this new era, guidelines for establishing a new relationship between state government and its localities should be established. 


\section{CHAPTER 7. SUMMARY AND CONCLUSIONS}

The current and projected highway deficits at the state level can be solved by adopting several financial mechanisms. This study suggests three alternatives: adjusting the current tax system; maintaining the current fuel tax system supplemented by other forms of user fees; and replacing the current fuel tax system with a new usage-based pricing scheme (ISCURP).

Pricing and financing strategies have enormous impacts not only on financial effectiveness but also on the efficiency and equity of the highway system. Considering the breadth and depth of the problem and reviewing preceding studies, this study proposed an evaluation framework for alternatives. The major criteria include the adequacy of revenue sources, the impacts on system efficiency and equity, the cost of implementation, public acceptability, and compatibility with federal policy.

Possible alternatives were evaluated and compared based on the framework. The most innovative approach, to replace the current fuel tax system, appears to have the best potential in achieving revenue adequacy, system efficiency, and equity. On the other hand, the implementation of this alternative could be cost-prohibitive as well as could face strong opposition from the public at this time. Experience has shown, however, that implementation costs likely will decline as the necessary technologies mature in the market and public attitude changes over time. The long-term federal goals align very well with the alternative of a comprehensive pricing scheme.

This study suggests, as a possible option, stepwise adaptation of a new system, targeting a long-term goal of having a usage-based comprehensive road pricing. Hypothesizing that the entire process of system overhaul would require 20 years, the time frame should consist of short, medium, and long-term goals. In the short-term, funding tools that require negligible cost to plan and launch should be implemented, including an increase of and inflation-indexing of the fuel tax system, indexing of the vehicle registration fee system, along with other minor tax adjustments where possible. In the medium-term, a pilot study for ISCURP could be completed. In both the 
short and medium-term periods, there needs to be a strategy constructed to inform and educate the public as the new system is gradually ushered in.

In the long-term, a structure needs to be designed whereby highway agencies can estimate reliably preservation and maintenance costs by facility type and user classification. It also should be technologically possible to charge users fees/taxes distinctively. To implement such a system, data acquisition and analysis modules are needed that interactively calibrate system costs and assist in setting relevant prices for each group of users. 


\section{LIST OF REFERENCES}

AASHTO (2002), Transportation - Invest in America: The Bottom Line, Washington, D.C.

Adams, Matthew, Rachel Hiatt, Mary C. Hill, Ryan Russo, Martin Wachs and Asha Weinstein (2001), Financing Transportation in California: Strategies for Change, Institute of Transportation Studies, University of California at Berkeley, UCB-ITS-RR-2001-2

Arnott, Richard and Marvin Kraus (1995), "Self-Financing of Congestible Facilities in a Growing Economy", Boston College Working Papers in Economics 304, Boston College Department of Economics

Balmer, Ueli (2004), The Window of Opportunity: "How the obstacles to the introduction of the Swiss heavy goods vehicle fee (HVF) have been overcome", International Conference on Managing Transport Demand through User Charges - Experience to Date, London

Bureau of Transportation Statistics (BTS) (2005a), Pocket Guide to Transportation 2005, U.S. Department of Transportation, Washington D.C.

Bureau of Transportation Statistics (BTS) (2005b), Survey of State Funding for Public Transportation 2004, U.S. Department of Transportation, Washington, D.C., Retrieved from: http://downloads.transportation.org/scopt-funding_survey.pdf

Burris, Mark and Justice Appiah (2003), An Examination of Houston's QuickRide Participants by Frequency of QuickRide Usage, Technical Report 2, IAC Contract No. 12-2XXIA004, Texas Transportation Institute

Dill, Jennifer and Asha Weinstein (2007), "How to Pay for Transportation? A Survey of Public

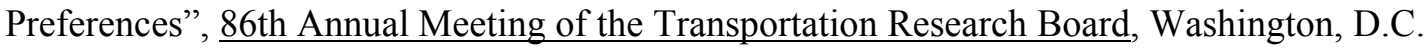


Energy Information Administration (EIA) (2007), Annual Energy Outlook 2007 - with Projections to 2030, DOE/EIA-0383, U.S. Department of Energy, Washington D.C.

ENO Transportation Foundation (2002), The Role of Fast and Intertwined Regular (FAIR) Lanes in the New York Metropolitan Region, http://www.fhwa.dot.gov/policy/otps/fairlanes.htm

Farrell, Seona and Wafaa Saleh (2005), "Road-user charging and the modeling of revenue allocation", Transport Policy, Vol.12, pp.431-442

FHWA (1997), 1997 Federal Highway Cost Allocation Study, USDOT, retrieved from www.fhwa.dot.gov/policy/hcas/summary/index.htm

FHWA (2000a), Addendum to the 1997 Federal Highway Cost Allocation Study - Final Report, USDOT, retrieved from http://www.fhwa.dot.gov/policy/hcas/addendum.htm

FHWA (2000b), Documentation for Using the State HCAS Tool, Federal Highway Administration, Office of Transportation Policy Studies

FHWA (2000c), Guidelines for Conducting A State Highway Cost Allocation Study Using the State HCAS Tool, Office of Transportation Policy Studies

FHWA (2002), 2002 Status of the Nation's Highways, Bridges, and Transit: Conditions \& Performance, Washington D.C.

FHWA (2003), A Guide for HOT Lane Development, FHWA-OP-03-009, Washington D.C.

FHWA (2004a), Measuring Travel Time in Freight-Significant Corridors, retrieved from HTTP://OPS.FHWA.DOT.GOV/FREIGHT/TIME.HTM

FHWA (2004b), Value Pricing Project Quarterly Reports: October - December 2004, retrieved from http://www.fhwa.dot.gov/policy/otps/valuepricing.htm

FHWA (2005a), Safe, Accountable, Flexible, Efficient Transportation Equity Act: A Legacy for Users - A Summary of Highway Provisions, Office of Legislation and Intergovernmental Affairs, Program Analysis Team, August 25, 2005 
FHWA (2005b), Value Pricing Project Quarterly Reports: July - September 2005, retrieved from http://www.fhwa.dot.gov/policy/otps/valuepricing.htm

FHWA (2007), Value Pricing Project Quarterly Reports: April - June 2007, retrieved from http://www.fhwa.dot.gov/policy/otps/valuepricing.htm

Forkenbrock, D. and G. E. Weisbrod, (2001), Guidebook for Assessing the Social and Economic Effects of Transportation Projects, NCHRP Report 456, Transportation Research Board-National Research Council

Fwa, T.F. and K.C. Sinha (1987a), "Estimation of Environmental and Traffic Loading Effects on Highway Pavements", Australian Road Research, Vol. 17, No. 4, pp. 256-264

Fwa T.F. and K.C. Sinha (1987b), "Validity of Weight Distance Concept as a Basis for Highway Taxation”, Transportation Research Part A, Vol.21, No. 6, pp.451-548

Goldman, Todd, Sam Corbett and Martin Wachs (2001), Local Option Transportation Taxes in the United States, Institute of Transportation Studies, University of California, at Berkeley, UCBITS-RR-2001-3

Gomes, Paulo, João Canário, Paulo André, Rob Postema, and Harvey Appelbe (2004), “ARMAS Phase II - Active Road Management Assisted By Satellite", Presented in NAVITEC 2004, Netherlands

Goodwin, Phil B. (1989), The Rule of Three: a Possible Solution to the Political Problem of Competing Objectives for Road Pricing, Traffic Engineering and Control, Vol. 30, No. 10, pp. 495-497

Goodwin, Phil B., Joyce Dargay and Mark Hanly (2004), "Elasticities of Road Traffic and Fuel Consumption with Respect to Price and Income: A Review," Transport Reviews, Vol. 24, No. 3, $275-292$

Haltum, David Van and Mariia Zimmerman (1996), Buying Time: A Guidebook for Those Considering Congestion Relief Tolls in Their Communities, Hubert H. Humphrey Institute of Public Affairs, University of Minnesota, Minneapolis 
Hamideh, Ashad, Jung Eun Oh, Samuel Labi, and Fred Mannering (2006), “An Econometric Analysis of Post-Election Opinion Surveys: Understanding Public Acceptance of Local

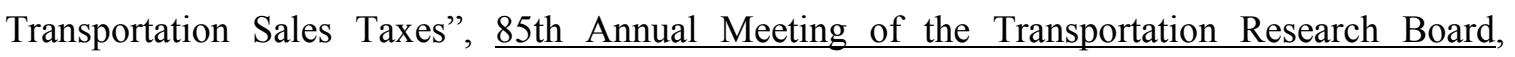
Washington, D.C.

Harvey, Greg and Elizabeth Deakin (1998), Technical Methods for Analyzing Pricing Measures to Reduce Transportation Emissions, EPA Report 231-R-98-006

Indiana Department of Transportation (2005), INDOT Business Plan 2006-2007. Mitchell E. Daniels Jr. and Thomas O Sharp, September 2005.

Indiana Legislative Services Agency and Office of Fiscal and Management Analysis (ILSA \& OFMA) (2005), Indiana Handbook of Taxes, Revenues, and Appropriations, Fiscal Year 2005

Kim, David S., David Porter, and Robin Wurl (2002), Technology Evaluation for Implementation of VMT Based Revenue Collection Systems - Final Report, the Oregon Department of Transportation, Road User Fee Task Force

Kockelman, Kara M. and Sukumar Kalmanje (2005), "Credit-based congestion pricing: a policy proposal and the public's response", Transportation Research Part A, Vol. 39, pp. 671-690

Kockelman, Kara M., Kaethe V. Podgorski, Michelle Bina, and Shashank Gadda (2006), "Public Perceptions of Pricing Existing Roads and Other Transportation Policies: The Texas Perspective", 85th Annual Meeting of the Transportation Research Board. Washington, DC.

Lawrence, Gary C. (2006), A Two-Phase Study of Attitudes of Washington State Voters toward Transportation Issues, Lawrence Research, Prepared for Washington State Transportation Commission.

Lindsey, Robin (2006), “Do Economist Reach a Conclusion on Road Pricing?”, Econ Journal Watch, Volume 3, Issue 2, pp. 292-379

Litman, Todd (2005), London Congestion Pricing - Implications for Other Cities, Victoria Transport Policy Institute, Victoria, Canada 
Macquarie Infrastructure Group (MIG) (2007), Macquarie Infrastructure Group Homepage, http://www.macquarie.com.au/au/mig/asset_portfolio.htm

Martin, Tim C. (2002), "Estimating Heavy Vehicle Road Wear Costs for Bituminous-Surfaced Arterial Roads", Journal of Transportation Engineering, Vol. 128, No. 2, March/April 2002, pp.103-110

Matas, Anna and Jose-Luis Raymond (2003), "Demand Elasticity on Tolled Motorways," Journal of Transportation and Statistics, Vol. 6, No. 2/3, 2003

Metschies, Gerhard P. (2005), International Fuel Prices 2005, 4th Edition - 172 Countries, Federal Ministry for Economic Cooperation and Development, Germany

Minnesota Department of Transportation (MnDOT) (2006), Mileage Based User Fee Demonstration Project: Market Assessment Survey Results, MN/RC - 2006-39B, Cambridge Systematics, Inc.

Mohring, Herbert and Mitchell Harwitz (1962), Highway Benefits - An Analysis Framework, Northwestern University Press, Evanston, Illinois

National Cooperative Highway Research Program (NCHRP) (2006), Future Financing Options to Meet Highway and Transit Needs, NCHRP Project 20-24 (49), Transportation Research Board, Washington D.C.

National Chamber Foundation (NCF) of the U.S. Chamber of Commerce (2005), Future Highway and Public Transportation Financing - Study Release Event, Washington D.C.

Oh, Jung Eun, Samuel Labi, and Kumares C. Sinha (2007), "Implementation and Evaluation of Self-Financing Highway Pricing Schemes - A Case Study", $\underline{\text { 86th Annual Meeting of }}$ Transportation Research Board, Washington D.C.

Orange County Transportation Authority (OCTA) (2004), Success in the Fast Lanes - Fiscal Year 2004 Annual Report for 91 Express lanes, retrieved from http://www.91expresslanes.com/ 
Owusu-Antwi, E.B., L. Titus-Glover, L. Khazanovich, and J.R. Roessler (1997), Development and Calibration of Mechanistic-Empirical Distress Models for Cost Allocation - Final Report, Washington D.C., Federal Highway Administration

Poole Jr., Robert W. (2005), “Orange County's 91 Express Lanes: A Transportation and Financial Success, Despite Political Problems”, Policy Brief, 39, Reason Foundation

Pratt, Michael D. and George E. Hoffer (1985), "The Responsiveness of Heavy Vehicle Registrations to Interstate Tax Differentials", Atlantic Economic Journal, Vol.13, Issue 3, pp. 9596

PRoGRESS (2003), WP3—Final Demonstration Implementation Report (Version 1.2). PRoGRESS Project 2000-CM.10390, Competitive and Sustainable Growth Programme

PRoGRESS (2004b), Main Project Report - Final Report, PRoGRESS Project 2000-CM.10390, Competitive and Sustainable Growth Programme

PRoGRESS (2004a), WP6-Recommendations and Exploitation Practical Implementation Guide for Cities (Version 1.0). PRoGRESS Project 2000-CM.10390, Competitive and Sustainable Growth Programme

Raux, Charles and Stéphanie Souche (2003), An Analytic Framework of Pricing Acceptability: Application to Four Case Studies, Acceptability of Transport Pricing Strategies, edited by Jens Schade and Bernhard Schlag, Chapter 1, Elsevier, Oxford

Rennacker (2004), A Case for Congestion Pricing and Toll Indexing with the Public Response, Mineta Transportation Institute, MTI Report MTM 290-04, June 2004

Rienstra, S.A., P. Rietveld, and E.T. Verhoef (1999), “The Social Support for Policy Measures in Passenger Transport - A Statistical Analysis for the Netherlands", Transportation Research Part D, Vol.4, pp.181-200

Rosalion, N., and Martin, T. (1999), Analysis of historical data on pavement performance, ARRB Transport Research Contract Report RE7134, Australian Board Research Board, Vermont South, Victoria. 
Rothengatter, W., and C. Doll (2002), "Design of a User Charge for Heavy-Duty Vehicles on German Motorways Considering the Objectives of Efficiency, Fairness, and Environmental Protection: Findings from the European Union Research Project Desire”. IATSS Research, Vol.26, Issue 1, pp. 6-16.

Samuel, Peter (2005), "Should States Sell Their Toll Roads?" Public Policy 334, Reasons Foundation, Los Angeles, May 2005

San Diego State University Foundation (SDSU) (2001), I-15 Congestion Pricing Project Monitoring and Evaluation Services: Task 13 - Phase II Year Three Overall Report, SDSU Department of Civil and Environmental Engineering

Schade, Jens and Bernhard Schlag (2003), Acceptability of Transport Pricing Strategies: An Introduction, Acceptability of Transport Pricing Strategies, edited by Jens Schade and Bernhard Schlag, Chapter 1, Elsevier, Oxford

Schwarz-Herda, F. (2004), Design of the New Austrian Heavy Vehicle Fee. In Managing Transport Demand Through User Charges: Experience to Date. European Conference of Ministers of Transport, London, Retrieved from http://www1.oecd.org/cem/topics/env/London04.htm

Sinha, K.C., S. Labi, S. Hodge, G. Tine, and H. Shah (2005), An Assessment of Highway Financing Needs in Indiana, Technical Report FHWA/IN/JTRP/2005-09, West Lafayette, IN

Sinha, K.C., S. Saha, T.F. Fwa, A. Tee, and H.L. Michael (1989), 1988 Update of the Indiana Highway Cost Allocation Study, Joint Highway Research Project, FHWA/IN/JHRP-89-4

Sinha, K.C., T.F. Fwa, E.C. Ting, R.M. Shanteau, M. Saito, and H.L. Michael (1984), Indiana Highway Cost-Allocation Study: A Report on Methodology, Joint Highway Research Project, FHWA/IN/JHRP-84-4

Skyway Concession Company, LLC (SCC) (2005), Chicago Skyway Homepage, http://www.chicagoskyway.org/

Small, Kenneth A. (1992), Urban Transportation Economics, Routledge 
Sorensen, Paul A. and Brian D. Taylor (2005), Review and Synthesis of Road-Use Metering and Charging Systems, TRB, Washington D.C.

South Carolina Department of Transportation (SCDOT) (2003), Transportation Funding Options for the State of South Carolina 2003-2022, Transportation Funding Series Special Report No. 3, FHWA-SC-03-05, Jim Self Center on the Future

TRB (Transportation Research Board) (2005), Special Report 285: The Fuel Tax and Alternatives for Transportation Funding, Committee for the Study of the Long-Term Viability of Fuel Taxes for Transportation Finance, Washington D.C.

Verhoef, Erik T. and Jan Rouwendal (2004), "Pricing, Capacity Choice, and Financing in Transportation Networks", Journal of Regional Science, V44, pp.405-435

Vickrey, William (1994), Public Economics - Selected Papers by William Vickrey, Edited by Richard Arnott, Anthony B. Atkinson, Kenneth Arrow, and Jacques H. Drèze, Cambridge University Press

VTPI (Victoria Transport Policy Institute) (2005a), Evaluating Pricing Strategies - Factors to Consider When Evaluating TDM Strategies that Change Transportation Prices, TDM Encyclopedia, http://www.vtpi.org/tdm/tdm70.htm (Updated May 9, 2005)

VTPI (Victoria Transport Policy Institute) (2005b), Fuel Taxes - Increasing Fuel Taxes and Fees, TDM Encyclopedia, http://www.vtpi.org/tdm/tdm17.htm (Updated December 14, 2005)

VTPI (Victoria Transport Policy Institute) (2005c), Road Pricing - Congestion Pricing, Value Pricing, Toll Roads and HOT Lanes, TDM Encyclopedia, http://www.vtpi.org/tdm/tdm35.htm (Updated December 14, 2005)

VTPI (Victoria Transport Policy Institute) (2005d), Transportation Cost and Benefit Analysis Roadway Costs, TDM Encyclopedia, http://www.vtpi.org/tca/tca0506.htm (Updated October 31, 2005)

Wachs, Martin (2003), A Dozen Reasons for Raising Gasoline Taxes, Research Report, UCBITS-RR-2003-1, ISSN 0192-4095 
Werder, H. (2004), Impact of the Heavy Vehicle Fee: Central Pillar of the Swiss Transport Policy. In Managing Transport Demand through User Charges: Experience to Date. European Conference of Ministers of Transport, London, January 23, 2004.

Whitty, James (2003), Road User Fee Task Force: Report to the 72nd Oregon Legislative Assembly on the Possible Alternatives to the Current System of Taxing Highway Use Through Motor Vehicle Fuels Taxes, Oregon Department of Transportation

Whitty, James, Jack Svadlenak, and Darel Capps (2006), Public Involvement and Road User Charge Development: Oregon's Experience, Oregon Department of Transportation

Yang, Hai and Qiang Meng (2000), "Highway Pricing and Capacity Choice in a Road Network under a Build-Operate-Transfer Scheme”, Transportation Research Part A, V34, pp.207-222

Yang, Hai and Qiang Meng (2002), “A Note on "Highway Pricing and Capacity Choice in a Road Network under a Build-Operate-Transfer Scheme" ", Transportation Research Part A, V36, pp.659-663 
Appendix A. Forecasting Toll Revenue on a Typical Interstate in Indiana

Revenues from the tolls on an interstate corridor were forecasted using Indiana Statewide Travel Demand Model (ISTDM), the TransCAD based macroscopic transportation simulation. The model includes over 20,000 links (11,200 miles) of state highways within the state border. Also the model network connects 4,720 internal traffic analysis zones via 9,900 centroid connectors.

Tolls on road segments can be incorporated within the model network by modifying the link-by-link database. In particular, cent-per-mile rates can be established by entering values in the link attribute, "toll road". One drawback of the methodology is that, within the structure of ISTDM database, a particular link can be assigned only by a single value of toll rate. In other words, toll schedule with different rates by vehicle type cannot be directly modeled using ISTDM.

In this regard, this study conducted indirect analysis on toll revenue based on demand elasticity with respect to tolls. In order to obtain demand elasticity values of the users on a typical interstate (the characteristics of typical interstates are given in Section 4.2.1), the model was run for several toll rate scenarios, varied from no toll to 5 cents-per-mile rate for all links of an interstate. Toll scenarios were run with two assumptions on the monetary value of travel time: one is the default value of ISTDM (version 4.0), \$16.44 per hour; and the other value, \$23.03 per hour, was obtained by getting VMT weighted average of the values from Frokenbrock and Weisbrod (2001), converted to 2006 dollars. The calculation procedure is presented in Table A.1.

Table A.1 Average Travel Time Value Calculation

\begin{tabular}{|c|c|c|c|c|c|c|c|c|}
\hline & Small auto & $\begin{array}{l}\text { Medium } \\
\text { auto }\end{array}$ & 4-tire truck & 6-tire truck & $\begin{array}{c}\text { 3- or 4- } \\
\text { axle truck }\end{array}$ & \begin{tabular}{|c|}
$\begin{array}{c}4 \text {-axle } \\
\text { comb truck }\end{array}$ \\
\end{tabular} & $\begin{array}{c}\text { 5-axle } \\
\text { comb truck }\end{array}$ & Total \\
\hline $\begin{array}{l}\text { A. On-the-clock } \\
\text { (25\% of total demand) }\end{array}$ & $\$ 34.33$ & $\$ 34.70$ & $\$ 24.77$ & $\$ 30.61$ & $\$ 33.13$ & $\$ 36.02$ & $\$ 36.70$ & \\
\hline $\begin{array}{l}\text { B. Off-the-clock } \\
\text { ( } 75 \% \text { of total demand) }\end{array}$ & $\$ 17.54$ & $\$ 17.58$ & $\$ 18.50$ & $\$ 30.61$ & $\$ 33.14$ & $\$ 38.04$ & $\$ 38.73$ & \\
\hline C. $0.25 \mathrm{~A}+0.75 \mathrm{~B}$ & $\$ 21.74$ & $\$ 21.86$ & $\$ 20.07$ & $\$ 30.61$ & $\$ 33.14$ & $\$ 37.54$ & $\$ 38.22$ & \\
\hline $\begin{array}{l}\text { D. Annual VMT } \\
\text { (in thousand) }\end{array}$ & \multicolumn{2}{|c|}{29,036} & 13,147 & 2,747 & 1,037 & 1,562 & 1,475 & 49,004 \\
\hline E. $C \times D$ & \multicolumn{2}{|c|}{$\$ 631.17$} & $\$ 263.82$ & $\$ 84.08$ & $\$ 34.37$ & $\$ 58.64$ & $\$ 56.38$ & $\$ 1,128.47$ \\
\hline F. Average Value & \multicolumn{8}{|c|}{$\$ 1,128,470 / 49,004=\$ 23.03$} \\
\hline
\end{tabular}

Source: Frokenbrock and Weisbrod (2001), converted into 2006 dollar 
Results of toll impact analyses are presented in Tables A.2 and A.3, in terms of annual VMT and toll revenue, respectively. Introducing tolls and increasing toll rates would result in decrease in annual VMT. Since the demand is inelastic, however, the revenue generated would increase. Furthermore, it is observed from the results that, as the higher the travel time value, the demand is more inelastic, since the same amount of toll would be equivalent to less amount of generalized travel cost. These relationships are revealed in Figures A.1 and A.2.

Table A.2 Toll Impact on Demand (annual VMT in 1000) by Vehicle Type and Travel Time Value

\begin{tabular}{|l|r|r|r|r|r|r|}
\hline \multicolumn{1}{|c|}{ Toll Rate ( $\phi /$ mile) } & \multicolumn{1}{|c|}{0} & 1 & 2 & 3 & 4 & 5 \\
\hline Travel Time Value: $\$ 16.44 / \mathrm{hr}$ \\
\hline Auto & 1,606 & 1,468 & 1,346 & 1,214 & 1,085 & 973 \\
Single Unit Truck & 266 & 260 & 253 & 241 & 228 & 218 \\
Combination Truck & 211 & 197 & 179 & 166 & 136 & 103 \\
\hline Total & 2,083 & 1,925 & 1,778 & 1,621 & 1,448 & 1,249 \\
\hline Travel Time Value: \$23.03/hr \\
\hline Auto & 1,606 & 1,502 & 1,411 & 1,324 & 1,231 & 1,148 \\
Single Unit Truck & 266 & 261 & 257 & 251 & 243 & 235 \\
Combination Truck & 211 & 199 & 191 & 177 & 168 & 158 \\
\hline Total & 2,083 & 1,963 & 1,859 & 1,752 & 1,642 & 1,541 \\
\hline
\end{tabular}

Table A.3 Toll Impact on Annual Revenue (in \$1000) by Vehicle Type and Travel Time Value

\begin{tabular}{|l|r|r|r|r|r|r|}
\hline \multicolumn{1}{|c|}{ Toll Rate ( $\varnothing /$ mile) } & 0 & 1 & 2 & 3 & 4 & 5 \\
\hline Travel Time Value: \$16.44/hr| \\
\hline Auto & 0 & 14,680 & 26,916 & 36,424 & 43,390 & 48,667 \\
Single Unit Truck & 0 & 2,600 & 5,060 & 7,240 & 9,109 & 10,882 \\
Combination Truck & 0 & 1,966 & 3,580 & 4,980 & 5,421 & 5,160 \\
\hline Total & 0 & 19,246 & 35,556 & 48,644 & 57,921 & 62,436 \\
\hline Travel Time Value: \$23.03/hr \\
\hline Auto
\end{tabular}




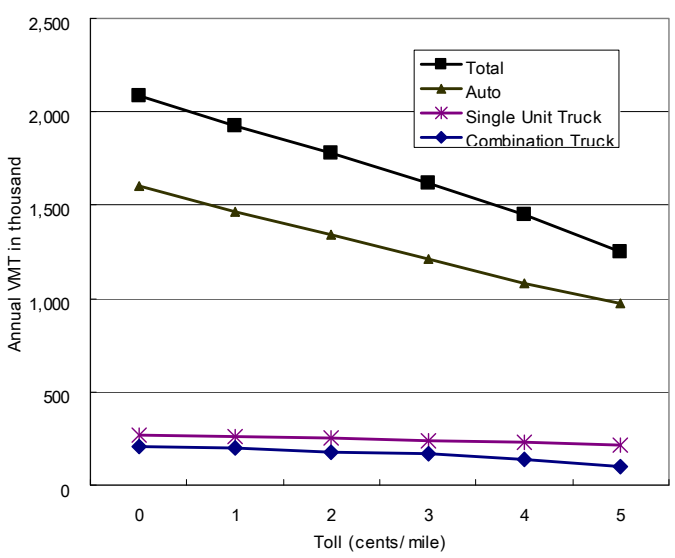

(a) Travel Time Value $=\$ 16.44 / \mathrm{hr}$

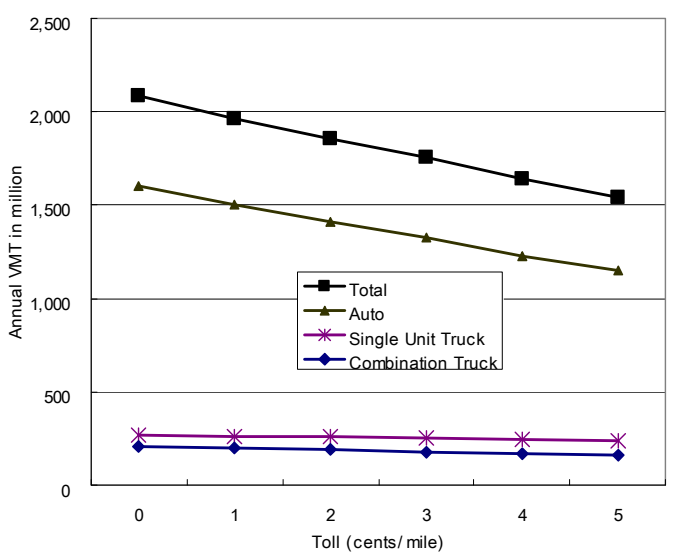

(b) Travel Time Value $=\$ 23.03 / \mathrm{hr}$

Figure A.1 Toll Impact on Demand (VMT) by Vehicle Type and Travel Time Value

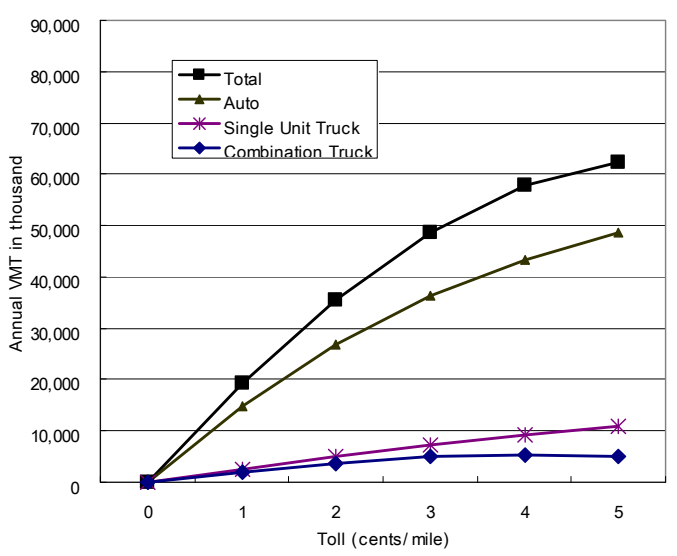

(a) Travel Time Value $=\$ 16.44 / \mathrm{hr}$

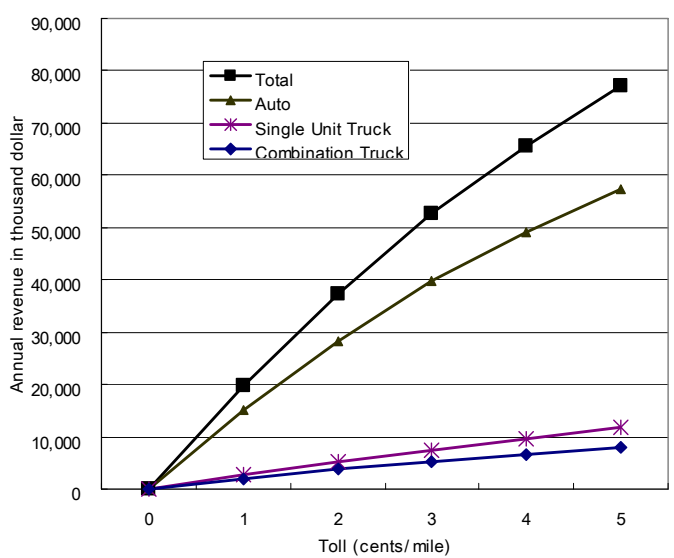

(b) Travel Time Value $=\$ 23.03 / \mathrm{hr}$

Figure A.2 Toll Impact on Revenue by Vehicle Type and Travel Time Value

As a next step, arc elasticities of demand and revenue with respect to tolls were assessed using the following equations.

$$
\begin{gathered}
e_{\text {demand }}=\frac{\left(V M T_{\text {affer }}-V M T_{\text {before }}\right)}{\left(\text { toll }_{\text {affer }}-\text { toll }_{\text {before }}\right)} \cdot \frac{\left(\text { toll }_{\text {affer }}+\text { toll }_{\text {before }}\right)}{\left(V M T_{\text {affer }}+V M T_{\text {before }}\right)} \\
e_{\text {revenue }}=\frac{\left(\text { revenue }_{\text {affer }}-\text { revenue }_{\text {before }}\right)}{\left(\text { toll }_{\text {affer }}-\text { toll }_{\text {before }}\right)} \cdot \frac{\left(\text { toll }_{\text {affer }}+\text { toll }_{\text {before }}\right)}{\left(\text { revenue }_{\text {affer }}+\text { revenue }_{\text {before }}\right)}
\end{gathered}
$$


Based on the simulation results above, arc elasticity values were calculated for the changes in toll rates as shown in Tables A.4 and A.5. For example, demand elasticities for the toll change from 3 to 5 cents per mile are $-0.44,-0.21$, and -0.93 for automobiles, single unit truck, and combination truck, respectively, when travel time is assumed to be $\$ 16.44$ per hour. Overall, demand is inelastic, that is, the absolute values of demand elasticity are less than 1, and therefore, as the toll rate increases, the revenue also increases. It is noted that the demand becomes more elastic at higher toll rates, in a sense that the absolute values increase, as graphically depicted in Figures A.3. Due to this trend, revenue elasticity decreases as the toll rate increases, as Figure A.4 shows.

Table A.4 Arc Elasticity of Demand with Respect to Toll Rate

\begin{tabular}{|l|l|l|l|l|l|l|l|l|l|l|l|l|l|l|l|l|l|}
\hline Toll Change $(\notin / \mathrm{mile})$ & $0 \sim 1$ & $1 \sim 2$ & $2 \sim 3$ & $3 \sim 4$ & $4 \sim 5$ & $0 \sim 2$ & $1 \sim 3$ & $2 \sim 4$ & $3 \sim 5$ & $0 \sim 3$ & $1 \sim 4$ & $2 \sim 5$ & $0 \sim 4$ & $1 \sim 5$ & $0 \sim 5$ \\
\hline Travel Time Value: $\$ 16.44 / \mathrm{hr}$ \\
\hline Auto & -0.04 & -0.13 & -0.26 & -0.39 & -0.49 & -0.09 & -0.19 & -0.32 & -0.44 & -0.14 & -0.25 & -0.37 & -0.19 & -0.30 & -0.25 \\
Single Unit Truck & -0.01 & -0.04 & -0.12 & -0.20 & -0.20 & -0.03 & -0.08 & -0.16 & -0.21 & -0.05 & -0.11 & -0.18 & -0.05 & -0.11 & -0.10 \\
Combination Truck & -0.03 & -0.14 & -0.19 & -0.71 & -1.22 & -0.08 & -0.17 & -0.41 & -0.93 & -0.12 & -0.31 & -0.63 & -0.12 & -0.31 & -0.34 \\
\hline Total & -0.04 & -0.12 & -0.23 & -0.40 & -0.67 & -0.08 & -0.17 & -0.31 & -0.52 & -0.12 & -0.24 & -0.41 & -0.18 & -0.32 & -0.25 \\
\hline Travel Time Value: $\$ 23.03 / \mathrm{hr}$ \\
\hline Auto & -0.03 & -0.09 & -0.16 & -0.26 & -0.31 & -0.06 & -0.13 & -0.21 & -0.29 & -0.10 & -0.17 & -0.24 & -0.13 & -0.20 & -0.17 \\
Single Unit Truck & -0.01 & -0.02 & -0.06 & -0.12 & -0.15 & -0.02 & -0.04 & -0.09 & -0.13 & -0.03 & -0.06 & -0.10 & -0.03 & -0.06 & -0.06 \\
Combination Truck & -0.03 & -0.06 & -0.19 & -0.19 & -0.26 & -0.05 & -0.12 & -0.20 & -0.22 & -0.09 & -0.14 & -0.22 & -0.09 & -0.14 & -0.14 \\
\hline Total & -0.03 & -0.08 & -0.15 & -0.23 & -0.28 & -0.06 & -0.11 & -0.19 & -0.26 & -0.09 & -0.15 & -0.22 & -0.12 & -0.18 & -0.15 \\
\hline
\end{tabular}

Table A.5 Arc Elasticity of Revenue with Respect to Toll Rate

\begin{tabular}{|l|l|l|l|l|l|l|l|l|l|l|l|l|l|l|l|l|l|}
\hline Toll Change $(\phi / m i l e)$ & $0 \sim 1$ & $1 \sim 2$ & $2 \sim 3$ & $3 \sim 4$ & $4 \sim 5$ & $0 \sim 2$ & $1 \sim 3$ & $2 \sim 4$ & $3 \sim 5$ & $0 \sim 3$ & $1 \sim 4$ & $2 \sim 5$ & $0 \sim 4$ & $1 \sim 5$ & $0 \sim 5$ \\
\hline Travel Time Value: $\$ 16.44 / \mathrm{hr}$ \\
\hline Auto & 1.00 & 0.88 & 0.75 & 0.61 & 0.52 & 1.00 & 0.85 & 0.70 & 0.58 & 1.00 & 0.82 & 0.67 & 1.00 & 0.80 & 1.00 \\
Single Unit Truck & 1.00 & 0.96 & 0.89 & 0.80 & 0.80 & 1.00 & 0.94 & 0.86 & 0.80 & 1.00 & 0.93 & 0.85 & 1.00 & 0.93 & 1.00 \\
Combination Truck & 1.00 & 0.87 & 0.82 & 0.30 & -0.22 & 1.00 & 0.87 & 0.61 & 0.07 & 1.00 & 0.78 & 0.42 & 1.00 & 0.78 & 1.00 \\
\hline Total & 1.00 & 0.89 & 0.78 & 0.61 & 0.34 & 1.00 & 0.87 & 0.72 & 0.50 & 1.00 & 0.84 & 0.64 & 1.00 & 0.79 & 1.00 \\
\hline Travel Time Value: $\$ 23.03 / \mathrm{hr}$ \\
\hline Auto & 1.00 & 0.92 & 0.85 & 0.75 & 0.69 & 1.00 & 0.90 & 0.81 & 0.73 & 1.00 & 0.89 & 0.79 & 1.00 & 0.88 & 1.00 \\
Single Unit Truck & 1.00 & 0.98 & 0.94 & 0.88 & 0.85 & 1.00 & 0.97 & 0.92 & 0.87 & 1.00 & 0.96 & 0.91 & 1.00 & 0.96 & 1.00 \\
Combination Truck & 1.00 & 0.95 & 0.81 & 0.82 & 0.74 & 1.00 & 0.91 & 0.82 & 0.79 & 1.00 & 0.90 & 0.81 & 1.00 & 0.90 & 1.00 \\
\hline Total & 1.00 & 0.93 & 0.86 & 0.77 & 0.72 & 1.00 & 0.91 & 0.83 & 0.76 & 1.00 & 0.90 & 0.81 & 1.00 & 0.89 & 1.00 \\
\hline
\end{tabular}




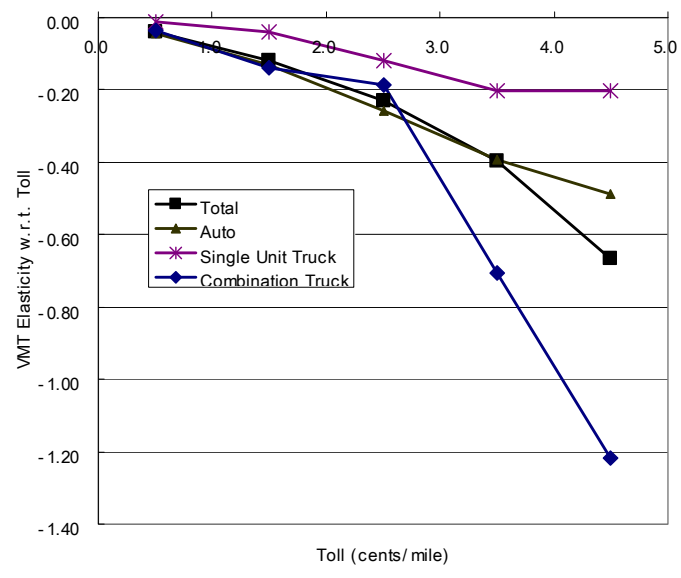

(a) Travel Time Value $=\$ 16.44 / \mathrm{hr}$

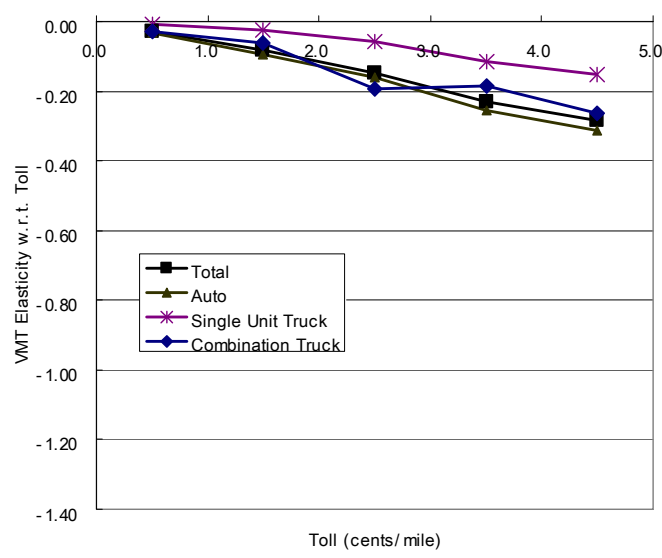

(b) Travel Time Value $=\$ 23.03 / \mathrm{hr}$

Figure A.3 Arc Elasticity of Demand with Respect to Toll Rate

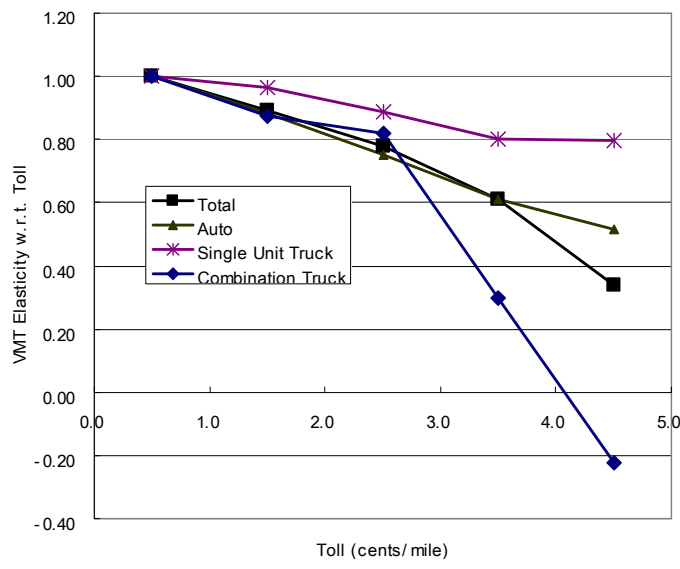

(a) Travel Time Value $=\$ 16.44 / \mathrm{hr}$

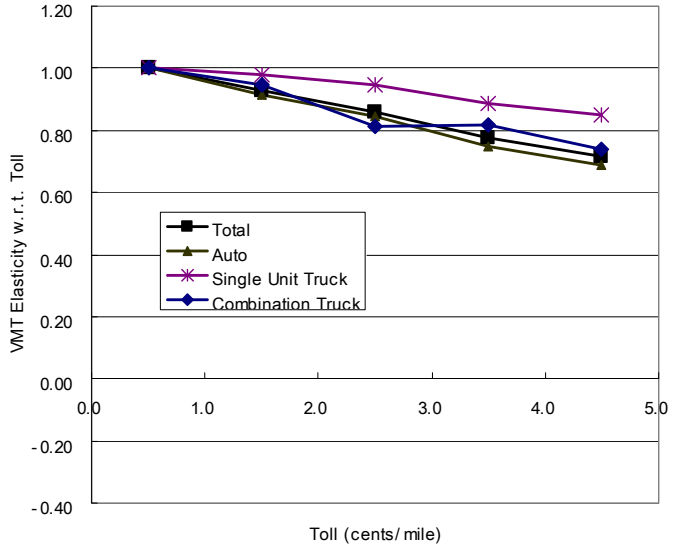

(b) Travel Time Value $=\$ 23.03 / \mathrm{hr}$

Figure A.4 Arc Elasticity of Revenue with Respect to Toll Rate

As mentioned above, results obtained directly from the ISTDM simulation are only for the scenarios where the same per mile tolls are imposed regardless of vehicle types. More practical toll schedules were established as in Table A.7, comparably to the current toll rates of the Indiana Toll Road, which are listed in Table A.6. 
Table A.6 Toll Rates of Indiana Toll Road by Vehicle Type (2007)

\begin{tabular}{|c|c|c|c|c|c|c|}
\hline Number of Axles & 2 & 3 & 4 & 5 & 6 & 7 \\
\hline cents/mile & 2.97 & 6.37 & 11.15 & 14.34 & 16.89 & 31.39 \\
\hline
\end{tabular}

Table A.7 Established Toll Rate Scenarios

\begin{tabular}{|c|ccc||c|ccc|}
\hline \multirow{2}{*}{ Scenarios } & \multicolumn{3}{|c||}{ Toll Rates $(\phi /$ mile $)$} & \multirow{3}{*}{ Scenarios } & \multicolumn{3}{c|}{ Toll Rates $(\phi / \mathrm{mile})$} \\
\cline { 2 - 4 } \cline { 6 - 8 } & Auto & SUT & CT & & Auto & SUT & CT \\
\hline 1 & 2 & 7 & 14 & 4 & 3.5 & 8.5 & 17 \\
2 & 2.5 & 7.5 & 15 & 5 & 3.5 & 9 & 18 \\
3 & 3 & 8 & 16 & 6 & 4 & 10 & 20 \\
\hline
\end{tabular}

* SUT: Single Unit Trucks; CT: Combination Trucks

In order to analyze toll impacts on demand and revenue under various toll structures, the elasticity values calculated above were referred to. Since the toll rates on automobiles of the established scenarios ( 2 through 4 cents per mile) are within the range of ISTDM scenarios (0 through 5 cents per mile), VMT's and revenues of automobiles are obtained directly referring to the results from the ISTDM simulation runs. On the other hand, for estimation of truck demands, with trucks toll rates higher than 5 cents per mile in every scenario, elasticity values with respect to various rate changes were used. Especially, elasticity values that are associated with toll rate changes from 1, 2, 3, and 4 cents per mile to 5 cents per mile, respectively (i.e., the values in the shaded columns of Tables A.4 and A.5), were used in the analysis.

On the basis of maximum and minimum possible elasticity values by vehicle type, the minimum and maximum values for VMT and revenue under each scenario were calculated, as shown in Tables A.8 and A.9, respectively. 
Table A.8 The Minimum and Maximum Annual VMT by Scenario (in 000's)

\begin{tabular}{|c|c|c|c|c|c|}
\hline \multirow{2}{*}{\multicolumn{2}{|c|}{ Toll Schedule Scenarios }} & \multicolumn{2}{|c|}{ Travel Time Value $=\$ 16.44 / \mathrm{hr}$} & \multicolumn{2}{|c|}{ Travel Time Value $=\$ 23.03 / \mathrm{hr}$} \\
\hline & & \multirow{2}{*}{$\begin{array}{l}\text { Min VMT } \\
1345.79\end{array}$} & \multirow{2}{*}{$\begin{array}{l}\text { Max VMT } \\
1345.79\end{array}$} & \multirow{2}{*}{$\begin{array}{l}\text { Min VMT } \\
1345.79\end{array}$} & \multirow{2}{*}{$\begin{array}{c}\text { Max VMT } \\
1345.79\end{array}$} \\
\hline \multirow{4}{*}{1} & Auto: $2 \varnothing /$ mile & & & & \\
\hline & SUT: $7 \varnothing /$ mile & 184.94 & 222.69 & 195.97 & 229.91 \\
\hline & CT: $14 \varnothing /$ mile & 26.09 & 111.06 & 80.23 & 138.05 \\
\hline & Total & 1556.83 & 1679.54 & 1622.00 & 1713.76 \\
\hline \multirow{4}{*}{2} & Auto: $2.5 \phi / \mathrm{mile}$ & 1252.77 & 1290.34 & 1285.89 & 1308.59 \\
\hline & SUT: $7.5 \mathrm{c} / \mathrm{mile}$ & 200.37 & 225.20 & 206.29 & 235.86 \\
\hline & CT: $15 \phi /$ mile & 37.53 & 111.03 & 82.47 & 143.92 \\
\hline & Total & 1490.67 & 1626.57 & 1574.65 & 1688.37 \\
\hline \multirow{4}{*}{3} & Auto: $3 \phi /$ mile & 1214.13 & 1214.13 & 1214.13 & 1214.13 \\
\hline & SUT: $8 \notin /$ mile & 197.83 & 220.26 & 204.59 & 228.40 \\
\hline & CT: $16 \notin /$ mile & 15.04 & 108.45 & 81.59 & 136.59 \\
\hline & Total & 1427.00 & 1542.84 & 1500.31 & 1579.12 \\
\hline \multirow{4}{*}{4} & Auto: $3.5 \phi / \mathrm{mile}$ & 1126.40 & 1169.18 & 1156.82 & 1183.45 \\
\hline & SUT: $8.5 \notin / \mathrm{mile}$ & 195.51 & 219.21 & 203.04 & 227.74 \\
\hline & CT: $17 \phi /$ mile & 13.16 & 107.36 & 80.80 & 135.97 \\
\hline & Total & 1335.07 & 1495.75 & 1440.65 & 1547.17 \\
\hline \multirow{4}{*}{5} & Auto: $3.5 \phi / \mathrm{mile}$ & 1126.40 & 1169.18 & 1156.82 & 1183.45 \\
\hline & SUT: $9 \not /$ mile & 193.38 & 218.25 & 201.60 & 227.15 \\
\hline & CT: $18 \notin /$ mile & 11.49 & 143.78 & 80.07 & 151.84 \\
\hline & Total & 1331.28 & 1531.22 & 1438.50 & 1562.43 \\
\hline \multirow{4}{*}{6} & Auto: $4 \varnothing /$ mile & 1084.76 & 1084.76 & 1084.76 & 1084.76 \\
\hline & SUT: $10 \notin /$ mile & 189.60 & 208.94 & 196.85 & 216.21 \\
\hline & CT: $20 \notin / m i l e$ & 14.02 & 116.94 & 74.94 & 125.00 \\
\hline & Total & 1288.38 & 1410.65 & 1356.55 & 1425.98 \\
\hline
\end{tabular}


Table A.9 The Minimum and Maximum Annual Revenues by Scenario (in thousand dollars)

\begin{tabular}{|c|c|c|c|c|c|}
\hline \multirow{2}{*}{\multicolumn{2}{|c|}{ Toll Schedule Scenarios }} & \multicolumn{2}{|c|}{ Travel Time Value $=\$ 16.44 / \mathrm{hr}$} & \multicolumn{2}{|c|}{ Travel Time Value $=\$ 23.03 / \mathrm{hr}$} \\
\hline & & \multirow{2}{*}{$\begin{array}{c}\text { Min Revenue } \\
26,916\end{array}$} & \multirow{2}{*}{$\begin{array}{c}\text { Max Revenue } \\
26,916\end{array}$} & \multirow{2}{*}{$\begin{array}{c}\text { Min Revenue } \\
26,916\end{array}$} & Max Revenue \\
\hline \multirow{4}{*}{1} & Auto: $2 \varnothing /$ mile & & & & 26,916 \\
\hline & SUT: $7 \not /$ mile & 12,946 & 15,588 & 13,718 & 16,094 \\
\hline & CT: $14 \varnothing /$ mile & 3,653 & 15,548 & 11,232 & 19,327 \\
\hline & Total & 43,515 & 58,053 & 51,866 & 62,337 \\
\hline \multirow{4}{*}{2} & Auto: $2.5 \phi / \mathrm{mile}$ & 31,319 & 32,259 & 32,147 & 32,715 \\
\hline & SUT: $7.5 \phi / \mathrm{mile}$ & 15,028 & 16,890 & 15,471 & 17,690 \\
\hline & CT: $15 \phi /$ mile & 5,629 & 16,654 & 12,371 & 21,588 \\
\hline & Total & 51,976 & 65,803 & 59,990 & 71,992 \\
\hline \multirow{4}{*}{3} & Auto: $3 \phi /$ mile & 36,424 & 36,424 & 36,424 & 36,424 \\
\hline & SUT: $8 \notin /$ mile & 15,827 & 17,621 & 16,367 & 18,272 \\
\hline & CT: $16 \varnothing /$ mile & 2,406 & 17,352 & 13,055 & 21,855 \\
\hline & Total & 54,657 & 71,397 & 65,846 & 76,550 \\
\hline \multirow{4}{*}{4} & Auto: $3.5 \phi / \mathrm{mile}$ & 39,424 & 40,921 & 40,489 & 41,421 \\
\hline & SUT: $8.5 \mathrm{c} / \mathrm{mile}$ & 16,619 & 18,633 & 17,258 & 19,358 \\
\hline & CT: $17 \phi /$ mile & 2,237 & 18,251 & 13,735 & 23,116 \\
\hline & Total & 58,280 & 77,805 & 71,482 & 83,895 \\
\hline \multirow{4}{*}{5} & Auto: $3.5 \phi / \mathrm{mile}$ & 39,424 & 40,921 & 40,489 & 41,421 \\
\hline & SUT: $9 \phi /$ mile & 17,405 & 19,643 & 18,144 & 20,443 \\
\hline & CT: $18 \notin /$ mile & 2,068 & 25,881 & 14,413 & 27,331 \\
\hline & Total & 58,897 & 86,445 & 73,046 & 89,194 \\
\hline \multirow{4}{*}{6} & Auto: $4 \phi /$ mile & 43,390 & 43,390 & 43,390 & 43,390 \\
\hline & SUT: $10 \phi /$ mile & 18,960 & 20,894 & 19,685 & 21,621 \\
\hline & CT: $20 \notin /$ mile & 2,804 & 23,388 & 14,989 & 25,001 \\
\hline & Total & 65,155 & 87,673 & 78,064 & 90,013 \\
\hline
\end{tabular}




\section{Appendix B. Calculation of ISCURP Fee Rates Using Highway Cost Allocation Study}

In order to implement the concept of ISCURP (Section 4.3.2), a comprehensive distance-based pricing scheme, it is required to establish toll rates that vary according to vehicle type, location, and road function class. The self-financing approach introduced in Section 3.3.3 stated that a pricing scheme is optimal in terms of system efficiency when the cost can be fully recovered by the revenue. Also, a self-financing pricing scheme can be achieved for each category of highway subsystems to obtain maximum efficiency as well as modal equity.

As discussed in Section 3.4.3, highway cost allocation studies (HCAS) provide a framework that quantifies highway-related costs attributable to and user fee revenues contributed by each user group. The cost allocation analysis used in the present study adopted the State HCAS Tool developed by FHWA, supplied by Indiana-specific input parameters and modified as necessary. As results of the analysis, per-mile rates applicable for each vehicle type and each road functional class were determined. It should be noted that, however, there are several arguable assumptions associated with the classification and distribution of highway costs. In this regard, the present study performed sensitivity analysis with respect to the changes in inputs to provide ranges of fee rates, instead of using single values.

\section{Cost Items and Allocation}

According to the State HCAS Tool, highway cost items are classified as the following:

- New pavement costs: Costs for new construction, relocation, reconstruction, and widening of road segments, separately for flexible and rigid surface types

- $\quad 3 R$ costs: Costs for restoration, rehabilitation, and resurfacing, separately for flexible and rigid surface types

- Bridge-related costs: Costs for new bridge construction, replacement, and repairs

- Minimum construction costs: Costs for right-of-way, engineering, grading and drainage, etc.

- Non-load-related maintenance costs

- $\quad$ Load-related maintenance costs: Separately for flexible and rigid surface types

- Safety and enforcement related costs

Non-attributable costs include non-load-related maintenance, safety and enforcement related costs, in addition to minimum construction costs. All users getting benefit from the 
existence of the facility (directly or indirectly) are responsible for these costs, which can be allocated in terms of total vehicle-miles, axle-miles, or passenger-car equivalencies, depending on the source of these costs (Sinha et al., 1984).

Activities directly related to highway usage include new construction, repair, and rehabilitation of pavements and structures and load-related maintenance. These costs can be defined as attributable and they are allocated on the basis of an incremental approach (FHWA, 2000c; Sinha et al., 1984). Using this approach, costs associated with the minimum requirements of facility design, in terms of, for example, pavement thickness or width, that meets the operational and safety needs of the smallest or lightest vehicle, is assigned to all vehicles on the basis of a selected cost-allocator. Following the allocation of minimum costs, further incremental costs are allotted to vehicle classes requiring design elements additional to the minimum.

\section{Cost Allocation Guidelines}

Non-Attributable or Common Costs: In principle, not only the highway users, but also the rest of the society receives benefit from a highway system, indirectly through improved mobility, economic development, safety, etc. Quantifying non-users' benefit, however, is conceptually unclear and technically difficult since the benefit of non-users are mostly intertwined with those of users. Also, it is hardly feasible to obtain information that traces every link of economic activities, i.e. entities involved and benefits they receive, in relation with a highway system. In this regard, it has been common to limit the scope of the analysis to the users' benefit, assuming that other markets will function to reflect non-users' indirect benefit in accordance with changes in transportation market. For example, increase in highway user fees will cause change in shipping costs, which will eventually be transferred to end customers.

The scope of the problem being restricted to direct highway users, the amount of usage has been traditionally considered as a proxy of the benefit. According to the methods used in the federal HCAS, the most general measure of system use, non-weighted VMT, is recommended as a common cost allocator (FHWA, 2000c). Some of the common costs associated with the effective roadway space occupied by various vehicle types are allocated on the basis of passenger car equivalent (PCE) weighted VMT.

New Pavement Costs: Both in the federal and Indiana studies, thickness incremental method was applied for allocation of new pavement cost. According to this method, the minimum thicknesses, with which the minimum level of traffic load can be sustained, are considered as the 
basic cost component. In the Indiana study, the following thicknesses were considered as the minimum: For flexible pavement, surface course 1 inch, base course 3 inches, and sub-base course 4 inches; and for rigid pavement, 4-1/2 inches (Sinha et al., 1984). These values are comparable with the recommendations in the federal study: 2.08 to 3.1 for flexible pavement structural number and 4 to 6 inches for minimum concrete slab thickness (FHWA, 2000b). Pavement costs incurred by the construction of the minimum thickness are allocated on the basis of VMT.

Load-related portion of pavement costs, i.e. incremental costs, are generally allocated on the basis of ESAL miles, as in Indiana's study in 1984 and 1989. In the 1997 federal HCAS, the results from the National Pavement Cost Model (NAPCOM), representing relationships between axle weights and pavement distresses, were adopted (FHWA, 2000b; Owusu-Antwi, 1997). In NAPCOM, separate models were estimated for each of four distress types, two surface types, and ten road functional classes.

Bridge Related Costs (Structure Costs): In the federal study, bridge costs included new bridge construction, bridge replacement, and bridge repair. This classification is akin to that in the Indiana study, which included costs for structure construction, replacement and rehabilitation. Similar to the logic of the thickness incremental approach, the structure design that is adequate to accommodate light vehicles only is considered a common structure cost and shared by all vehicle classes. Vehicle classes that are successively larger and heavier are responsible for incrementally increasing costs.

Table B.1 Bridge Design Increment Used in the Indiana Study in 1984

\begin{tabular}{|l|l|l|}
\hline \multirow{2}{*}{ Design Vehicles } & \multicolumn{2}{|l|}{ Operating Weight Range (thousands of pounds) } \\
\cline { 2 - 3 } & Single Unit Trucks & Combinations \\
\hline HS20 & 40 and over & 54 and over \\
HS15 & 30 to 40 & 40.5 to 54 \\
H15 & 20 to 30 & 27 to 40.5 \\
H10 & 10 to 20 & 13.5 to 27 \\
H5 & 5 to 10 & 6.25 to 13.5 \\
H2.5 & 0 to 5 & 0 to 6.25 \\
\hline
\end{tabular}

\section{Critical Input Parameters and Assumptions}

Allocation of highway costs requires several input parameters and rules that should be determined from experiments and field observations. Selected critical factors are described below. 
Portion of Non-Attributable Costs: There are cost items for which it is often arguable whether they are attributable or non-attributable, or what portion of the cost, if not the whole amount, is attributable. In this regard, maintenance cost would be the one of the most controversial items. Although traffic load is one of the major causes of road wear, environmental impact such as severe climate condition can also considerably degrade pavement quality. Cost item categorization for the FHWA HCAS tool requires distinction between load-related and nonload-related costs, while most of the available data sources do not provide that information. Therefore, it is critical to determine the portion of maintenance cost for which the weather is responsible.

The Minimum Construction Requirements: As mentioned above, in order to allocate attributable costs using the incremental approach, minimum design requirements need to be determined. Changes in the minimum requirements would cause changes in cost responsibility between vehicle classes: The higher the minimum thickness, the greater is the cost responsibility of light vehicles and the smaller is that of heavy vehicles.

Relationship between Pavement Deterioration and Traffic Load: In order to allocate loadrelated costs, the cost-allocator that reflects impact of vehicle loads on pavement deterioration needs to be determined. As discussed above, relationships between load and deterioration by distress and surface type established in the NAPCOM study provide a source of this information. Changes in load equivalency factor (LEF) values will result in changes in cost responsibility.

\section{Data Acquisition and Manipulation}

The State HCAS Tool requires two important input data: state expenditures by highway functional class and by cost allocation category; and VMT values by vehicle configuration and highway functional class. Highway expenditures by cost category and by road function class were obtained from Highway Statistics published by FHWA. To smooth out fluctuations in the data, the study used the averages of the recent three and five years of highway expenditures, converted into 2006 dollars using construction price index, as shown in Table B.2. Annual VMT data by vehicle type and road functional class were obtained from Highway Performance Monitoring System (HPMS). Input data used for the analysis are summarized in Table B.3. 
Table B.2 Annual State Highway Expenditure by Road Functional Class (in thousand dollars)

\begin{tabular}{|c|c|c|c|c|c|c|c|c|c|c|c|}
\hline & Rur Int & Rur OPA & Rur MA & Rur MaC & Rur MnC & Urb Int & Urb OFE L & Urb OPA & Urb MA & Urb Coll & Total \\
\hline \multicolumn{12}{|c|}{ 3-year Average Expenditure (2003 2005) } \\
\hline New rigid pavement & 11,384 & 26,228 & 46,528 & 58,236 & 195 & 89,143 & 2,450 & 13,071 . & 1,715 & 497 & 249,449 \\
\hline New flexible pavement & 28,093 & 55,105 & 33,194 & 9,679 & 5 & 134,129 & 8,504 & 57,155 & 6,927 & 1,428 & 334,220 \\
\hline 3R flexible pavement & 3,434 & 12,234 & 21,703 & 146,185 & 491 & 8,031 & 1,464 & 7,810 & 1,025 & 284 & 334,220 \\
\hline $3 \mathrm{R}$ rig & 8,475 & 25,704 & 15,483 & 24,296 & 13 & 12,084 & 5,081 & 34,151 & 4,139 & 816 & 130,241 \\
\hline New & 668 & 5,067 & 4,967 & 4,064 & 12 & 1,282 & 73 & 468 & 58 & 483 & 17,142 \\
\hline Repla & 621 & 5,981 & 5,863 & 33,247 & 98 & 16,589 & 1,512 & 9,693 & 1,193 & 0 & 74,798 \\
\hline & 8,353 & 2,784 & 2,729 & 21,274 & 63 & 10,303 & 1,436 & 9,204 & 1,133 & 2 & 57,281 \\
\hline Resic &, 391 & 10,687 & 10,475 & 27,665 & 82 & 25,297 & 1,934 & 12,399 & 1,526 & 1,052 & 111,507 \\
\hline Non-1 &, 072 & 20,792 & 20,371 & 41,094 & 8,807 & 5,269 & 1,954 & 12,264 & 1,664 & 32 & 143,318 \\
\hline Load- & & 10,057 & 17,834 & 52,856 & 12,863 & 3,155 & 655 & 3,424 & 495 & 12 & 114,794 \\
\hline Load- & 167 & 21,130 & 12,723 & 8,785 & 348 & $4,748^{-\underline{\underline{n}}}$ & 2,275 & 14,972 & 2,001 & 35 & 100,184 \\
\hline Total & 159,100 & 770 & 191,870 & 427,382 & 22,977 & 310,029 & 27,339 & 174,612 & 21,875 & 4,642 & $1,535,594$ \\
\hline \multicolumn{12}{|c|}{ 5-year Average Expenditure (2003 2005) } \\
\hline \begin{tabular}{|l|} 
New flexible pavement \\
\end{tabular} & 14,201 & 28,699 & 50,896 & 35,009 & 119 & 97,139 & 2,665 & & 1,867 & 385 & 245,193 \\
\hline New & 35,042 & & & 5,818 & 3 & 146,160 & 9,251 & 62,148 & 7,543 & 1,104 & 363,677 \\
\hline 3R flexib & 6,372 & 17,925 & 31,789 & 126,699 & 431 & 55,885 & 1,868 & 9,963 & 1,309 & 453 & 252,696 \\
\hline $3 \mathrm{R}$ ri & 15,723 &, 661 & 22,679 & 21,057 & 12 & 84,088 & 6,485 & 43,566 & 5,287 & 1,301 & 237,859 \\
\hline New & 443 & 3,523 & 3,452 & 2,129 & 6 & 1,205 & 81 & 518 & 64 & 313 & 11,734 \\
\hline Replac & 412 & 12,592 & 12,339 & 34,114 & 102 & 21,873 & 1,617 & 10,363 & 1,277 & 0 & 94,689 \\
\hline Bridge re & 10,724 & 13,617 & 13,343 & 32,720 & 98 & 8,950 & 2,592 & 16,611 & 2,047 & 1 & 100,705 \\
\hline Residu & & & & 37,058 & 111 & 26,252 & 2,905 & 18,618 & 2,294 & 938 & 132,863 \\
\hline Non-load-related maint. & 33,293 & 25,591 & 25,253 & 54,453 & 6,729 & 6,886 & 2,482 & 15,669 & 2,099 & 42 & 172,496 \\
\hline Load-related flex pave maint. & 9,601 & 8,253 & 14,738 & 46,693 & 6,552 & 2,749 & 555 & 2,916 & 416 & 11 & 92,484 \\
\hline Load-related rigid pave maint. & 23,692 & 17,339 & 10,514 & 7,760 & 177 & 4,137 & 1,927 & 12,752 & 1,682 & 31 & 80,012 \\
\hline Total & 167,661 & \begin{tabular}{|l|}
238,898 \\
\end{tabular} & 234,444 & 403,511 & 14,341 & 455,325 & 32,426 & 207,338 & 25,886 & 4,581 & $1,784,409$ \\
\hline
\end{tabular}

Int: Interstate; OPA: other principal arterial; MA: minor arterial; MaC: major collector; MnC: minor collector; OFE: other freeway and expressway; Coll: collector

Source: Highway Statistics 2001 through 2006 
Table B.3 Annual VMT by Vehicle Configuration and Road Functional Class (2005) (in million)

\begin{tabular}{|c|c|c|c|c|c|c|c|c|c|c|c|}
\hline & Rur Int & Rur OPA & Rur MA & Rur MaC & Rur MnC & Urb Int & Urb OFE & Urb OPA & Urb MA & Urb Coll & Total \\
\hline Auto & $4,713.1$ & $3,295.6$ & $2,728.3$ & $5,403.5$ & 145.8 & $4,338.8$ & 621.9 & $5,110.5$ & $2,384.5$ & 257.0 & $29,036.2$ \\
\hline LT4 & $2,079.3$ & $1,625.3$ & $1,311.8$ & $2,029.7$ & 90.0 & $1,665.6$ & 252.6 & $3,032.1$ & 943.1 & 102.4 & $13,146.7$ \\
\hline SU2 & 679.5 & 311.9 & 247.7 & 489.3 & 5.4 & 432.7 & 90.6 & 423.6 & 63.6 & 1.7 & $2,746.9$ \\
\hline SU3 & 185.9 & 211.4 & 111.5 & 152.4 & 3.6 & 132.7 & 12.9 & 43.0 & 66.6 & 1.7 & 922.1 \\
\hline SU4+ & 36.6 & 19.9 & 10.5 & 14.3 & 0.2 & 23.6 & 1.0 & 3.5 & 5.4 & 0.1 & 115.2 \\
\hline $\mathrm{CS} 3$ & 12.6 & 5.4 & 3.8 & 3.6 & 0.2 & 10.4 & 1.3 & 2.3 & 1.5 & 0.2 & 41.3 \\
\hline CS4 & 20.5 & 13.9 & 3.2 & 3.0 & 0.3 & 16.9 & 2.5 & 5.0 & 1.6 & 0.2 & 67.2 \\
\hline $3 \mathrm{~S} 2$ & 805.1 & 163.6 & 55.9 & 56.6 & 3.7 & 302.5 & 18.6 & 42.6 & 4.1 & 0.3 & $1,453.1$ \\
\hline CS5 & 66.1 & 12.7 & 5.0 & 5.1 & 0.3 & 24.8 & 1.0 & 3.6 & 0.5 & 0.0 & 119.2 \\
\hline CS6 & 60.6 & 24.3 & 9.6 & 9.7 & 0.2 & 30.8 & 1.9 & 7.1 & 0.9 & 0.1 & 145.1 \\
\hline CS7+ & 35.4 & 13.8 & 5.4 & 5.5 & 0.1 & 17.8 & 1.1 & 4.2 & 0.5 & 0.0 & 83.8 \\
\hline CT4- & 0.2 & 0.1 & 0.1 & 0.1 & 0.0 & 0.1 & 0.0 & 0.0 & 0.0 & 0.0 & 0.6 \\
\hline CT5 & 52.0 & 3.8 & 5.0 & 5.1 & 0.2 & 21.0 & 1.9 & 2.2 & 1.0 & 0.1 & 92.3 \\
\hline CT6+ & 8.3 & 0.5 & 0.7 & 0.7 & 0.0 & 3.1 & 0.0 & 0.0 & 0.0 & 0.0 & 13.5 \\
\hline DS5 & 110.7 & 12.9 & 7.4 & 6.2 & 0.1 & 52.0 & 1.9 & 4.8 & 0.4 & 0.0 & 196.7 \\
\hline DS6 & 75.3 & 8.4 & 6.8 & 2.6 & 0.1 & 29.0 & 0.2 & 2.4 & 0.2 & 0.0 & 124.9 \\
\hline DS7 & 71.9 & 10.5 & 8.5 & 3.3 & 0.1 & 24.6 & 0.4 & 4.5 & 0.3 & 0.0 & 124.1 \\
\hline DS8+ & 152.0 & 22.6 & 18.3 & 7.1 & 0.2 & 52.6 & 0.8 & 9.7 & 0.7 & 0.0 & 264.0 \\
\hline TS & 44.0 & 4.9 & 4.0 & 1.5 & 0.0 & 15.0 & 0.2 & 2.1 & 0.2 & 0.0 & 72.0 \\
\hline Bus & 34.7 & 41.5 & 20.2 & 48.5 & 1.4 & 34.8 & 3.7 & 30.0 & 23.6 & 0.7 & 239.4 \\
\hline Total & $9,243.8$ & $5,803.1$ & $4,563.7$ & $8,247.8$ & 251.9 & $7,228.9$ & $1,014.6$ & $8,733.1$ & $3,498.6$ & 364.7 & $49,004.3$ \\
\hline
\end{tabular}

Int: Interstate; OPA: other principal arterial; MA: minor arterial; MaC: major collector; MnC: minor collector; OFE: other freeway and expressway; Coll: collector

Auto: automobiles and motorcycles; LT4: pickups, vans and other light 2-axle, four tire vehicles; SU2, SU3, SU4+: 2-, 3-, and 4- or more axle single unit trucks; CS3, CS4, 3S2, CS5, CS6, CS7+: 3-, 4-, 5-, 6-, and 7- or more axle tractor-semi-trailer trucks with two categories of 5-axle vehicles, one with standard tandem axles and one with split tandem axles; CT4-, CT5, CT6+: 3-, 4-, 5-, and 6- or more axle truck-trailer combinations; DS5, DS6, DS7, DS8+: 5-, 6-, 7-, and 8- or more axle twin trailer/semi-trailer combinations TS: Triple trailer combinations; and Bus: buses

Source: Highway Performance Monitoring System

\section{Cost Allocation Results: The Base Case}

For the critical input variables discussed above, base case values were established as the following:

- Portion of non-load-related: Fwa and Sinha (1987a) studied Indiana's data and concluded that $9.3 \%$ and $37.7 \%$ of maintenance costs were incurred by weather influence, respectively for flexible and rigid pavements. Rosalion and Martin (1999) found that $45 \%$ of road wear for flexible pavements was due to weather condition. Martin observed that the weather was responsible for 35\% of maintenance cost based on recent data (Martin, 2002). In the present study, 40\% was used as the weather impact for both pavement types.

- Minimum pavement thickness: The present study followed the FHWA recommendations; structure number 2.1 was the minimum for flexible pavements, and 4.0 inches of slab thickness was the minimum for rigid pavements. 
- Load Equivalency Factors: Indiana specific values from the NAPCOM study, some of which are presented in Table 3, were used as the base case input.

Using the inputs described above, the base case results were obtained as summarized in Table B.4. The results indicated that the average per mile fee rate should be 3.14 cents to cover the total state highway expenditure. When applied to a 3-vehicle configuration, the rate for automobiles is 1.21 cents per mile, 9.18 cents for single unit trucks, and 23.54 cents for combination trucks. Results with a 20 -vehicle classification are also found in Table B.4.

Table B.4 HCAS Results: Cost Responsibility with the Base Case Inputs (cents/mile)

\begin{tabular}{|c|c|c|c|c|c|c|c|c|c|c|c|c|c|}
\hline & \multicolumn{6}{|c|}{ Rural } & \multicolumn{6}{|c|}{ Urban } & \multirow{2}{*}{ Average } \\
\hline & Int & OPA & MA & $\mathrm{MaC}$ & $\mathrm{MnC}$ & Average & Int & OFE & OPA & MA & Coll & Average & \\
\hline \multicolumn{14}{|c|}{ 3-Vehicle Type Classification } \\
\hline Auto & 0.65 & 1.20 & 1.80 & 2.26 & 5.06 & 1.54 & 1.04 & 0.88 & 0.84 & 0.29 & 0.83 & 0.83 & 1.21 \\
\hline SUT & 1.91 & 7.95 & 12.31 & 19.65 & 32.12 & 9.72 & 7.65 & 7.29 & 9.91 & 5.58 & 20.91 & 8.26 & 9.18 \\
\hline $\mathrm{CT}$ & 6.38 & 30.27 & 53.18 & 109.90 & 135.69 & 18.79 & 33.29 & 37.09 & 62.12 & 27.64 & 71.86 & 37.02 & 23.54 \\
\hline Average & 1.72 & 3.37 & 4.20 & 5.18 & 9.12 & 3.58 & 4.29 & 2.69 & 2.00 & 0.63 & 1.27 & 2.63 & 3.14 \\
\hline \multicolumn{14}{|c|}{ 20-Vehicle Type Classification } \\
\hline Auto & 0.63 & 1.07 & 1.59 & 2.04 & 4.93 & 1.40 & 0.86 & 0.75 & 0.66 & 0.23 & 0.74 & 0.67 & 1.07 \\
\hline LT4 & 0.71 & 1.47 & 2.25 & 2.85 & 5.28 & 1.86 & 1.51 & 1.18 & 1.15 & 0.44 & 1.07 & 1.16 & 1.51 \\
\hline SU2 & 1.73 & 6.60 & 10.57 & 16.15 & 25.01 & 8.04 & 6.78 & 6.72 & 9.12 & 4.04 & 16.00 & 7.61 & 7.86 \\
\hline SU3 & 2.27 & 9.26 & 14.90 & 26.82 & 41.06 & 12.52 & 9.08 & 10.08 & 14.38 & 6.45 & 24.21 & 9.50 & 11.61 \\
\hline SU4+ & 3.32 & 14.58 & 23.83 & 42.94 & 64.22 & 15.84 & 15.16 & 17.31 & 25.30 & 11.55 & 44.63 & 15.88 & 15.81 \\
\hline $\mathrm{CS} 3$ & 2.08 & 8.12 & 13.14 & 20.86 & 32.25 & 7.94 & 8.27 & 8.65 & 12.09 & 5.30 & 20.19 & 8.89 & 8.21 \\
\hline $\mathrm{CS} 4$ & 2.49 & 10.16 & 16.53 & 27.96 & 41.59 & 8.48 & 10.93 & 11.72 & 16.78 & 7.64 & 28.38 & 12.19 & 9.74 \\
\hline $3 \mathrm{~S} 2$ & 5.99 & 29.02 & 48.34 & 104.04 & 144.64 & 17.29 & 30.75 & 37.73 & 55.92 & 27.84 & 97.88 & 34.07 & 21.49 \\
\hline CS5 & 5.44 & 25.36 & 42.64 & 80.48 & 112.54 & 15.06 & 28.21 & 32.88 & 48.53 & 23.63 & 84.56 & 30.86 & 18.98 \\
\hline CS6 & 6.38 & 31.01 & 50.80 & 110.56 & 151.12 & 26.21 & 32.77 & 41.64 & 61.29 & 31.33 & 108.12 & 38.31 & 29.55 \\
\hline CS7+ & 8.36 & 42.04 & 69.55 & 156.17 & 205.31 & 35.51 & 45.15 & 58.16 & 84.00 & 44.67 & 156.97 & 52.85 & 40.32 \\
\hline CT4- & 2.66 & 11.17 & 18.04 & 31.67 & 48.34 & 12.58 & 11.50 & 12.66 & 18.12 & 8.27 & 31.86 & 12.61 & 12.49 \\
\hline CT5 & 6.98 & 35.24 & 58.36 & 113.82 & 152.17 & 21.22 & 40.17 & 45.49 & 66.12 & 33.14 & 128.72 & 42.84 & 27.27 \\
\hline CT6+ & 3.81 & 16.65 & 27.21 & 55.81 & 78.89 & 9.87 & 16.63 & 20.99 & 31.27 & 15.12 & 52.54 & 16.78 & 11.49 \\
\hline DS5 & 5.77 & 28.42 & 47.82 & 93.89 & 105.18 & 14.23 & 32.98 & 39.45 & 58.05 & 32.98 & 100.95 & 35.30 & 20.57 \\
\hline DS6 & 5.98 & 30.30 & 50.67 & 118.74 & 109.50 & 14.69 & 34.20 & 45.39 & 67.51 & 44.12 & 105.08 & 36.81 & 20.30 \\
\hline DS7 & 9.29 & 49.29 & 81.34 & 209.42 & 219.20 & 27.50 & 53.65 & 75.07 & 108.62 & 69.78 & 178.84 & 62.43 & 35.84 \\
\hline DS8+ & 8.16 & 41.94 & 69.58 & 182.15 & 184.76 & 23.96 & 44.34 & 66.08 & 94.63 & 62.89 & 152.20 & 52.50 & 30.83 \\
\hline $\mathrm{TS}$ & 7.60 & 37.52 & 63.95 & 138.98 & 139.53 & 18.20 & 43.61 & 58.42 & 84.23 & 54.07 & 133.89 & 48.85 & 25.65 \\
\hline Bus & 2.01 & 8.27 & 13.41 & 25.50 & 32.82 & 13.57 & 7.80 & 8.72 & 12.91 & 5.88 & 20.07 & 9.15 & 11.75 \\
\hline Average & 1.72 & 3.37 & 4.20 & 5.18 & 9.12 & 3.58 & 4.29 & 2.69 & 2.00 & 0.63 & 1.27 & 2.63 & 3.14 \\
\hline
\end{tabular}

Auto: automobiles and motorcycles; SUT: Single Unit Truck; and CT: Combination Truck; LT4: pickups, vans and other light 2-axle, four tire vehicles; SU2, SU3, SU4+: 2-, 3-, and 4- or more axle single unit trucks; CS3, CS4, 3S2, CS5, CS6, CS7+: 3-, 4-, 5-, 6-, and 7- or more axle tractor-semi-trailer trucks with two categories of 5-axle vehicles, one with standard tandem axles and one with split tandem axles; CT4-, CT5, CT6+: 3-, 4-, 5-, and 6- or more axle truck-trailer combinations; DS5, DS6, DS7, DS8+: 5-, 6-, 7-, and 8- or more axle twin trailer/semi-trailer combinations TS: Triple trailer combinations; and Bus: buses 


\section{Cost Allocation Results: Sensitivity Analysis}

In order to assess the impact of changes in the critical input parameters, a sensitivity analysis was performed.

Non-Load-Related (NLR) Maintenance Cost: Non-load-related portion of pavement maintenance cost was varied from $10 \%$ to $100 \%$ to get the results in Table B.5. As shown in Figure B.1, the more of maintenance cost is non-load-related, the higher is the cost responsibility of lighter cars. It was also found that for a $10 \%$ increase in non-load-related maintenance cost from the basic input value, the cost responsibility dropped by 0.65 cents per mile for combination trucks and 0.15 cents per mile for single unit trucks.

Table B.5 Cost Responsibility with Various NLR Portion of Maintenance Cost (cents/mile)

\begin{tabular}{|c|c|c|c|c|c|c|c|c|c|c|}
\hline & \multicolumn{10}{|c|}{$\%$ of Non-Load-Related Maintenance Cost } \\
\hline & 10 & 20 & 30 & 40 & 50 & 60 & 70 & 80 & 90 & 100 \\
\hline \multicolumn{11}{|c|}{ 3-Vehicle Type Classification } \\
\hline Auto & 0.98 & 1.03 & 1.09 & 1.15 & 1.21 & 1.26 & 1.32 & 1.38 & 1.44 & 1.49 \\
\hline SUT & 9.79 & 9.64 & 9.49 & 9.33 & 9.18 & 9.02 & 8.87 & 8.72 & 8.56 & 8.41 \\
\hline $\mathrm{CT}$ & 26.13 & 25.48 & 24.83 & 24.18 & 23.54 & 22.89 & 22.24 & 21.59 & 20.95 & 20.30 \\
\hline Average & 3.14 & 3.14 & 3.14 & 3.14 & 3.14 & 3.14 & 3.14 & 3.14 & 3.14 & 3.14 \\
\hline \multicolumn{11}{|c|}{ 20-Vehicle Type Classification } \\
\hline Auto & 0.83 & 0.89 & 0.95 & 1.01 & 1.07 & 1.12 & 1.18 & 1.24 & 1.30 & 1.36 \\
\hline LT4 & 1.29 & 1.35 & 1.40 & 1.46 & 1.51 & 1.57 & 1.63 & 1.68 & 1.74 & 1.80 \\
\hline SU2 & 8.29 & 8.18 & 8.07 & 7.97 & 7.86 & 7.75 & 7.64 & 7.54 & 7.43 & 7.32 \\
\hline SU3 & 12.62 & 12.37 & 12.11 & 11.86 & 11.61 & 11.36 & 11.11 & 10.86 & 10.61 & 10.36 \\
\hline SU4+ & 17.32 & 16.94 & 16.56 & 16.19 & 15.81 & 15.43 & 15.06 & 14.68 & 14.30 & 13.92 \\
\hline CS3 & 8.68 & 8.56 & 8.44 & 8.33 & 8.21 & 8.09 & 7.97 & 7.85 & 7.73 & 7.61 \\
\hline CS4 & 10.48 & 10.32 & 10.16 & 10.00 & 9.84 & 9.68 & 9.52 & 9.36 & 9.20 & 9.04 \\
\hline $3 \mathrm{~S} 2$ & 24.03 & 23.39 & 22.76 & 22.12 & 21.49 & 20.85 & 20.22 & 19.59 & 18.95 & 18.32 \\
\hline CS5 & 21.03 & 20.51 & 20.00 & 19.49 & 18.98 & 18.47 & 17.96 & 17.45 & 16.94 & 16.42 \\
\hline CS6 & 32.98 & 32.13 & 31.27 & 30.41 & 29.55 & 28.69 & 27.84 & 26.98 & 26.12 & 25.26 \\
\hline $\mathrm{CS} 7+$ & 45.11 & 43.91 & 42.72 & 41.52 & 40.32 & 39.12 & 37.92 & 36.72 & 35.53 & 34.33 \\
\hline CT4- & 13.58 & 13.31 & 13.04 & 12.76 & 12.49 & 12.22 & 11.95 & 11.68 & 11.40 & 11.13 \\
\hline CT5 & 30.15 & 29.43 & 28.71 & 27.99 & 27.27 & 26.55 & 25.82 & 25.10 & 24.38 & 23.66 \\
\hline CT6+ & 12.48 & 12.24 & 11.99 & 11.74 & 11.49 & 11.24 & 10.99 & 10.74 & 10.50 & 10.25 \\
\hline DS5 & 22.21 & 21.80 & 21.39 & 20.98 & 20.57 & 20.16 & 19.75 & 19.34 & 18.92 & 18.51 \\
\hline DS6 & 21.96 & 21.54 & 21.13 & 20.71 & 20.30 & 19.88 & 19.47 & 19.05 & 18.64 & 18.23 \\
\hline DS7 & 39.82 & 38.82 & 37.83 & 36.84 & 35.84 & 34.85 & 33.86 & 32.87 & 31.87 & 30.88 \\
\hline DS8+ & 34.13 & 33.31 & 32.48 & 31.66 & 30.83 & 30.01 & 29.18 & 28.36 & 27.54 & 26.71 \\
\hline $\mathrm{TS}$ & 28.10 & 27.49 & 26.87 & 26.26 & 25.65 & 25.03 & 24.42 & 23.80 & 23.19 & 22.58 \\
\hline Bus & 12.56 & 12.35 & 12.15 & 11.95 & 11.75 & 11.55 & 11.35 & 11.15 & 10.95 & 10.75 \\
\hline Average & 3.14 & 3.14 & 3.14 & 3.14 & 3.14 & 3.14 & 3.14 & 3.14 & 3.14 & 3.14 \\
\hline
\end{tabular}




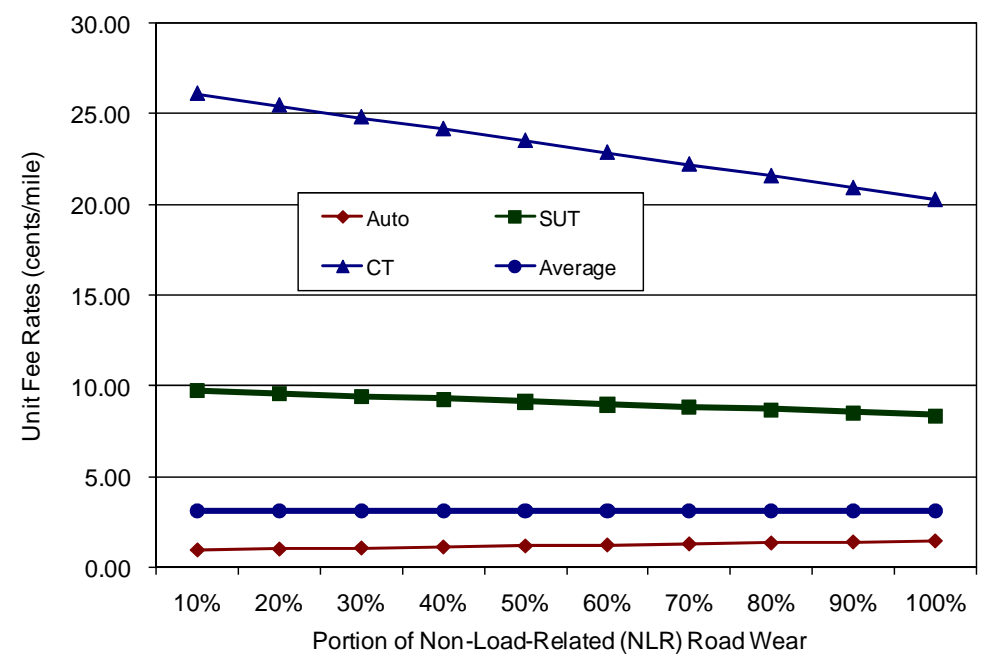

Figure B.1 Cost Responsibility with Various NLR Portion of Maintenance Cost

Minimum Pavement Thickness: Minimum pavement thickness was changed as follows: from 2.1 to 3.1 for flexible pavement structure number; from 4.2 to 6.0 inches for rigid pavement slab thickness. The sensitivity analysis results are presented in Table B.6 and Figure B.2. With higher standards for minimum thickness, cost responsibilities of heavier vehicles decreased as the common cost to be shared by all vehicles got larger. Within the range of minimum thickness considered, however, the changes in cost responsibility of lighter vehicles were not significant. It was observed that $8 \%$ increase in minimum thickness would reduce cost responsibility of combination trucks by as much as 0.37 cents per mile. 
Table B.6 Cost Responsibility with Various Minimum Pavement Thickness (cents/mile)

\begin{tabular}{|c|c|c|c|c|c|c|}
\hline $\begin{array}{l}\text { Min thickness (Flex structure } \\
\text { number/ Rigid slab inches) }\end{array}$ & $2.1 / 4.0$ & $2.3 / 4.4$ & $2.5 / 4.8$ & $2.7 / 5.2$ & $2.9 / 5.6$ & $3.1 / 6.0$ \\
\hline \multicolumn{7}{|l|}{ 3-Vehicle Type Classification } \\
\hline Auto & 1.15 & 1.18 & 1.21 & 1.24 & 1.27 & 1.30 \\
\hline SUT & 9.33 & 9.28 & 9.22 & 9.16 & 9.11 & 9.05 \\
\hline $\mathrm{CT}$ & 24.18 & 23.82 & 23.45 & 23.08 & 22.71 & 22.35 \\
\hline Average & 3.14 & 3.14 & 3.14 & 3.14 & 3.14 & 3.14 \\
\hline \multicolumn{7}{|l|}{ 20-Vehicle Type Classification } \\
\hline Auto & 1.01 & 1.03 & 1.05 & 1.07 & 1.09 & 1.11 \\
\hline LT4 & 1.46 & 1.51 & 1.56 & 1.60 & 1.65 & 1.70 \\
\hline SU2 & 7.97 & 7.92 & 7.86 & 7.81 & 7.76 & 7.71 \\
\hline SU3 & 11.86 & 11.80 & 11.73 & 11.67 & 11.60 & 11.54 \\
\hline SU4+ & 16.19 & 16.01 & 15.83 & 15.65 & 15.47 & 15.29 \\
\hline $\mathrm{CS} 3$ & 8.33 & 8.31 & 8.29 & 8.26 & 8.24 & 8.22 \\
\hline CS4 & 10.00 & 9.95 & 9.91 & 9.86 & 9.81 & 9.76 \\
\hline $3 \mathrm{~S} 2$ & 22.12 & 21.80 & 21.48 & 21.16 & 20.84 & 20.52 \\
\hline CS5 & 19.49 & 19.20 & 18.90 & 18.60 & 18.31 & 18.01 \\
\hline CS6 & 30.41 & 29.94 & 29.47 & 28.99 & 28.52 & 28.05 \\
\hline CS7+ & 41.52 & 40.79 & 40.07 & 39.35 & 38.63 & 37.90 \\
\hline CT4- & 12.76 & 12.65 & 12.53 & 12.41 & 12.29 & 12.18 \\
\hline CT5 & 27.99 & 27.44 & 26.89 & 26.33 & 25.78 & 25.23 \\
\hline CT6+ & 11.74 & 11.67 & 11.60 & 11.54 & 11.47 & 11.40 \\
\hline DS5 & 20.98 & 20.64 & 20.29 & 19.95 & 19.61 & 19.26 \\
\hline DS6 & 20.71 & 20.41 & 20.10 & 19.80 & 19.49 & 19.18 \\
\hline DS7 & 36.84 & 36.19 & 35.55 & 34.90 & 34.25 & 33.61 \\
\hline DS8+ & 31.66 & 31.18 & 30.71 & 30.24 & 29.77 & 29.30 \\
\hline TS & 26.26 & 25.81 & 25.36 & 24.92 & 24.47 & 24.02 \\
\hline Bus & 11.95 & 11.93 & 11.91 & 11.89 & 11.87 & 11.85 \\
\hline Average & 3.14 & 3.14 & 3.14 & 3.14 & 3.14 & 3.14 \\
\hline
\end{tabular}




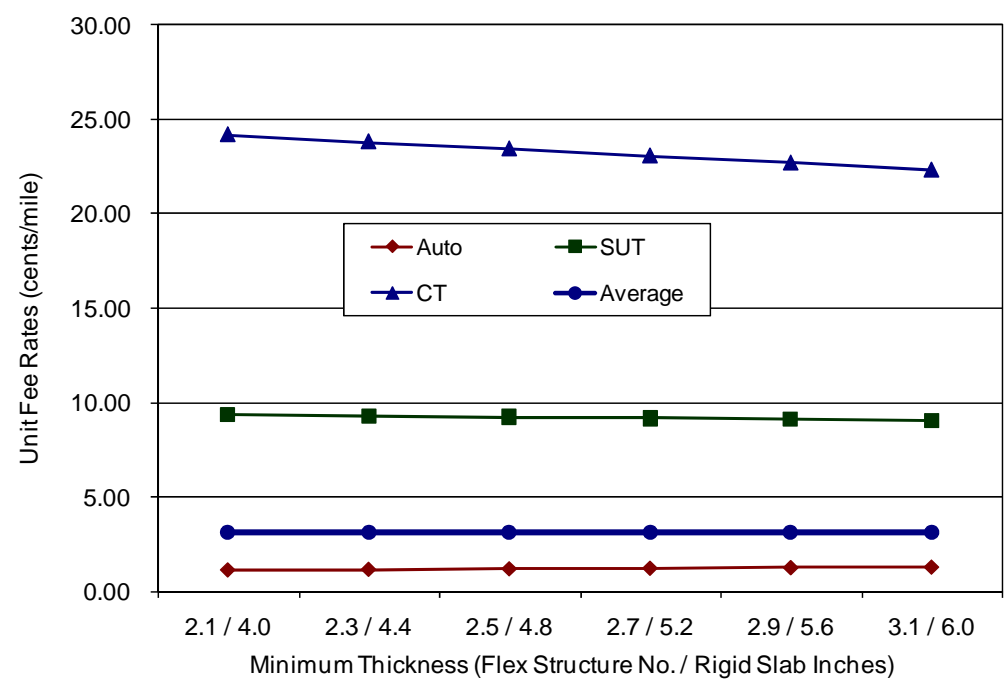

Figure B.2 Cost Responsibility with Various Minimum Pavement Thickness

Load Equivalency Factors: Various levels of Load Equivalency Factors were considered to assess the impacts of heavier vehicles. Having Indiana specific values of NAPCOM deterioration models as default, the study tested for $1,25,50,75$, and 99 percentile of the national average values of LEF. The results are presented in Table B.7 and Figure B.3. It was observed that at most 2.66 cents per mile of reduction in cost responsibility can be expected for combination trucks under the assumption that their LEF values were $99 \%$ of national values, while for single unit trucks the largest change would be an increase of $2.17 \notin / \mathrm{mile}$. 
Table B.7 Cost Responsibility with Various LEF Values (cents/mile)

\begin{tabular}{|c|c|c|c|c|c|c|}
\hline \multirow{2}{*}{$\begin{array}{c}\text { Load Equivalency } \\
\text { Factor }\end{array}$} & \multirow{2}{*}{$\begin{array}{l}\text { Indiana } \\
\text { Parameters }\end{array}$} & \multicolumn{5}{|c|}{ National Average } \\
\hline & & 1 percentile & 25 percentile & 50 percentile & 75 percentile & 99 percentile \\
\hline \multicolumn{7}{|c|}{ 3-Vehicle Type Classification } \\
\hline Auto & 1.15 & 1.22 & 1.18 & 1.16 & 1.15 & 1.12 \\
\hline SUT & 9.33 & 10.27 & 10.72 & 10.88 & 11.06 & 11.50 \\
\hline $\mathrm{CT}$ & 24.18 & 21.73 & 21.69 & 21.72 & 21.70 & 21.52 \\
\hline Average & 3.14 & 3.14 & 3.14 & 3.14 & 3.14 & 3.14 \\
\hline \multicolumn{7}{|c|}{ 20-Vehicle Type Classification } \\
\hline Auto & 1.01 & 1.07 & 1.03 & 1.02 & 1.01 & 0.98 \\
\hline LT4 & 1.46 & 1.55 & 1.50 & 1.48 & 1.46 & 1.42 \\
\hline SU2 & 7.97 & 9.73 & 10.37 & 10.61 & 10.91 & 11.66 \\
\hline SU3 & 11.86 & 10.75 & 10.72 & 10.69 & 10.60 & 10.27 \\
\hline SU4+ & 16.19 & 15.87 & 16.43 & 16.65 & 16.94 & 17.55 \\
\hline CS3 & 8.33 & 10.10 & 10.52 & 10.65 & 10.83 & 11.30 \\
\hline CS4 & 10.00 & 10.65 & 10.98 & 11.11 & 11.28 & 11.80 \\
\hline $3 \mathrm{~S} 2$ & 22.12 & 18.60 & 18.20 & 18.09 & 17.84 & 16.98 \\
\hline CS5 & 19.49 & 19.93 & 20.75 & 21.12 & 21.56 & 22.82 \\
\hline CS6 & 30.41 & 24.82 & 24.12 & 23.87 & 23.60 & 22.43 \\
\hline CS7+ & 41.52 & 34.26 & 33.68 & 33.53 & 33.25 & 32.10 \\
\hline CT4- & 12.76 & 12.45 & 12.79 & 12.94 & 13.13 & 13.58 \\
\hline CT5 & 27.99 & 27.51 & 28.88 & 29.56 & 30.39 & 32.82 \\
\hline CT6+ & 11.74 & 10.31 & 10.08 & 9.98 & 9.86 & 9.40 \\
\hline DS5 & 20.98 & 23.91 & 25.36 & 25.93 & 26.72 & 29.14 \\
\hline DS6 & 20.71 & 22.22 & 23.18 & 23.58 & 24.12 & 25.85 \\
\hline DS7 & 36.84 & 32.33 & 31.86 & 31.74 & 31.52 & 30.64 \\
\hline DS8+ & 31.66 & 28.14 & 27.77 & 27.69 & 27.49 & 26.71 \\
\hline $\mathrm{TS}$ & 26.26 & 30.24 & 32.07 & 32.75 & 33.71 & 36.58 \\
\hline Bus & 11.95 & 11.98 & 11.98 & 11.93 & 11.84 & 11.50 \\
\hline Average & 3.14 & 3.14 & 3.14 & 3.14 & 3.14 & 3.14 \\
\hline
\end{tabular}

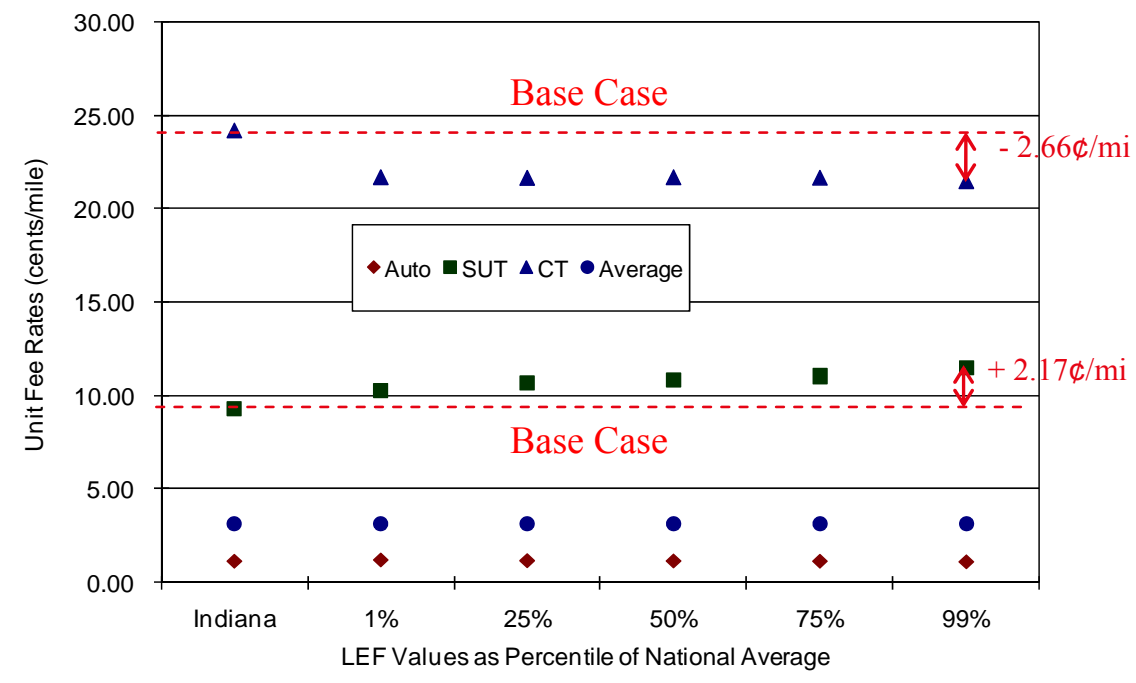

Figure B.3 Cost Responsibility with Various LEF Values 